Portland State University

PDXScholar

7-27-1976

\title{
Electrical Conductivity of Thin Lecithin-cholesterol Membranes due to 2,4-D, 2,4-DB, 2,4,5-T and 2,4-DCP
}

Malkanthi Paulis

Portland State University

Follow this and additional works at: https://pdxscholar.library.pdx.edu/open_access_etds

Part of the Physics Commons

Let us know how access to this document benefits you.

\section{Recommended Citation}

Paulis, Malkanthi, "Electrical Conductivity of Thin Lecithin-cholesterol Membranes due to 2,4-D, 2,4-DB, 2,4,5-T and 2,4-DCP" (1976). Dissertations and Theses. Paper 2555.

https://doi.org/10.15760/etd.2552

This Thesis is brought to you for free and open access. It has been accepted for inclusion in Dissertations and Theses by an authorized administrator of PDXScholar. Please contact us if we can make this document more accessible: pdxscholar@pdx.edu. 
AN ABSTRACT OF THE THESIS OF Malkanthi Paulis for the Master of Science in Physics presented July 27, 1976.

Title: Electrical Conductivity of Thin Lecithin-cholesterol Membranes due to $2,4-\mathrm{D}, 2,4-\mathrm{DB}, 2,4,5-\mathrm{T}$ and $2,4-\mathrm{DCP}$.

APPROVED BY MEMBERS OF THE THESIS COMMITTEE:
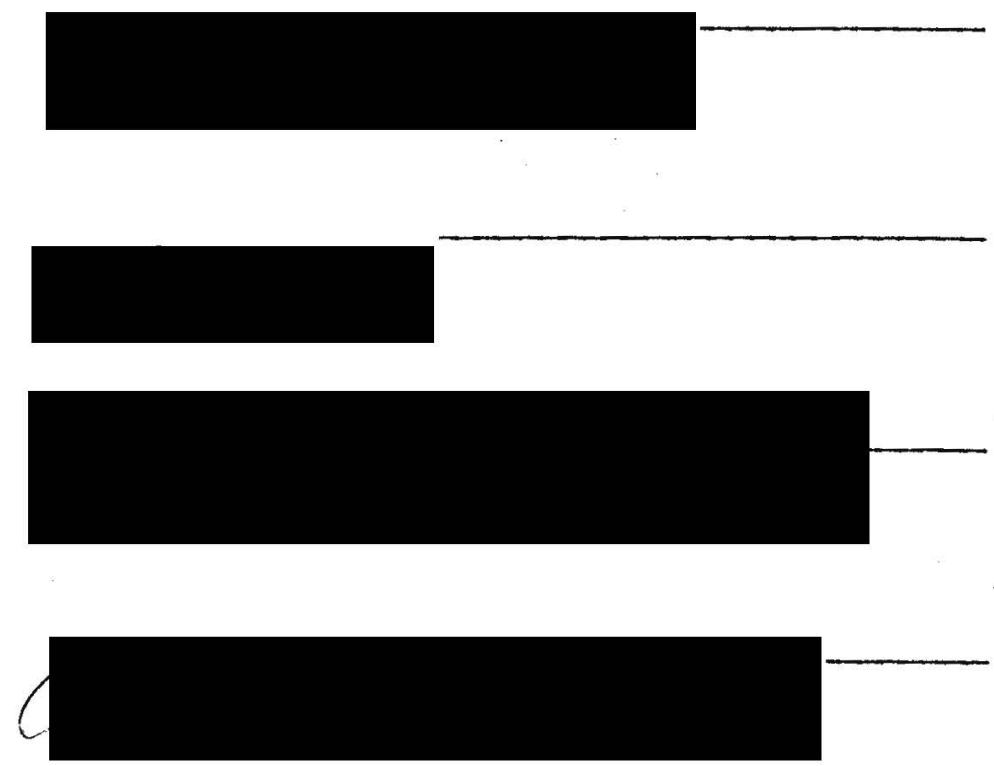

The effect of the following pesticides on DC electrical conductivity of lecithin-cholesterol membranes has been studied: endothall, paraquat, diquat, $2,4-D, 2,4-D B, 2,4,5-T, 2,4-D C P$. It has been found that the ions of endotha11, paraquat and diquat are essentially membrane impermeable and that they do not bind to the membrane surface. In contrast, 2,4-D, 2,4-DB, 2,4,5-T and 2,4-DCP induce electrical conductivity in lecithincholesterol membranes and in addition they also cause an increase in the nonactin $-\mathrm{K}^{+}$membrane conductivity. 
The compounds 2,4-D, 2,4-DB, 2,4,5-T and 2,4-DCP basically behave as class II uncouplers. The kinetic scheme of charge transfer across the membrane, based on the assumption that the membrane is permeable both to the negatively charged dimers and to the neutral molecules of pesticides, satisfactorily explains the basic features of the experimental results: the concentration dependence of pesticide-induced membrane conductance, effect of proton concentration on membrane conductance, and the effect of pesticide concentration on the voltage dependence of membrane conductance. It fails to predict the effect of proton concentration on the voltage dependence of membrane conductance.

The enhancement of nonactin $-\mathrm{K}^{+}$membrane conductance by the pesticide is presumably due to the adsorption of the ionized form of the pesticide at the membrane surface. It was found that the Gouy-Chapman diffuse double layer theory was not applicable for the calculation of surface membrane potential due to the adsorbed ions. 
ELECTRICAL CONDUCTIVITY OF THIN LECITHIN-CHOLESTEROL

MEMBRANES DUE TO 2,4-D, 2,4-DB

$2,4,5-\mathrm{T}$ AND 2,4-DCP

by

Malkanthi Paulis

A thesis submitted in partial fulfillment of the requirements for the degree of

\author{
MASTER OF SCIENCE \\ in \\ Physics
}

Portland State UnIversity

1976 


\section{TO THE OFFICE OF GRADUATE STUDIES AND RESEARCH:}

The members of the Committee approve the thesis of

Malkanthi Paulis presented July 27, 1976.

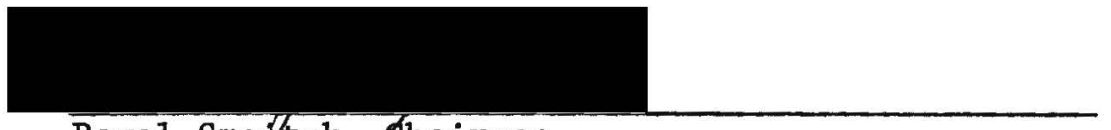

Pavel Smejtek, Chairman

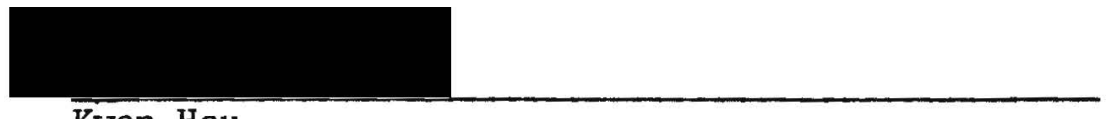

Kwan Hsu

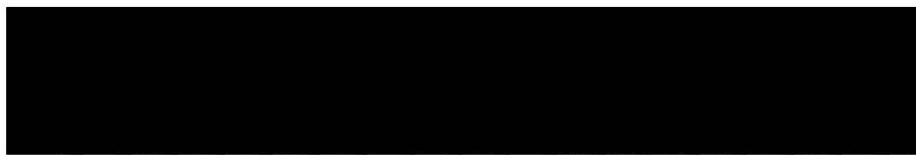

Mark Gurevitch

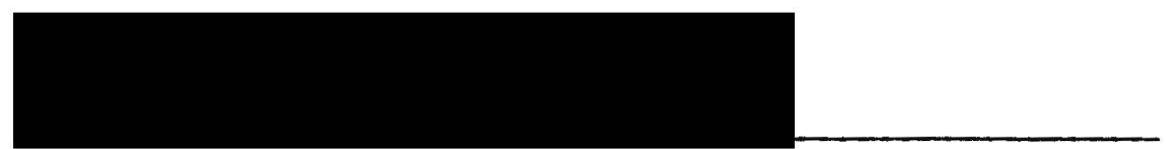

Joann S. Loehr

APPROVED:

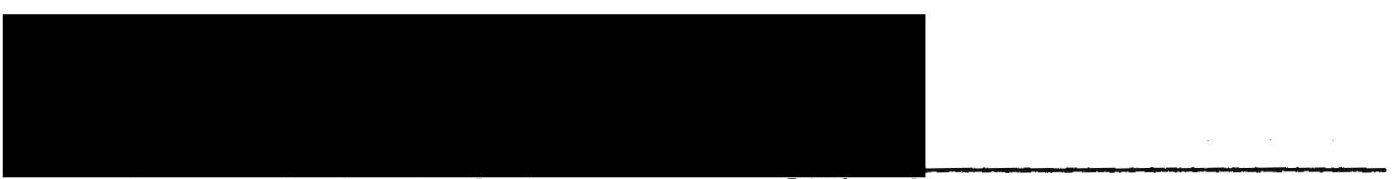

Mark Gurevitch, Head, Department of Physics

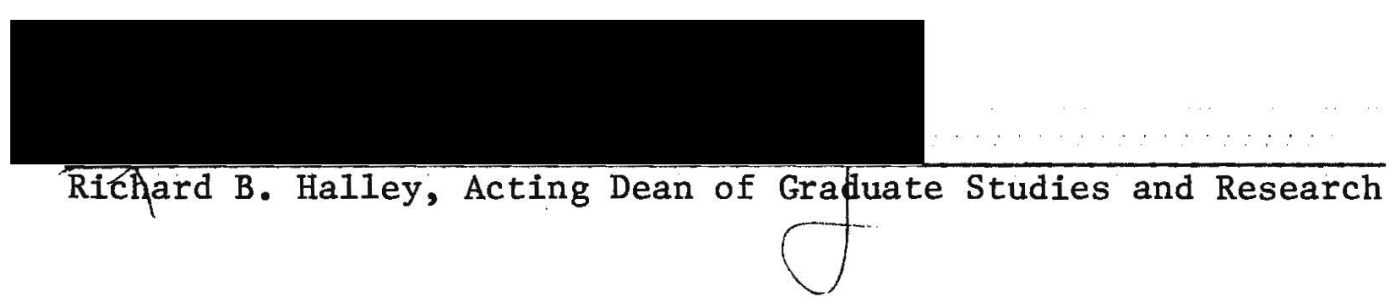




\section{ACKNOWLEDGEMENTS}

I wish to express great appreclation to Dr. Pavel Smejtek for his invaluable guldance and encouragement. Also I wish to thank Dr. Kwan Hsu for Introducing me to many of the experimental methods assoctated with this project and for her help in the preparation of this manuscript.

It is a pleasure to thank my friends Rich Doty and Suzanne Clarke who drew the graphs and figures and helped with proofreading. This investigation was supported by the Grant ES 937 from the NatIonal Institute of Health.

Malkanth1 Paulis

Summer 1976, Portland. 
TABLE OF CONTENTS

PAGE

ACKNOWLEDGMENTS

iii

LIST OF TABLES

vi

LIST OF FIGURES

vii

CHAPTER

I

INTRODUCTION

Proton Transfer Mechan1sm

Relay Mechan1sm

Proton Carrier Mechanism

Dimer Transport Mechanism

Endotha11

Paraquat and Diquat .................. 10

$2,4-D, 2,4-D B, 2,4,5-T$ and $2,4-D C P \ldots \ldots \ldots \ldots 11$

II EXPERIMENTAL METHODS .................... 13

Materials ......................... 13

Experimental Set Up ................... 14

Membrane Formation .................. 16

Electrical Measurements ............... 17

III EXPERIMENTAL RESULTS ................... 18

Exploratory Experiments with Endothall

Paraquat and Diquat $\ldots \ldots \ldots \ldots \ldots \ldots \ldots \ldots \ldots$ 
Experiments with $2,4-\mathrm{D}, 2,4-\mathrm{DB}, 2,4,5-\mathrm{T}$ and 2m4-DCP

Effect of Proton Concentration on Pesticide-induced Membrane Conductivity

Concentration Dependence of Pesticide-

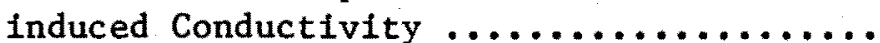

Voltage Dependence of Pesticideinduced Membrane Conductivity as a Function of Pesticide Concentration and $\mathrm{pH}$

Effect of Pesticides on the Nonactininduced Membrane Conductivity .......... 30

Exploratory Experiments with Endotha11,

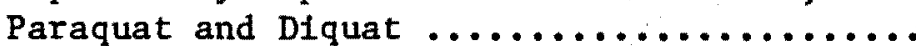

Experiments with 2,4-D, 2,4-DB, 2,4,5-T

and $2,4-D C P$

Kinetic Scheme of Charge Transfer for

Class II Uncouplers

Analysis of the Current-Voltage

Characteristics

Membrane Surface Charge

Theory of Diffuse Double Layer and the Use of Nonactin as a Probe for the Membrane Surface Potential

Analysis and Discussion of the Data on

Membrane Surface Charge

V SUMMARY AND CONCLUSIONS ................. 79 


\section{LIST OF TABLES}

TABLE

PAGE

I Dissoctation Properties of Studied

Pestic1des $\ldots \ldots \ldots \ldots \ldots \ldots \ldots \ldots \ldots \ldots \ldots \ldots \ldots$

II Analysis of Nonactin-2,4-D Data to

Determine Membrane Charging at

pH 2.7

III Analysis of Nonactin-2,4-DB Data to

Determine Membrane Charging at

$\mathrm{pH} 5.0$

68

IV Analysis of Nonactin-2,4,5-T Data to

Determine Membrane Charging at

pH $2.4 \ldots \ldots \ldots \ldots \ldots \ldots \ldots \ldots \ldots \ldots \ldots \ldots \ldots$

V Analysis of Nonactin-2,4-DCP Data to

Determine Membrane Charging at

pH 9.5

VI Analysis of the Experimental Data for

the Effect of Ionic Strength or

Surface Charge due to $2,4-D$ 


\section{LIST OF FIGURES}

1. Molecular Models of Lecithin and Cholesterol ....

2. Arrangement of Phospholipid Molecules in

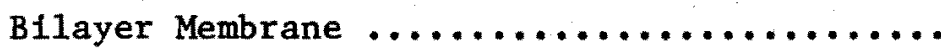

3. Schematic Representation of Mechanism of Direct Transfer of Protons Across the Membranes ....

4. Scheme of Ion Transfer Across the Membrane According to the Relay Transfer Mechanism ... 7

5. Scheme of Proton Carrier Mechanism for Class I Uncouplers $\ldots \ldots \ldots \ldots \ldots \ldots \ldots \ldots \ldots \ldots \ldots \ldots$

6. Scheme of Dimer Transport Mechantsm for Class

II Uncouplers $\ldots \ldots \ldots \ldots \ldots \ldots \ldots \ldots \ldots \ldots \ldots$

7. Experimental Set Up for Measurements of DC

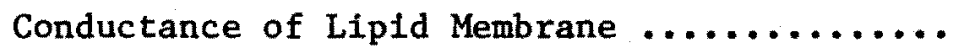

8. $\mathrm{pH}$ Dependence of Conductivity of LecithinCholesterol Lipid Membranes in the Presence of $1 \mathrm{mM}$ of 2,4-D in the Aqueous Solution

9. pH Dependence of Conductivity of LecithinCholesterol Lipid Membranes in the Presence of $1 \mathrm{mM}$ of $2,4-\mathrm{DB}$ in the Aqueous Solution 
10. pH Dependence of Conductivity of Lecithin-

Cholestero1 Lipid Membranes in the

Presence of $0.1 \mathrm{mM} \mathrm{2,4,5-T}$ in the Aqueous

Solution $\ldots \ldots \ldots \ldots \ldots \ldots \ldots \ldots \ldots \ldots \ldots$

11. $\mathrm{pH}$ Dependence of Conductivity of Lecithin-

Cholesterol Lipid Membranes in the

Presence of $0.4 \mathrm{mM} \mathrm{2,4-DCP}$ in the Aqueous

Solution

12. Effect of Concentration of 2,4-D at $\mathrm{pH} 2.7$ on

Membrane Conductance

13. Effect of Concentration of $2,4-\mathrm{DB}$ at $\mathrm{pH} 5.0$ on

Membrane Conductance .................

14. Effect of Concentration of $2,4,5-\mathrm{T}$ at $\mathrm{pH} 2,4$

on Membrane Conductance .............

15. Effect of Concentration of 2,4-DCP at $\mathrm{pH} 9.5$ on Membrane Conductance

16. Effect of Proton Concentration in the Aqueous

Solution on the Voltage Dependence of

Membrane Conductance for $0.4 \mathrm{mM} \mathrm{2,4-DCP}$

Membrane Conductance 1s Normalized to that

at $25 \mathrm{mV}$

17. Effect of Concentration of 2,4-DCP on the Voltage Dependence of Membrane Conductance at $\mathrm{pH}$ 9.5. Membrane Conductance is

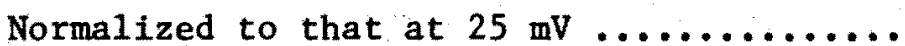


18. Nonactin-K $\mathrm{K}^{+}$- induced Membrane Conductivity as a Function of $\mathrm{pH}$ in the Absence of Pesticides

19. The Effect of Presence of 2,4-D on the

Conductivity Induced by Nonactin-K $\mathrm{K}^{+}$

Complex at pH $2.7 \ldots \ldots \ldots \ldots \ldots \ldots \ldots \ldots \ldots \ldots \ldots \ldots \ldots$

20. The Effect of Presence of 2,4-DB on the Conductivity Induced by Nonactin- ${ }^{+}$ Complex at pH 5.0

21. The Effect of Presence of $2,4,5-T$ on the Conductivity Induced by Nonactin- $\mathrm{K}^{+}$ Complex at pH $2.4 \ldots \ldots \ldots \ldots \ldots \ldots \ldots \ldots \ldots \ldots \ldots \ldots \ldots \ldots$

22. The Effect of Presence of 2,4-DCP on the Conductivity Induced by Nonactin-K $\mathrm{K}^{+}$ Complex at pH 9.5

23. Effect of Ionic Strength of the Aqueous Solution on the Level of Nonactin-induced Conductivity (at $25 \mathrm{mV}$ ) Enhanced by the

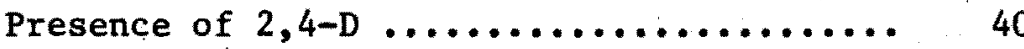

24. Kinet1c Scheme of Charge Transfer ........... 44

25. Comparison of Theoretical and Experimental Voltage Dependence of Membrane Conductance for $0.1 \mathrm{mM} 2,4-\mathrm{DCP}$ 
26. Comparison of Theoretical and Experimental

Voltage Dependence of Membrane

Conductance for $0.25 \mathrm{mM} 2,4-\mathrm{DCP} \ldots \ldots \ldots \ldots 54$

27. Comparison of Theoretical and Experimental

Voltage Dependence of Membrane

Conductance for $0.4 \mathrm{mM} 2,4-\mathrm{DCP} \ldots \ldots \ldots \ldots \ldots 55$

28. Comparison of Theoretical and Experimental

Voltage Dependence of Membrane

Conductance for $0.7 \mathrm{mM} 2,4-\mathrm{DCP} \ldots \ldots \ldots \ldots \ldots$

29. Comparison of Theoretical and Experimental

Vo1tage Dependence of Membrane

Conductance for $2 \mathrm{mM} 2,4-D C P \ldots \ldots \ldots \ldots 57$

30. Dependence of $\bar{x}$ on the Concentration of

$2,4-\mathrm{DCP} \ldots \ldots \ldots \ldots \ldots \ldots \ldots \ldots \ldots \ldots \ldots \ldots \ldots \ldots, 58$

31. Effect of $\mathrm{pH}$ on the Voltage Dependence of

Membrane Conductance Normalized at

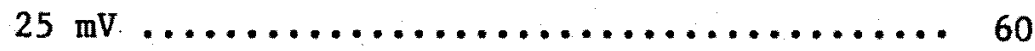

32. Change in the Membrane Surface Potential as a

Function of the Pesticide Concentration ..... 66

33. Concentration Dependence of Membrane

Conductivity Induced by $2,4-D$ at

$\mathrm{pH} 2.7 \ldots \ldots \ldots \ldots \ldots \ldots \ldots \ldots \ldots \ldots \ldots \ldots \ldots \ldots$

34. Concentration Dependence of Membrane

Conductivity Induced by $2,4-\mathrm{DB}$

at $\mathrm{pH} 5.0 \ldots \ldots \ldots \ldots \ldots \ldots \ldots \ldots \ldots \ldots \ldots \ldots \ldots \ldots$ 
35. Concentration Dependence of Membrane

Conductivity Induced by $2,4,5-T$

at $\mathrm{pH} 2.4 \ldots \ldots \ldots \ldots \ldots \ldots \ldots \ldots \ldots \ldots \ldots$

36. Concentration Dependence of Membrane

Conductivity Induced by $2,4-D C P$

at $\mathrm{pH} 9.5 \ldots \ldots \ldots \ldots \ldots \ldots \ldots \ldots \ldots \ldots \ldots \ldots \ldots \ldots \ldots \ldots$

37. Effect of Ionic Strength on Nonactin-K ${ }^{+}$

Conductance Enhanced by $2,4-D \ldots \ldots \ldots \ldots . . \ldots 77$ 
CHAPTER I

INTRODUCTION

Blological membranes play a fundamental role in processes assoclated with 1ife. They provide physical and biochemical compartmentalization, regions for organization of energy transduction mechanIsms, sites for enzymatic reactions, and selective transport of metabolites. In our present work we are interested in the effect of different pesticides on the charge transport properties of membranes.

The major constituents of biological membranes are protein and 11pid, the latter being mainly comprised of phospholipid and cholesterol. A characteristic feature of lipid molecules is that they have two regions with different properties: a polar head with uneven electron density distribution, and a nonpolar tail consisting of hydrocarbon chains with more or less unfform electron density distribution (Fig. 1). It is this property which determines the orfentation of lipid molecules when in contact with an aqueous solvent. As would be expected, the minimum energy configuration is one in which the contact between polar and nonpolar constituents is at a minimum. This corresponds to a bilayer, with the hydrocarbon chains of the lipid molecules in close contact, and the polar regions in contact with the aqueous phase. Indeed, recent $\mathrm{X}$-ray diffraction studies indicate that all blological membranes are bilayers, regardless of their spectfic function (1). The arrangement of lipid molecules as a bilayer in an aqueous medium is shown in Fig. 2. 


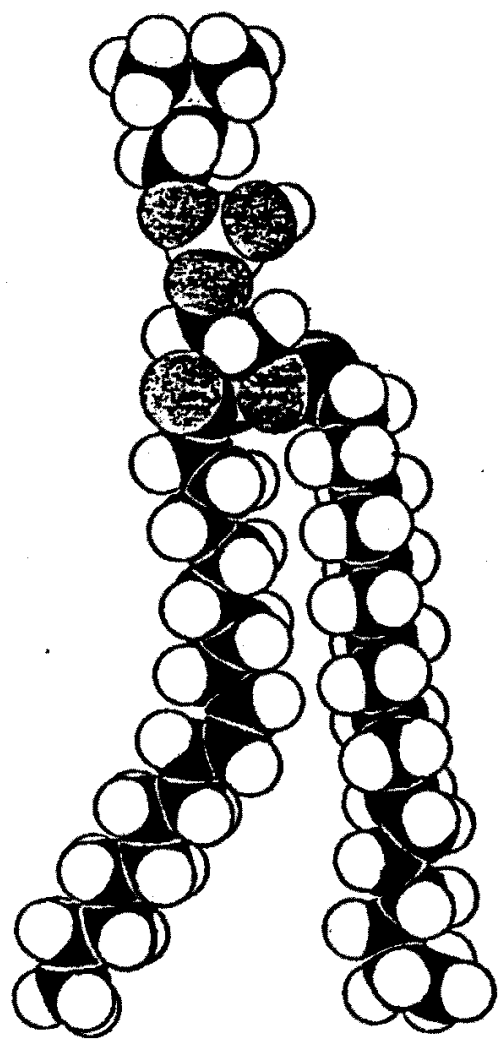

\section{LECITHIN}

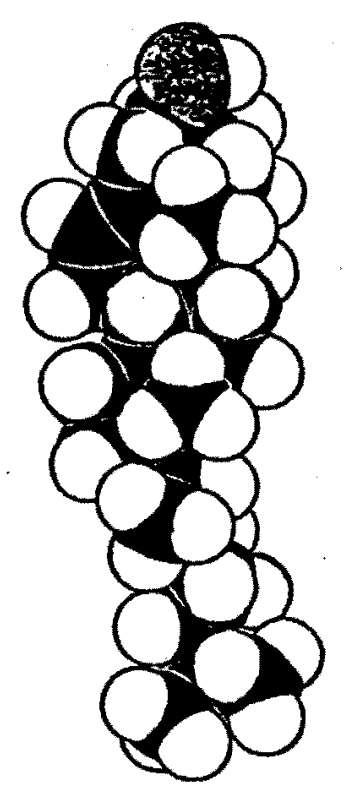

CHOLESTEROL

FIg. 1 Molecular models of lecithin and cholesterol.

Since the discovery of Wueller, Rudin, Tien, and Wescott (2) that relatively stable lipid bilayer membranes could be formed in vitro, these structures have been extensively studied as models for biological membranes. These artificial membranes resemble the structure of biological membranes in thickness and in dielectric constant. Because of the absence of complicated compounds such as proteins, the artificial membrane allows a more direct investigation of the mechanism of penetration of lons through 11pid structures by measuring its electrical characteristics. 
$\begin{array}{lll}\text { AQUEOUS } & \text { BIMOLECULAR } & \text { AQUEOUS } \\ \text { SOLUTION } & \text { MEMBRANE } & \text { SOLUTION }\end{array}$

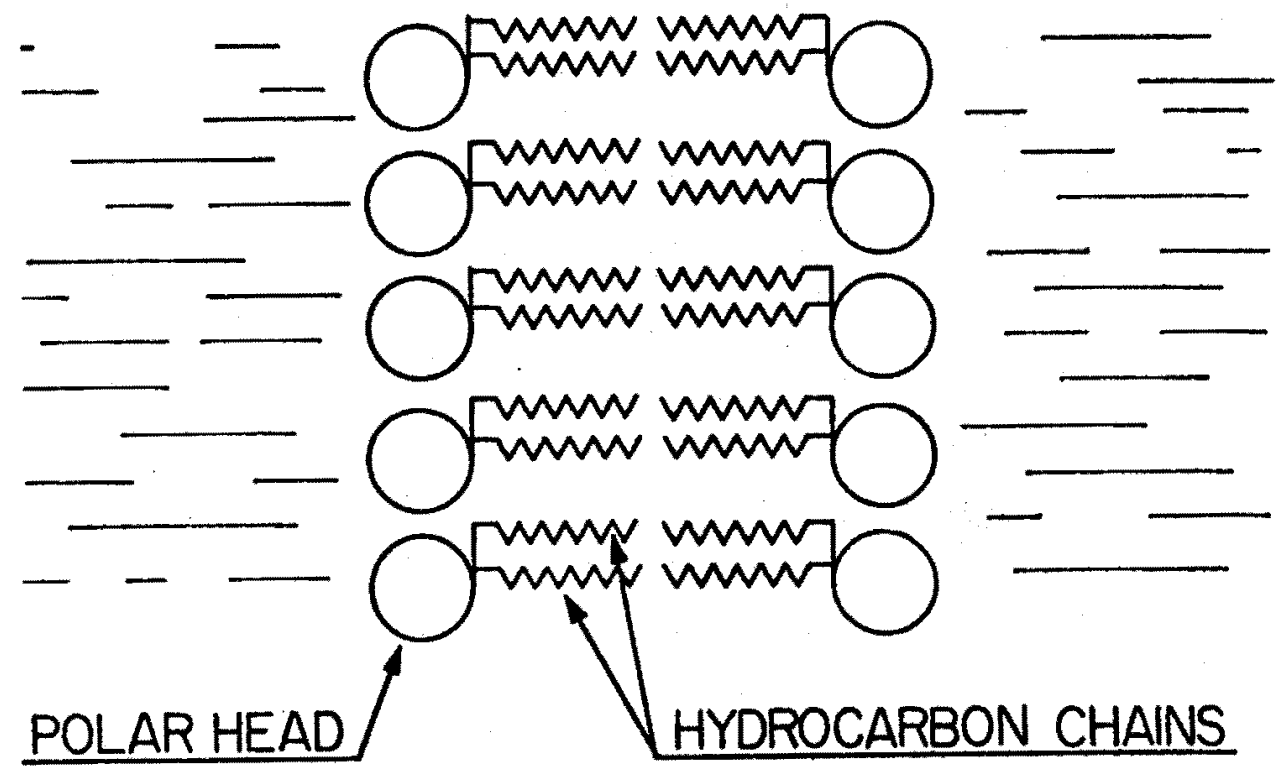

Fig. 2. Arangement of phospholipid molecules in bilayer membrane.

One of the most easily measurable properties of the lipid bilayer membrane is the DC conductivity of the membranes in aqueous electrolytic solutions. The electrical conductivity of an unmodifled lipid bilayer is very smal1. This is because the membrane is not very permeable to ions such as $\mathrm{H}^{+}, \mathrm{OH}^{-}, \mathrm{K}^{+}$, and $\mathrm{Cl}^{-}$. The low conductivity can be explained by considering the difference in self energy of the Ions in high and low dielectric medium. The self energy of an ton represented as a conductive sphere with charge $q$ and radius $R$ in a medium of dielectric constant $\varepsilon$, is given by

$$
E=\frac{q^{2}}{8 \pi \varepsilon_{0} R} \frac{1}{\varepsilon}
$$


Therefore the extra energy which is required to transfer an Ion from a medium with high dielectric constant $\varepsilon_{w}$, such as water, into a less polarizable medium $\varepsilon_{m}$, such as lipid membrane can be written as

$$
\Delta E=\frac{q^{2}}{8 \pi \varepsilon_{o}^{R}}\left(\frac{1}{\varepsilon_{m}}-\frac{1}{\varepsilon_{w}}\right)
$$

Since the energy difference is inversely proportional to the radius of the lon, the energy barrier for lons with a small radius is higher than that for large lonic molecules. For example, an Ion 1ike tetraphenyl borate which has excess electron charge distributed over four benzene rings, enters or partitions more easily into 11pids than $\mathrm{H}^{+}$or $\mathrm{Na}^{+}$. In fact, it has been found that the electrical conductivity of the membrane is increased by many orders of magnitude in the presence of these large lipid soluble molecular ions (3).

Antiblotics are a class of substances which have been studied extensively by means of the measurement of electrical conductivity of bilayer lipid membranes. Examples are nonactin and valinomycin. It has been found that the membrane conductivity is enhanced markedly when these substances and the alkall cations such as $\mathrm{K}^{+}$and $\mathrm{Na}^{+}$are present in the aqueous electrolytic solution $(4,5)$. It has been concluded that these 1ipid soluble molecules act as carriers for the membrane impermeable alkal1 ions.

Since the chemi-osmotic hypothesis has been put forward by Mitchell, great attention has been paid to the studies of the action of uncoupling agents of oxidative phosphorylation on artificial bilayer membranes. According to this hypothesis, uncouplers increase the proton 
permeability of the mitochondrial membranes, thus preventing the formation of the $\mathrm{pH}$ gradient which is postulated to be the driving force for the synthesis of ATP from ADP and phosphate. This aspect of Mitchel1's hypothesis has been tested by experiments with lipid bilayer membranes. The membrane conductivity has been observed to increase by several orders of magnitude in the presence of small amounts of these uncouplers. From these studies it has been concluded that the uncouplers enhance the membrane conductivity by means of helping the impermeable $\mathrm{H}^{+}$Ions to penetrate the membrane $(6)$; in other words, the uncouplers act as proton carriers. This is in agreement with Mitchell's chemi-osmotic hypothesis.

It has been found that the conductivity of 11pid bilayer membranes increases with uncoupler concentration and is $\mathrm{pH}$ dependent, showing a maximum at a certain $\mathrm{pH}$ value. Uncouplers are now classifled according to the dependence of conductance upon thelr concentration in the aqueous solution. A class I uncoupler is one which exhibits a linear dependence of membrane conductivity with uncoupler concentration, and a class II uncoupler exhibits quadratic dependence. LeBlanc pointed out that there should be at least two mechanisms of charge transport to account for the two different classes of uncouplers (7).

Several hypotheses have been proposed to explain the mechanism by which the electrical conductivity of the membrane is increased in the presence of uncouplers of oxidative phosphorylation: (a) Proton Transfer Mechanlsm, proposed by Markin et al. (8), (b) Relay Mechanism, proposed by Chizmadzhev et a1. (9), (c) Proton Carrier Mechanism, first proposed by Markin et a1. $(8,10)$, and further developed by LeBlanc $(7)$, and 
(d) Dimer Transport Mechanism, proposed Independently by Lea and Croghan (11) and by Finkelstein (12). The last one is particualrly applied to class II uncouplers.

\section{Proton Transfer Mechanism.}

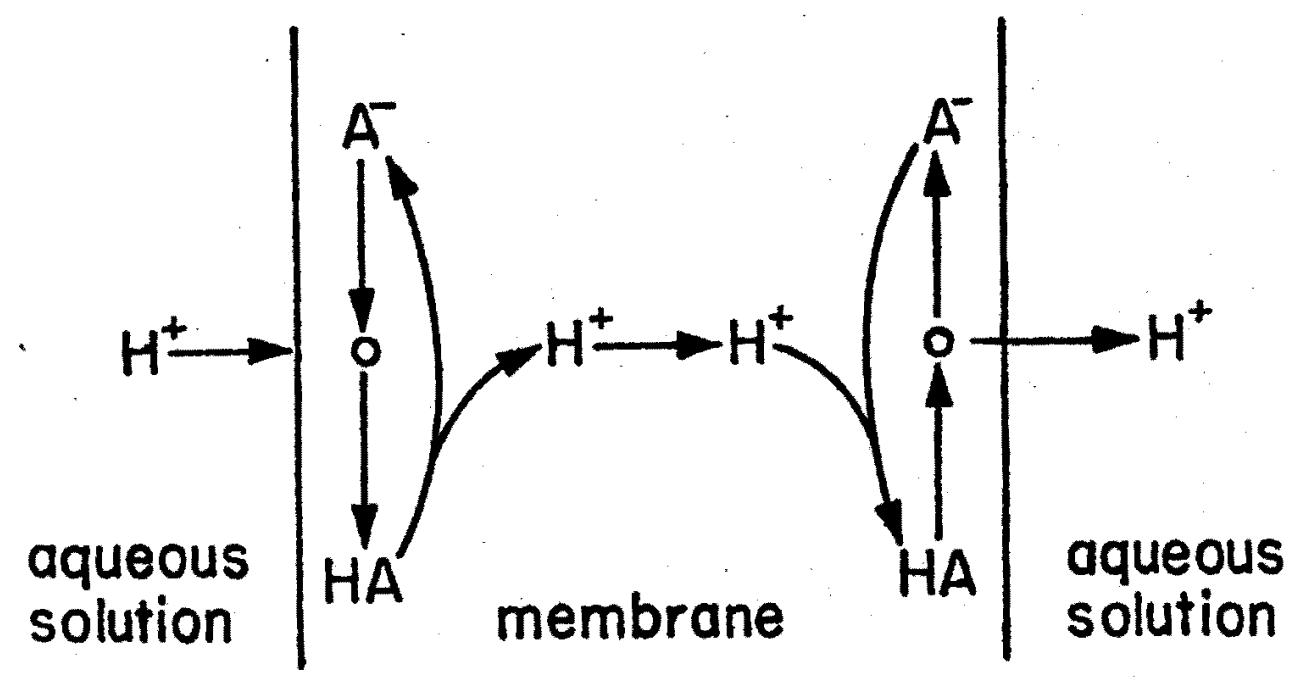

Fig. 3. Schematic representation of mechanism of direct transfer of protons across the membrane.

In this model, the uncoupler anion $\mathrm{A}^{-}$adsorbed at the membrane surface combines with a proton from the aqueous phase and thus enables the proton to penetrate through the interface into the membrane hydrocarbon region (Fig. 3). Within the membrane the proton is assumed to dissociate again and migrate across the membrane to the opposite interface where it is expelled by means of a similar mechanism. According to this model, the conductivity should increase monotonically with the proton concentration: thus existence of a conductivity maximum at a certain $\mathrm{pH}$ of the aqueous phase can not be explained. 
Relay Mechanism.

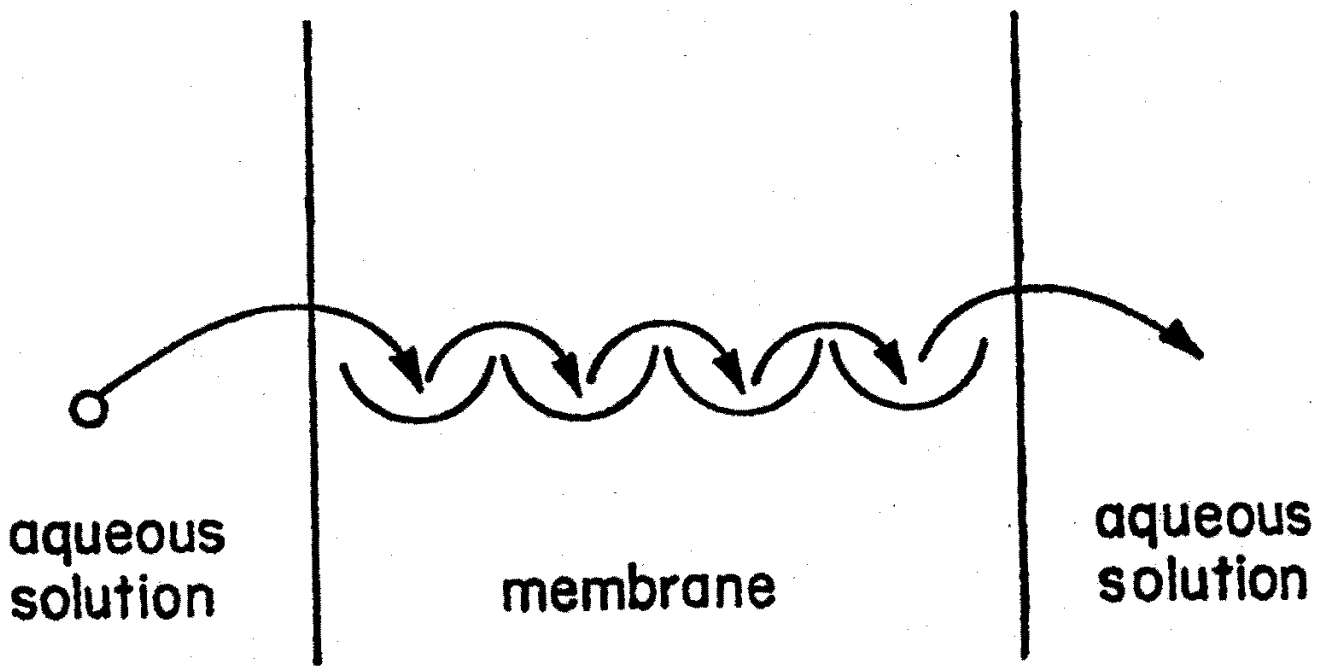

Fig. 4. Scheme of Ion transfer across the membrane according to the relay transfer mechanism.

Here it is assumed that in the membrane there are molecules or groups forming a chaln of sites across the membrane which can form complexes with the membrane permeable Ions (Fig. 4). The ions from the solution strike the site present at the surface and then move under the action of the field, along the chain by jumping from one site to the other. Although this theory can predict correctly the pH dependence of membrane conductivity, it is unable to explain the concentration dependence of the conductivity for different classes of uncouplers.

\section{Proton Carrier Mechanism.}

The uncoupler anion $\mathrm{A}^{-}$at one membrane boundary, links up with proton $\mathrm{H}^{+}$from the solution, diffuses in the neutral form across the membrane, and releases the proton into the opposite solution. This anion $\mathrm{A}^{-}$then moves back to the first boundary, completing the cycle 


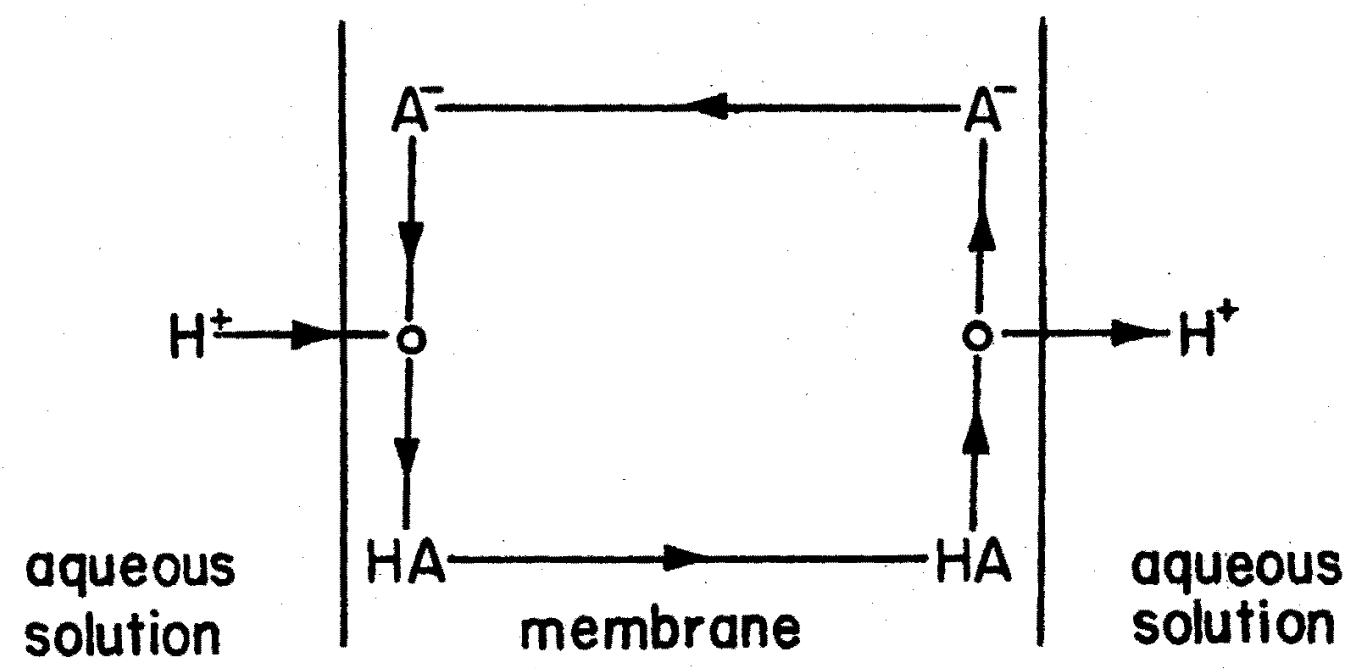

Flg. 5. Scheme of proton carrier mechanism for class I uncouplers.

(Fig. 5). With this mode1, the occurrence of a conductivity maximum at a certain $\mathrm{pH}$ of the aqueous solution can be explained, and the dependence of the conductivity on the concentration of the membrane modifier is linear. This model has been found suitable for class I uncouplers such as carbonylcyanide m-chlorophenylhydrazone (CCCP) (7).

\section{Dimer Transport Mechanism.}

The basic feature of this model is that the membrane permeable ion is a dimer $\mathrm{HA}_{2}^{-}$. The model predicts the quadratic concentration dependence of conductivity, thus it was proposed to explain the properties of class II uncouplers. Another important feature that has been observed is the "be11 shaped" $\mathrm{pH}$ dependence of conductivity which can be simply explained by the $\mathrm{pH}$ dependence of neutral and antonic form of the uncoupler. The end result of this mechanism is a transfer of protons from one side of the membrane to the other (Fig. 6). 


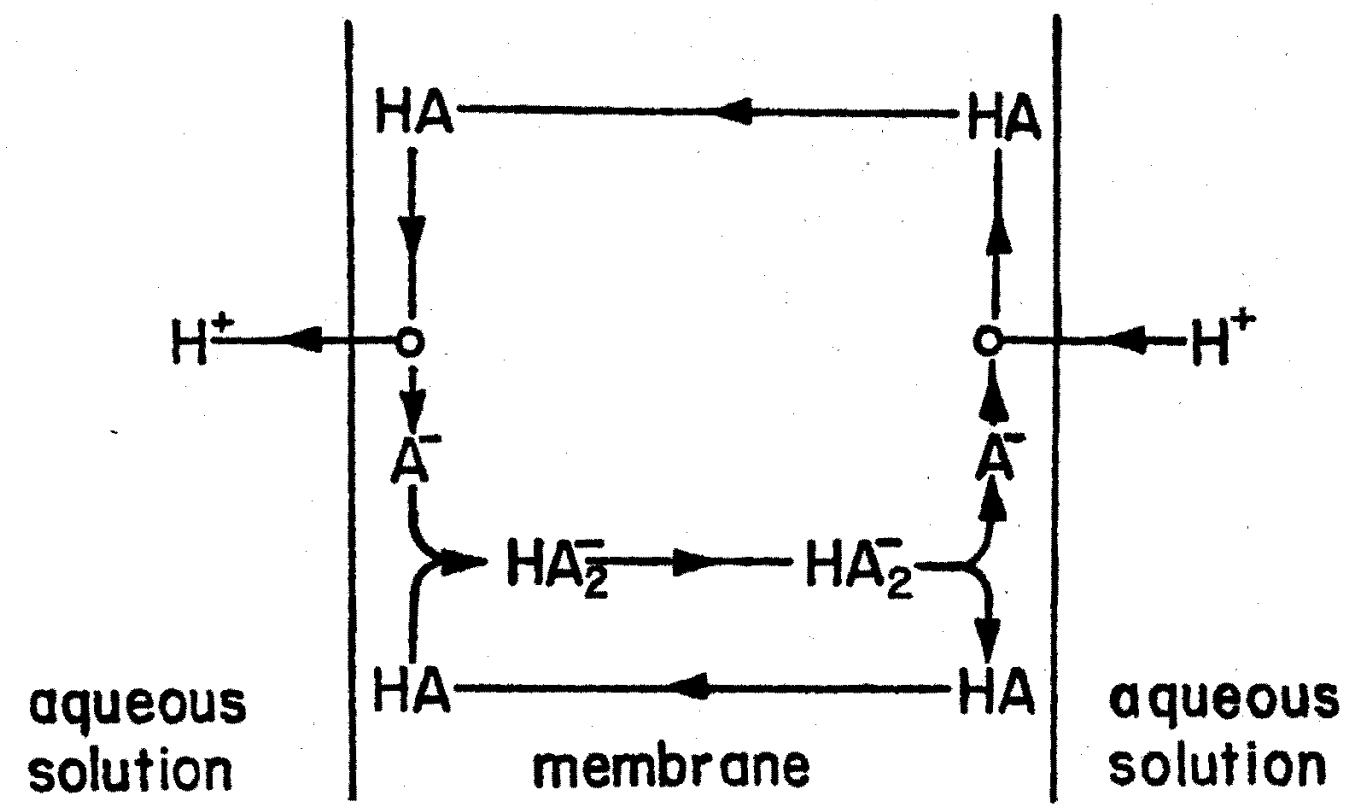

F1g. 6. Scheme of Dimer Transport Mechanism for Class II Uncouplers

Since the toxicity of some pesticides has its origin in uncoupling oxidative phosphorylation from ATP synthesis, we have selected some pesticides to investigate their effect on DC conductivity of lectthincholesterol lipid membranes. They are endothall, paraquat, and diquat, and a series of phenoxy compounds, which are 2,4-dichlorophenoxy acetic acid $(2,4-D), 2,4-d i c h l o r o p h e n o x y$ butyric acid $(2,4-D B), 2,4,5-$ trichlorophenoxy acetic acid $(2,4,5-T)$, and 2,4-dichlorophenol (2,4-DCP).

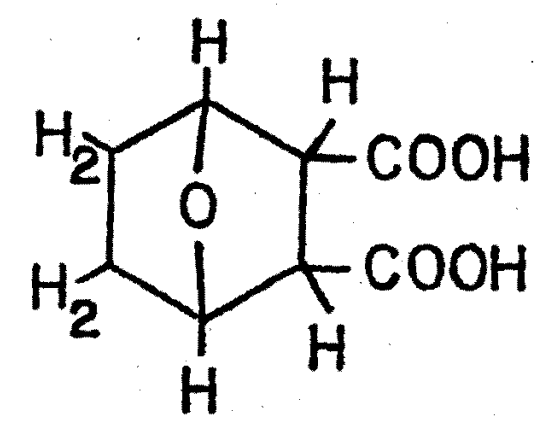


Endotha11, 7-oxabicyclo (2.2.1) heptane-2,3-dicarboxy1ic acid, is a ring structured, water soluble compound which is used as a general purpose herbicide and as an aquatic weed herbicide $(13,14)$. The herbicidal action of this compound is not well defined since little is known of 1 ts metabolism in plants. As this molecule possesses two ionizable carboxy1 groups (- $\mathrm{COOH})$, we were interested in investigating the permeability of endotha11 fons across the lipid bilayer membranes.

\section{$\underline{\text { Paraquat and Diquat }}$}
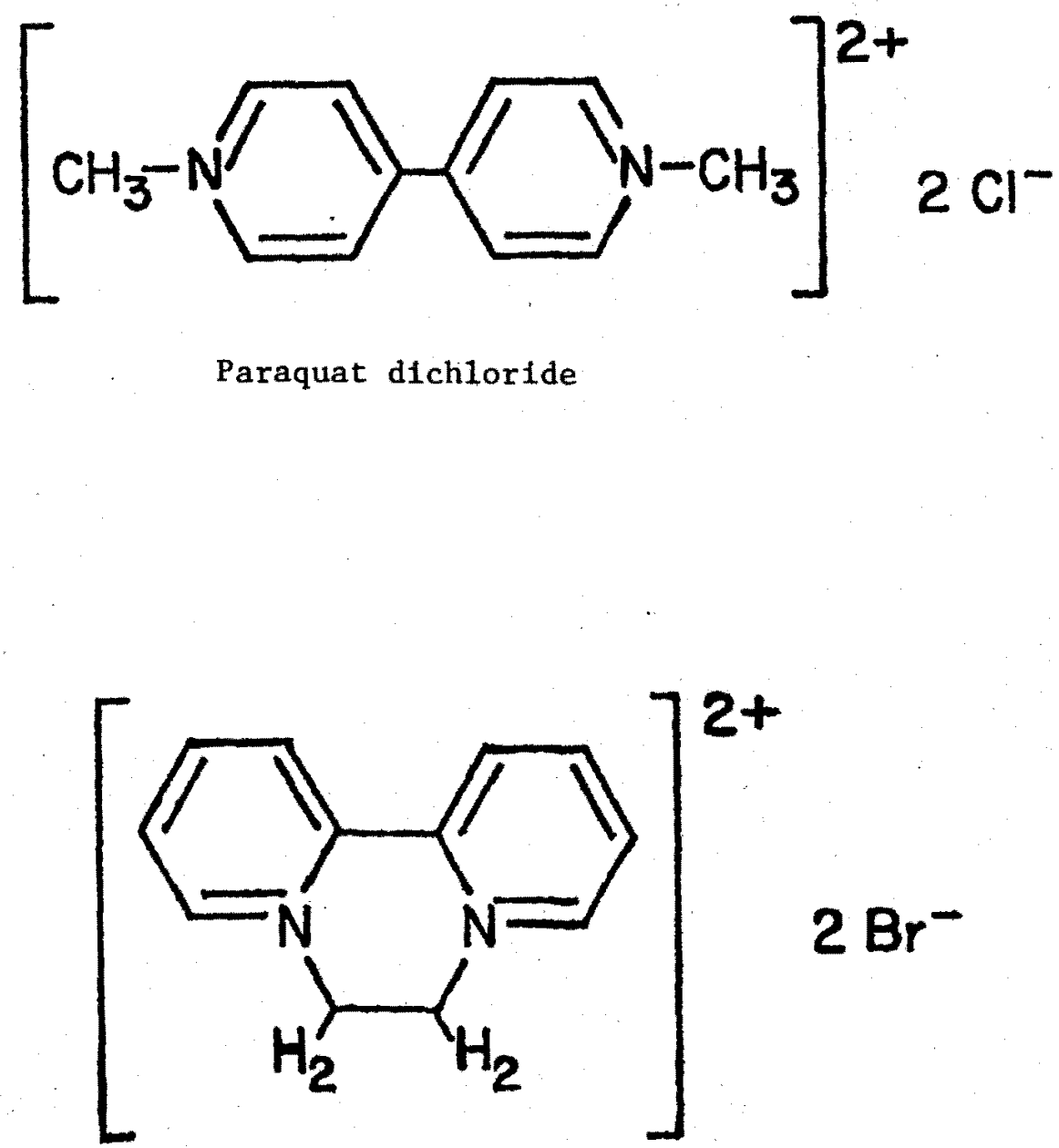

Diquat dibromide 
Paraquat, 1,1'-dimethyl -4,4'-bipyridinium 1on, and diquat, 6,7 dihydrodipyrido $\left(1,2-a: 2^{\prime}, 1^{\prime}-c\right)$ pyrazinedium ion, are known as bipyridylium herbicides, and are used as general contact weed control agents (15). The main herbicidal activity of these compounds is by producing free radicals (which are toxic to plants) formed by electron transfer during photosynthesis $(16,17)$. Since these compounds form cations in solution and also because their activity is related to the electron transport, we were interested in their effect on electrical conductivity.

$2,4-D, 2,4-D B, 2,4,5-T$, and $2,4-D C P$
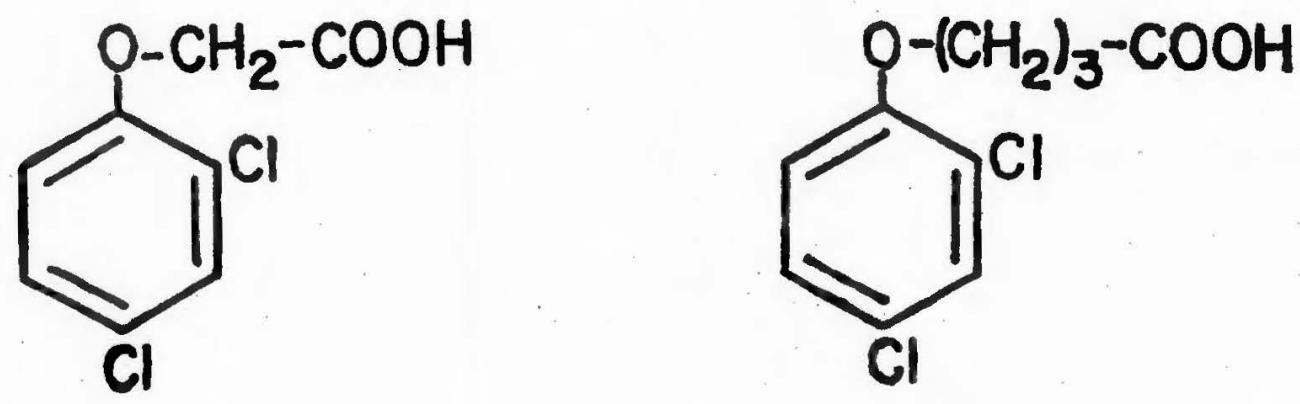

$2,4-D$

$2,4-1 \mathrm{DB}$
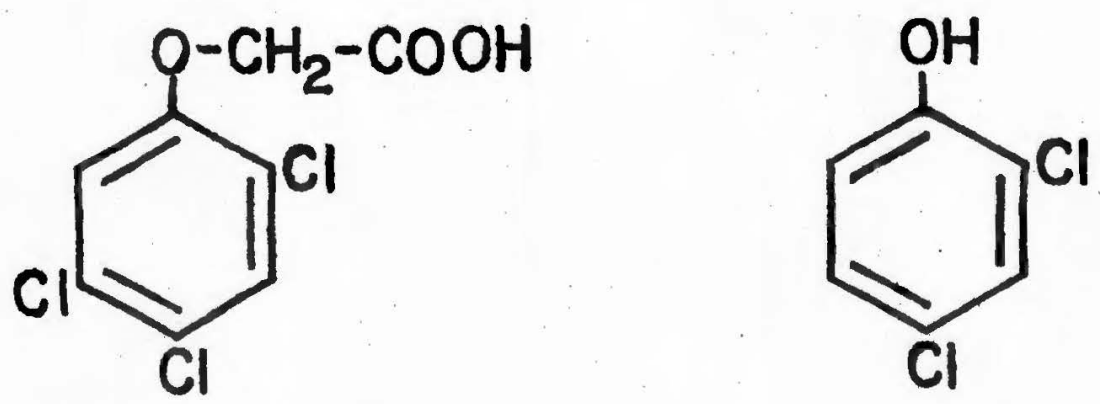

$2,4,5-T$

$2,4-D C P$ 
2,4-dichlorophenoxy acetic actd $(2,4-D), 2,4-d i c h l o r o p h e n o x y$ butyric acid $(2,4-D B)$, and $2,4-t r i c h l o r o p h e n o x y$ acetic acid $(2,4,5-T)$, are classified as pehnoxy compounds and have a wide herbicidal action. They have been known to act as uncouplers of oxidative phosphorylation (18), and as compounds that unbalance the hormonal growth (19). Their presence affects synthesis of different kinds of proteins (20); some affect photosynthesis (21). For its structural similarity we also include 2,4-dichlorophenol $(2,4-D C P)$ into this group. This compound is also known to be an uncoupling agent of oxidative phosphorylation (22). Therefore it is of interest to know the effect of these substances on the electrical conductivity of lipid bllayer membranes assuming that better understanding of charge translocation will contribute to elucidating their pesticidal activity on a molecular level. 
CHAPTER II

\section{EXPERIMENTAL METHODS}

\section{Materials:}

The chromatographically pure lecithin used to form the membrane was from fresh chicken egg yolks and purified by Dr. Kwan Hsu using the method of Singleton et al. (23) with some modifications (24). The lipid was stored in chloroform solution under nitrogen atmosphere in sealed ampoules at $-15^{\circ} \mathrm{C}$ until use. Recrystalized cholesterol was a gift from Dr. David McClure of the Chemistry Department. Endothal1 ( $99.99 \%$ pure) was obtained from Penwalt Corporation, Tacoma, Wash. Ortho paraquat and diquat from Chevron Company, San Francisco, Cal, were 100\% pure. 2,4dichlorophenoxy acetic acid $(2,4-D)$, (purity 99\%) and 2,4,5-trichlorophenoxy acetic acid $(2,4,5-\mathrm{T})$, (purity $99 \%+$ ) were recelved from Dow Chemical Company, Midland, Mich, and 2,4-dichlorophenoxy butyric acid (purity 99.4\%) was from Chapman Division of Rhodia Inc., Portland, OR. 2,4-dichlorophenol (2,4-DCP) was purchased from Aldrich Company and was repurified by sublimation method. Purity of this compound was judged from its melting point, by comparing its UV spectra with those given by Lang (25), and from its infra-red spectra (26). Nonactin was a gift from Squibb Institute of Medical Research. N-decane was purchased from Aldrich Chemical Company, Milwaukee, Wis.

The membrane forming solution was prepared by dissolving weighed amounts of lecithin and cholesterol in n-decane. The lecithin concen- 
tration was kept around $5 \mathrm{mM}$ and the cholesterol mole fraction used was 0.8 . The electrolytic solution contained $0.1 \mathrm{M} \mathrm{KCl}, 5 \times 10^{-4} \mathrm{M} \mathrm{KOH}$ and buffer composed of potassium dibasic phosphate, potassium citrate and boric acid in the ratio $1: 1: 0.25(0.2 \mathrm{M} / 0.2 \mathrm{M} / 0.05 \mathrm{M})$. Unless stated, these data represent the salt composition of the aqueous solution. Stock solutions of pesticides were prepared in $10^{-3} \mathrm{M} \mathrm{KOH}$. Buffer, $\mathrm{KCl}$ and pesticides were mixed in appropriate ratios to get the final concentration required and were titrated with $\mathrm{KOH}$ or $\mathrm{LiOH}$ or $\mathrm{HCl}$ to adjust to the necessary $\mathrm{pH}$. The $\mathrm{pH}$ of the solution was determined with a Corning model $7 \mathrm{pH}$ meter. For the nonactin experiments, stock nonactin solution was prepared at about $10^{-3} \mathrm{M}$ in $\mathrm{EtOH}$ and kept in the refrigerator in a dark bottle. An approprlate amount of nonactin in ethyl alcohol solution was added to the pesticide solution; the volume of ethanol was about $0.5 \%$ of the total fluid. Deionized dist11led water from a millipore Q2 system, with resistivity exceeding $10 \mathrm{M} \mathrm{ohm}-\mathrm{cm}$, was used in the preparation. All the required electrolytic solutions, with or without pesticide, were made fresh every day from their stock solutions.

\section{Experimental Set Up}

The experimental set up shown in Fig. 7, consists of two main parts: the electrolyte filled cell with the artificial membrane and the electric circuit used to apply and measure the current and the voltage across the membrane.

The lecithin-cholesterol membrane was formed over a hole with a diameter of $1.925 \mathrm{~mm}$ in a cylindrical teflon cup situated in a transparent rectangular container. Thus the cell consisted of two compartments with the electrolytic solution separated by the membrane. Two different 


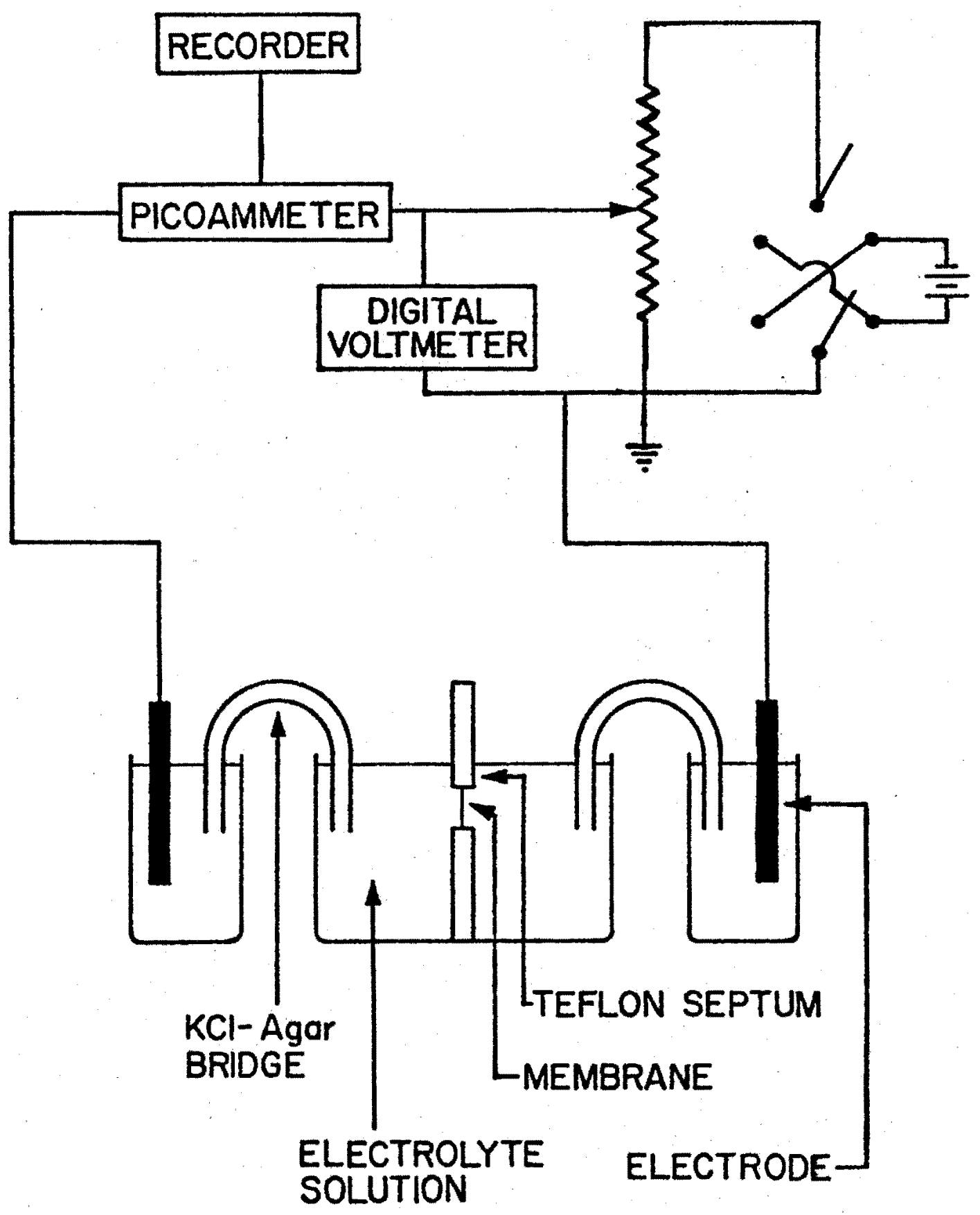

Figure 7. Experimental set up for measurements of DC conductance of lipid membranes. 
kinds of electrodes were used: fiber tip calomel (Corning Science Products, Corning, N.Y.) and Ag/AgCl (Annex Instruments, Santa Ana, Calif.). To prevent contamination of electrodes with pesticides, the electrodes were connected to the cell solutions by means of $\mathrm{KC1}$ saturated agar bridges. The resistance of calomel electrodes is of the order of $10 \mathrm{k} \Omega$, the resistance of the bridges is about $2 \mathrm{k} \Omega$. When the resistance of the membranes became comparable with the internal resistance of the calomel electrodes, $\mathrm{Ag} / \mathrm{AgC1}$ electrodes were used whose resistance was of the order of 10 ohms.

The electrical circult consisted of a Kelthley Picoammeter Model 417, a digital voltmeter, a chart recorder and a potentiometer circuit to apply a voltage across the membrane.

\section{Membrane Formation}

Membranes were formed by the brush technique (27), using sable brush (size 000, and 0000) to spread the membrane forming solution over the hole in the wall of the teflon cup immersed in the electrolyte solution. In all the conductivity measurements, membranes were formed in the electrolytic solution with or without the pesticide or nonactin.

For cleaning, the cell was boiled in $95 \%$ ethanol containing sodium hydroxide pellets and rinsed several times with deionized water. Several coatings of membrane forming solution were applied to the dry cell surface around the orifice, as well as on the edge, until an even reflecting surface was formed. Between successive coatings the solution was blown dry with nitrogen. When the cell was well prepared, the membrane lasted more than three hours.

The progress of thinning of the membrane was observed in reflected 
light through a microscope. In order to reduce the equilibration time and fluctuations of membrane area from membrane to membrane, the thickness of the torus was kept small by using minimal amounts of membrane forming solution to paint the membrane. Also the level of fluid in the cell was kept no more than 2-3 mm above the hole to minimize the hydrostatic pressure difference between the cell compartments due to the displacement of some of the electrolytic solution by the paint brush.

\section{E1ectrical Measurements}

The current-voltage data were taken after the membrane became black and the conductivity reached a constant level. W1th phenoxy compounds in the system the conductivity varied with time between upper and lower limits. This was judged from monitoring the current either continuously or Intermfttently at a voltage of about $25 \mathrm{mV}$ applied across the membrane. Current-voltage data were taken when the current stabilized at some Intermediate value. All the measurements were carried out at temperatures between $22^{\circ} \mathrm{C}$ and $23^{\circ} \mathrm{C}$.

Each data point shown in the figures represent an average value obtained from at least four different membranes; the error bar denotes one standard deviation. The specific conductance was calculated from the area of the hole; therefore, the values given in the figures represent the lower limits. Corrections for background membrane conductance were made when necessary. 
CHAPTER III

EXPERIMENTAL RESULTS

A. Exploratory Experiments with Endotha11, Paraquat and Diquat

\section{Al. Pesticide-induced Membrane Conductivity}

(a) Endothal1. The current-voltage characteristics of lipid bilayer membranes were measured in the presence of endothall in the aqueous solution. Endothall concentration varied from zero to $50 \mathrm{mM}$ and $\mathrm{pH}$ from 4 to 7 . In this $\mathrm{pH}$ range endothall dissociated first to the singly lonized form and finally to the doubly lonized form, since the endotha11 dissociation parameters are $\mathrm{pK}_{1}=3.4$ and $\mathrm{pK}_{2}=6.75$ (28). Under these conditions endothall did not induce electrical conductivity in 1ipid membranes.

(b) Paraquat and D1quat. Paraquat and diquat are water soluble organic salts which at neutral $\mathrm{pH}$ dissociate into positive and negative lons. Conductivity measurements were performed at $\mathrm{pH} 6$ and with concentrations from zero up to $100 \mathrm{mM}$. No significant increase of membrane conductivity was observed.

From these measurements it can be concluded that the lipid bilayer membrane is essentially impermeable to the ionic form of endotha11, paraquat and diquat. 
A2. Effect of Endotha11, Paraquat and Diquat on Nonactin-1nduced Membrane Conductivity

Although it was found that the membrane is not permeable to the Ionized form of these pesticides, it is possible that a change of membrane surface charge, due to adsorption of lonized pesticide molecules, may effect the transport of other lons across the membrane. It is known that the nonactin-induced conductivity is due to transport of the nonactin- $\mathrm{K}^{+}$complex across the membrane. It is expected therefore, on the basis of results reported by other investigators (29-32), that in the presence of a negative charge at the membrane surface the nonactininduced membrane conductivity would increase. Similarly, for a positive membrane surface charge, the conductivity would decrease (see section on surface charge). To test whether the membrane surface potential changes in the presence of endothall, paraquat or diquat, nonactin-induced membrane conductance was measured in their presence. The experiments were done at $\mathrm{pH} 6$ with nonactin concentration at $3.5 \mu \mathrm{M}$. In order to facilitate the development of greater surface potential due to the adsorbed pesticide related ions, the buffer concentration was lowered by a factor of 10 as compared to that used in the pesticide-induced conductivity measurements. The nonactin-induced membrane conductivity was measured in the absence and in the presence of pesticide in the aqueous phase. For endothall the concentration used was $10 \mathrm{mM}$, for paraquat it was $100 \mathrm{mM}$ and for diquat it was also $100 \mathrm{mM}$. No significant change of nonactin-induced conductance was observed in the presence of each pesticide. This indicates that the lonized form of the above pesticides does not adsorb at the membrane surface. 
B. Experiments with $2,4-D, 2,4-D B, 2,4,5-T$, and 2,4-DCP

B1. Effect of Proton Concentration on the Pesticide-Induced Membrane Conductivity

The experimental results giving the dependence of the membrane conductance on the $\mathrm{pH}$ of the aqueous phase are plotted in Figs. 8-11. Each data point represents the average value of conductance calculated from the current at a voltage of $25 \mathrm{mV}$ applied to the membrane. In these studies the concentration of pesticlde was chosen in such a way that pesticide precipitation did not occur at the lower $\mathrm{pH}$ used in the study. The following concentrations were used: 2,4-D (1mM), $2,4-\mathrm{DB}(0.1 \mathrm{mM}), 2,4,5-\mathrm{T}(0.1 \mathrm{mM})$, and $2,4-\mathrm{DCP}(0.4 \mathrm{mM})$. Typically, the high pesticide-induced conductivity in each run was about 1000 times greater than the membrane background conductivity.

For the phenoxy compounds, 2,4-D,2,4-DB and 2,4,5-T, the highest conductivity was observed at low $\mathrm{pH}$; that is, at high proton concentration in the aqueous phase. As the $\mathrm{pH}$ is increased, the membrane conductivity drops (Figs. 8-10). For 2,4-DCP, however, a maximum conductance is observed between $\mathrm{pH} 8$ and 8.5 ( $\mathrm{FIg}$. 11). At low $\mathrm{pH}$ a plateau is observed between $\mathrm{pH} 4$ and 6 at the conductance level of $4 \times 10^{-6} \mathrm{mho} / \mathrm{cm}^{2}$. Table I gives a list of pK values of the above pesticides. The experimental results show that a high membrane conductance occurs when the $\mathrm{pH}$ of the aqueous solution is close to the $\mathrm{pK}$ value of each pesticide.

B2. Concentration Dependence of Pestictde-induced Conductivity

Studies of the concentration dependence of induced conductivity are of considerable interest; since from their results, it is possible 


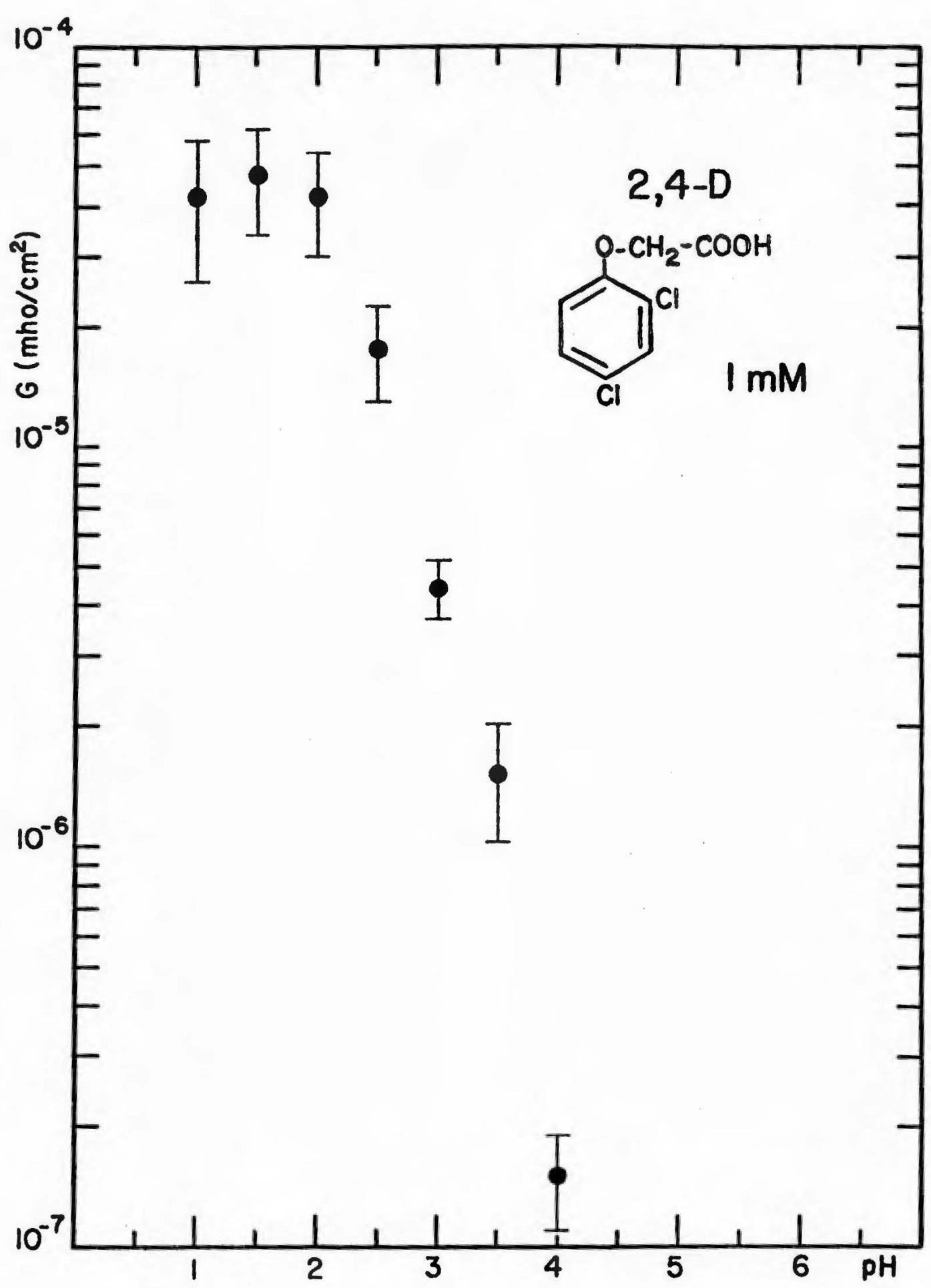

Figure 8. $\mathrm{pH}$ dependence of conductivity of lecithin-cholesterol lipid membranes in the presence of $1 \mathrm{mM}$ of 2,4-D in the aqueous solution. 


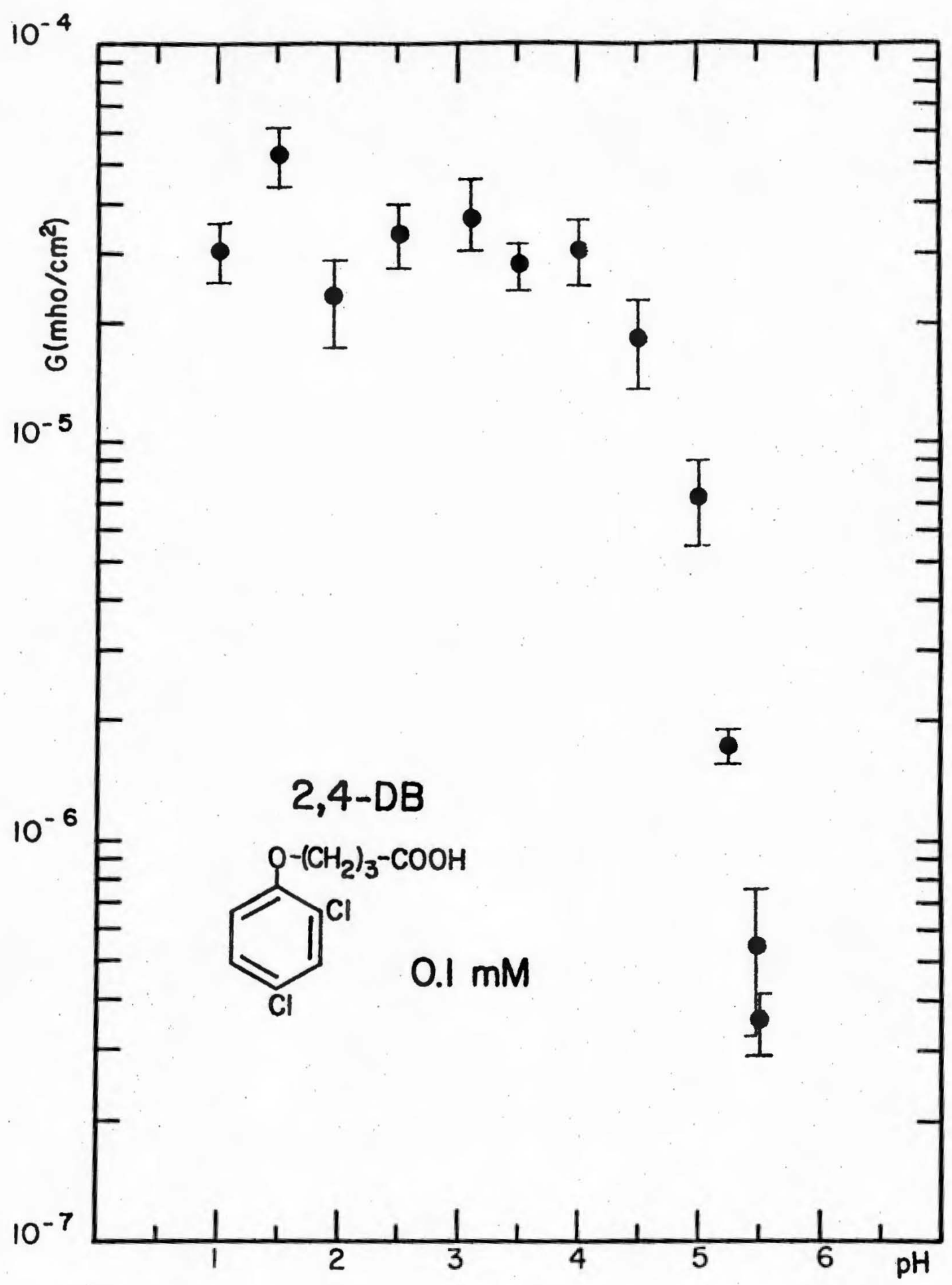

Figure 9. $\mathrm{pH}$ dependence of conductivity of lecithin-cholestero1 1ipid membranes in the presence of $0.1 \mathrm{mM} \mathrm{2,4-DB}$ in the aqueous solution. 


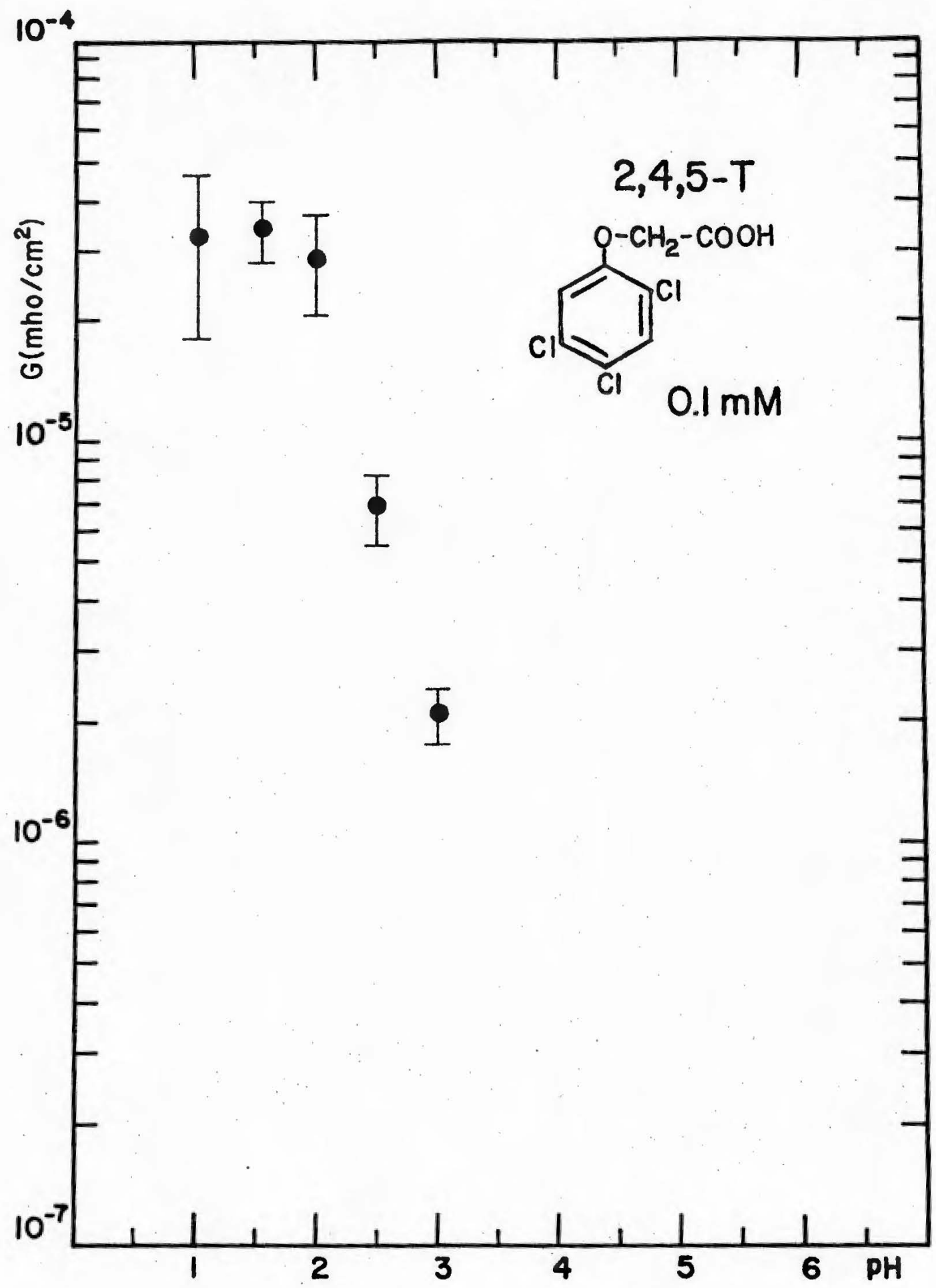

Figure 10. pH dependence of conductivity of lecithin-cholesterol lipid membranes in the presence of $0.1 \mathrm{mM} \mathrm{2,4,5-T}$ in the aqueous solution. 


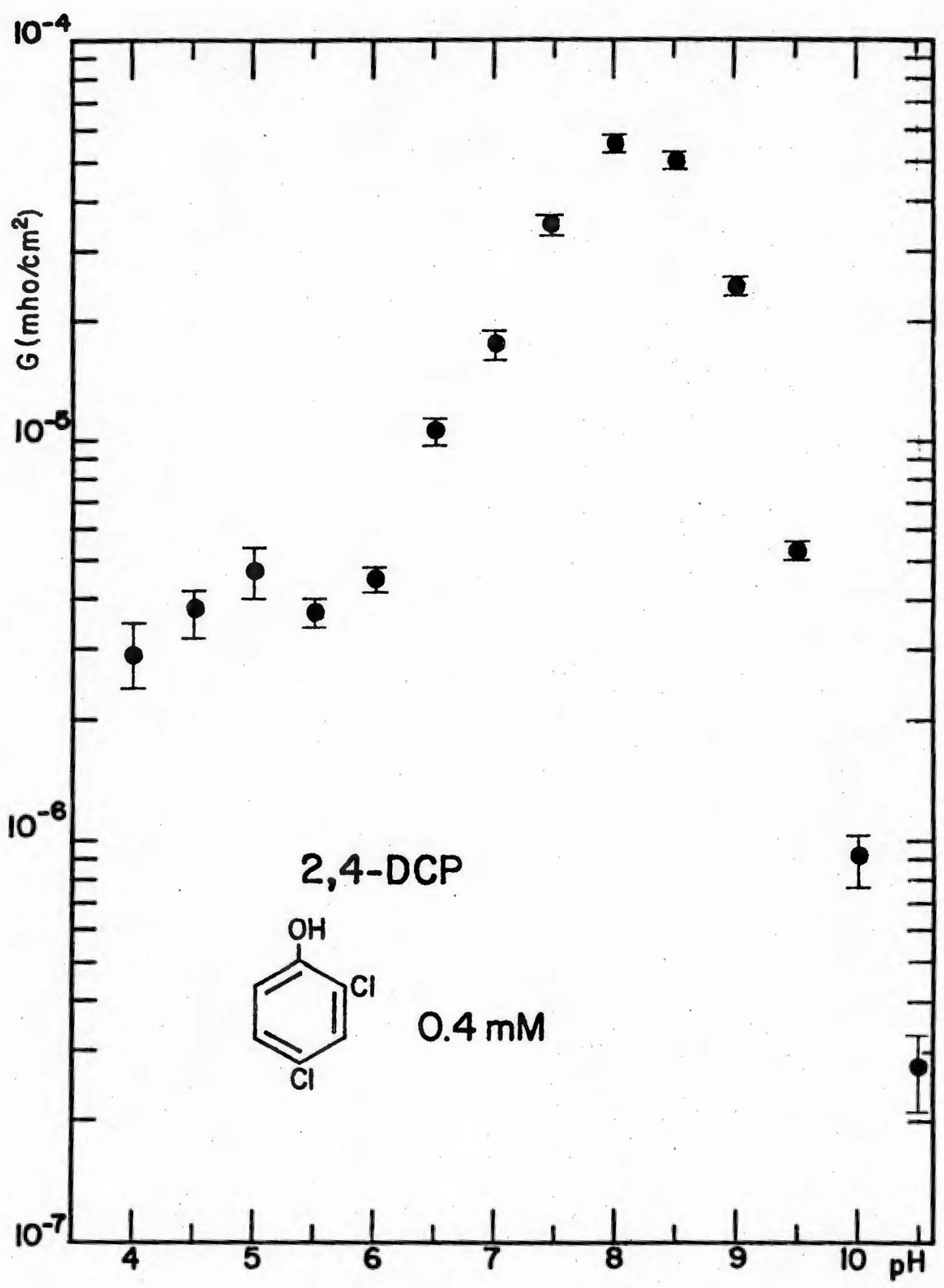

Figure 11. $\mathrm{pH}$ dependence of conductivity of lecithin-cholesterol 1ipid membranes in the presence of $0.4 \mathrm{mM} 2,4-D C P$ in the aqueous solution. 
to arrive at some insight into the kinetics of formation and the molecular structure of the membrane permeable ions.

These studies were done at a $\mathrm{pH}$ greater than the $\mathrm{pK}$ of the corresponding compounds, for two reasons. First, the water solubility of these pesticides generally increases with increasing $\mathrm{pH}$; under these conditions it is thus possible to cover a wider concentration range. Second, the experimental results reported for dinitrophenol (33) and pentachlorophenol (24) Indicate that the concentration dependence of membrane conductivity reveals the presence of the membrane surface charge at $\mathrm{pH}>\mathrm{pK}$.

TABLE I

DISSOCIATION PROPERTIES OF STUDIED PESTICIDES

\begin{tabular}{lrr} 
Compound & $\mathrm{pK}$ & Reference \\
\hline $2,4-\mathrm{D}$ & 2.73 & $(34)$ \\
& 2.63 & $(35)$ \\
& 2.80 & $(35)$ \\
& 3.31 & $(35)$ \\
$2,4-\mathrm{DB}$ & 4.58 & $(35)$ \\
$2,4,5-\mathrm{T}$ & 2.88 & $(34)$ \\
& 3.14 & $(35)$ \\
$2,4-\mathrm{DCP}$ & 7.80 & $(36)$ \\
& 7.80 & $(37)$
\end{tabular}

The experimental results are shown in Figs. 12-15 where the $10 \mathrm{~g}$ of membrane conductance was plotted vs the $10 \mathrm{~g}$ of pesticide concentration. The data indicate that in the first approximation the pesticideinduced membrane conductance is related to the pesticide concentration 


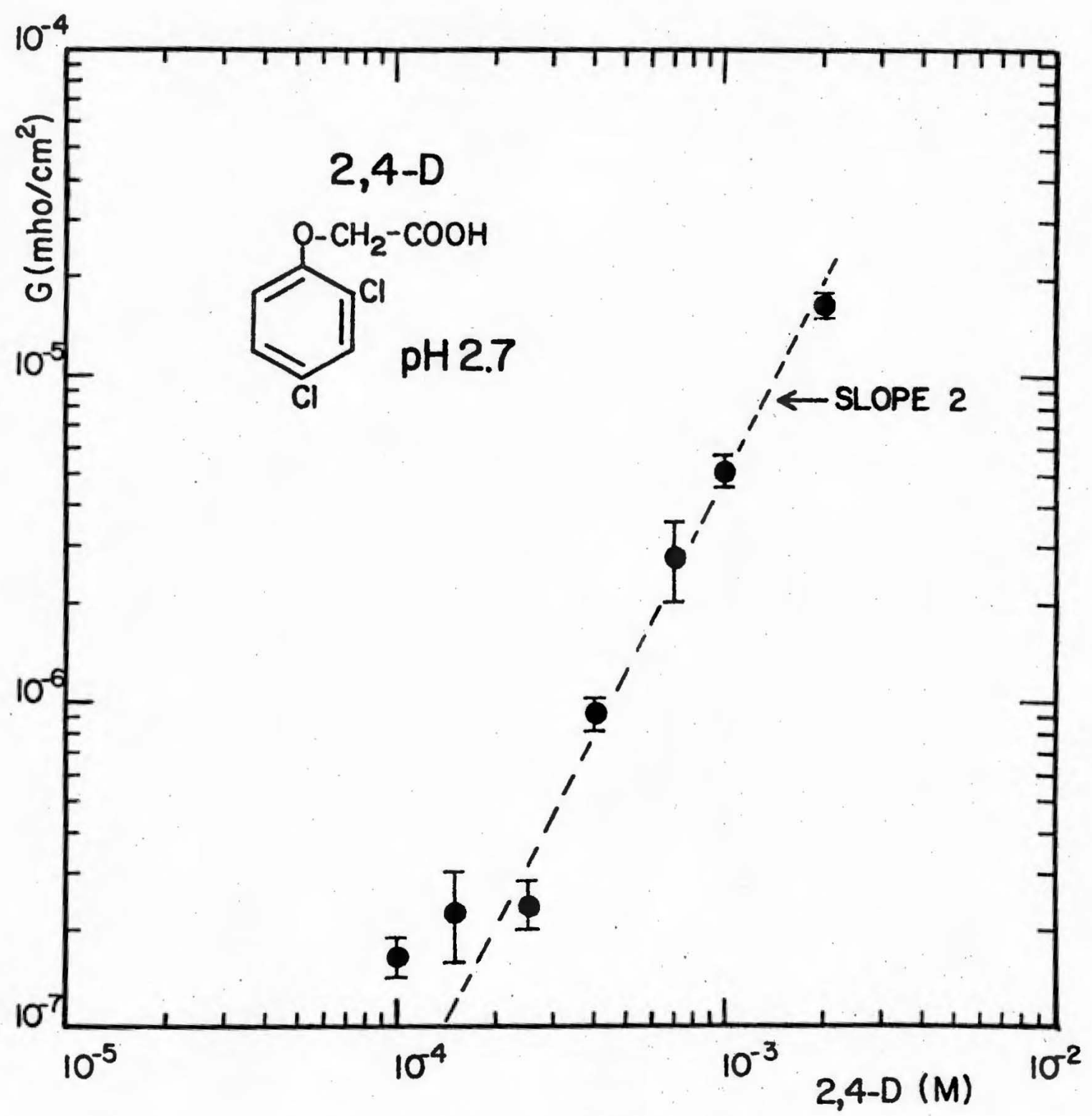

Figure 12. Effect of concentration of 2,4-D at pH 2.7 on membrane conductance. 


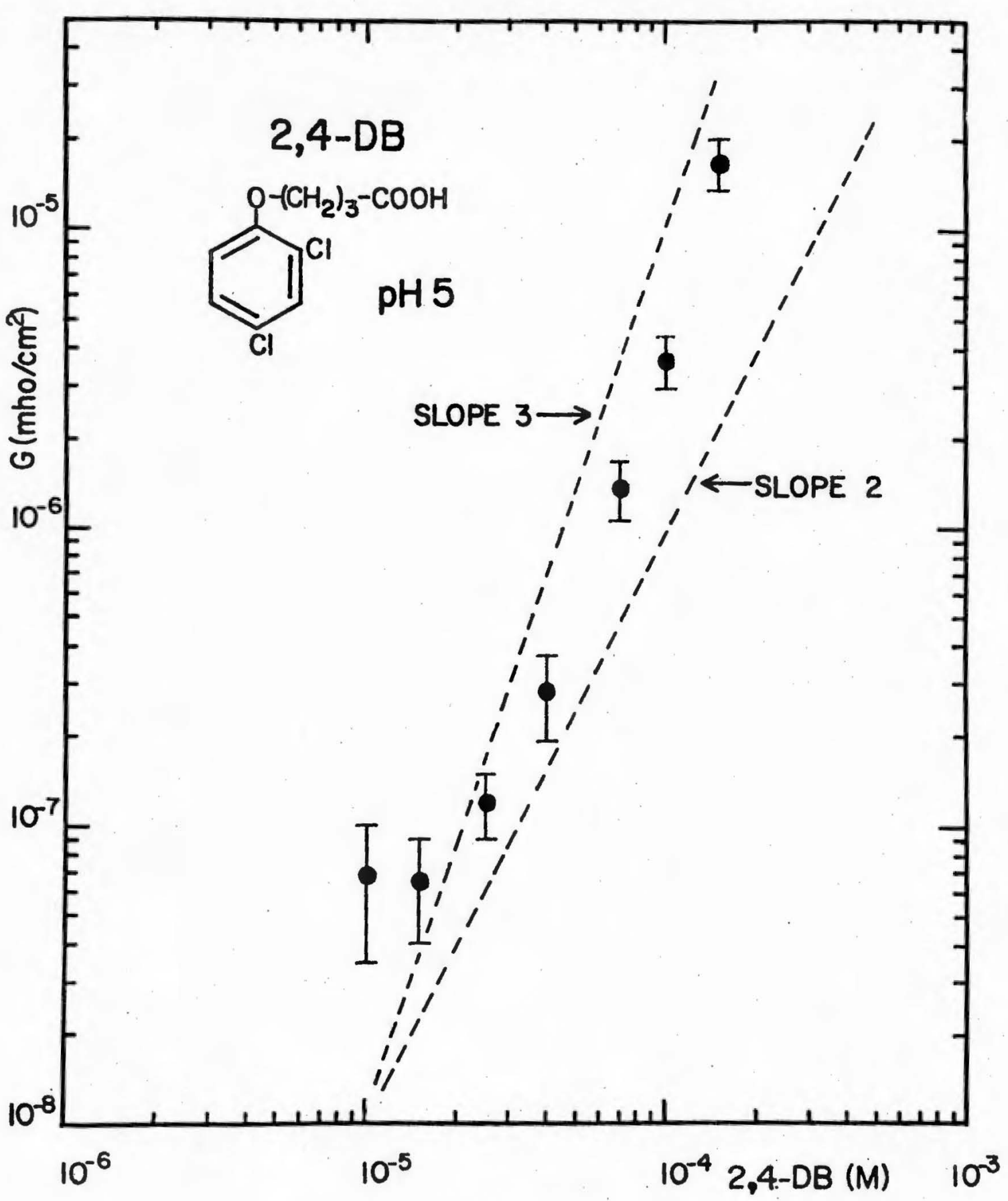

Figure 13. Effect of concentration of $2,4-\mathrm{DB}$ at $\mathrm{pH} 5.0$ on membrane conductance. 


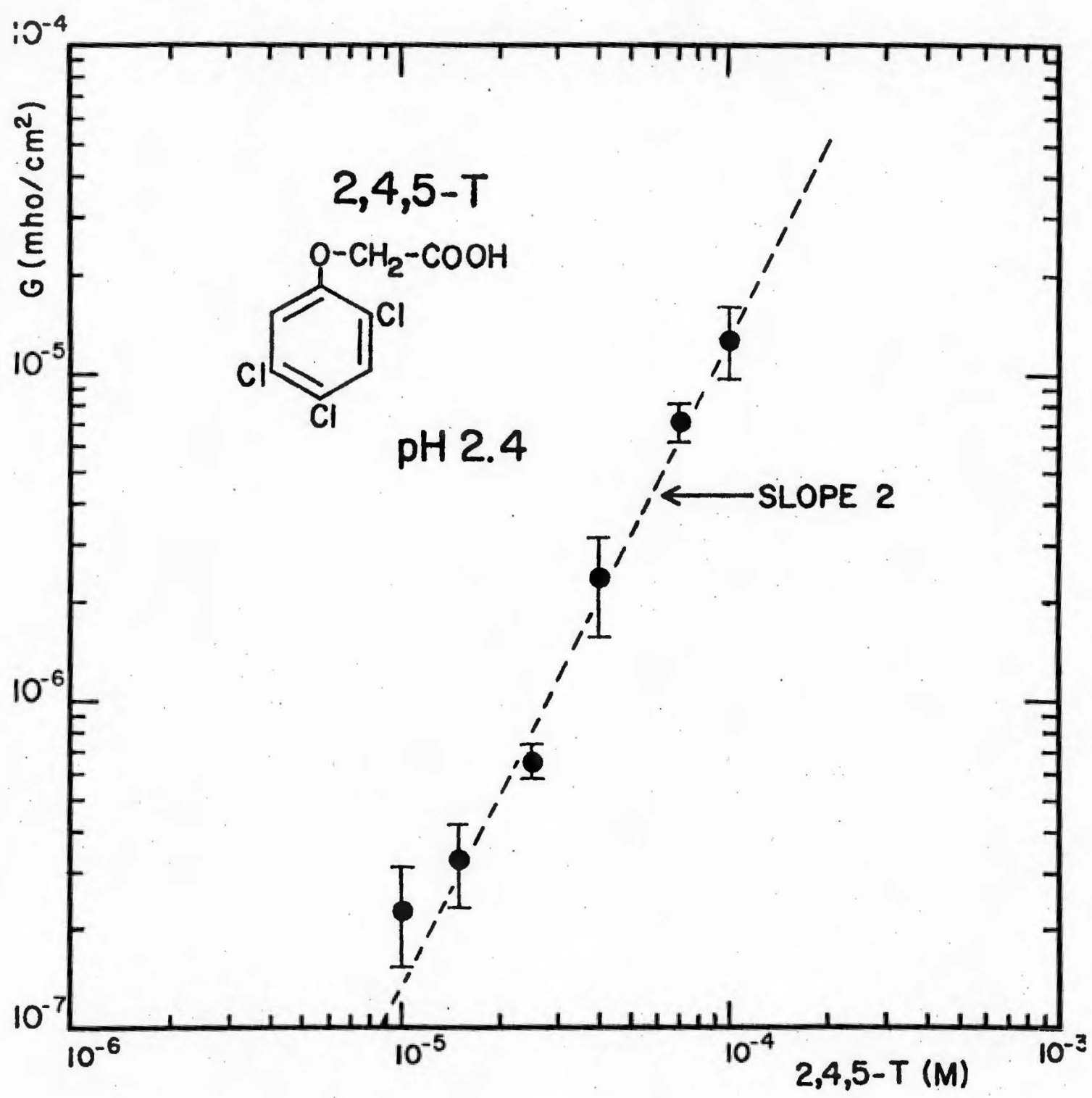

Figure 14. Effect of concentration of $2,4,5-\mathrm{T}$ at $\mathrm{pH} 2.4$ on membrane conductance. 


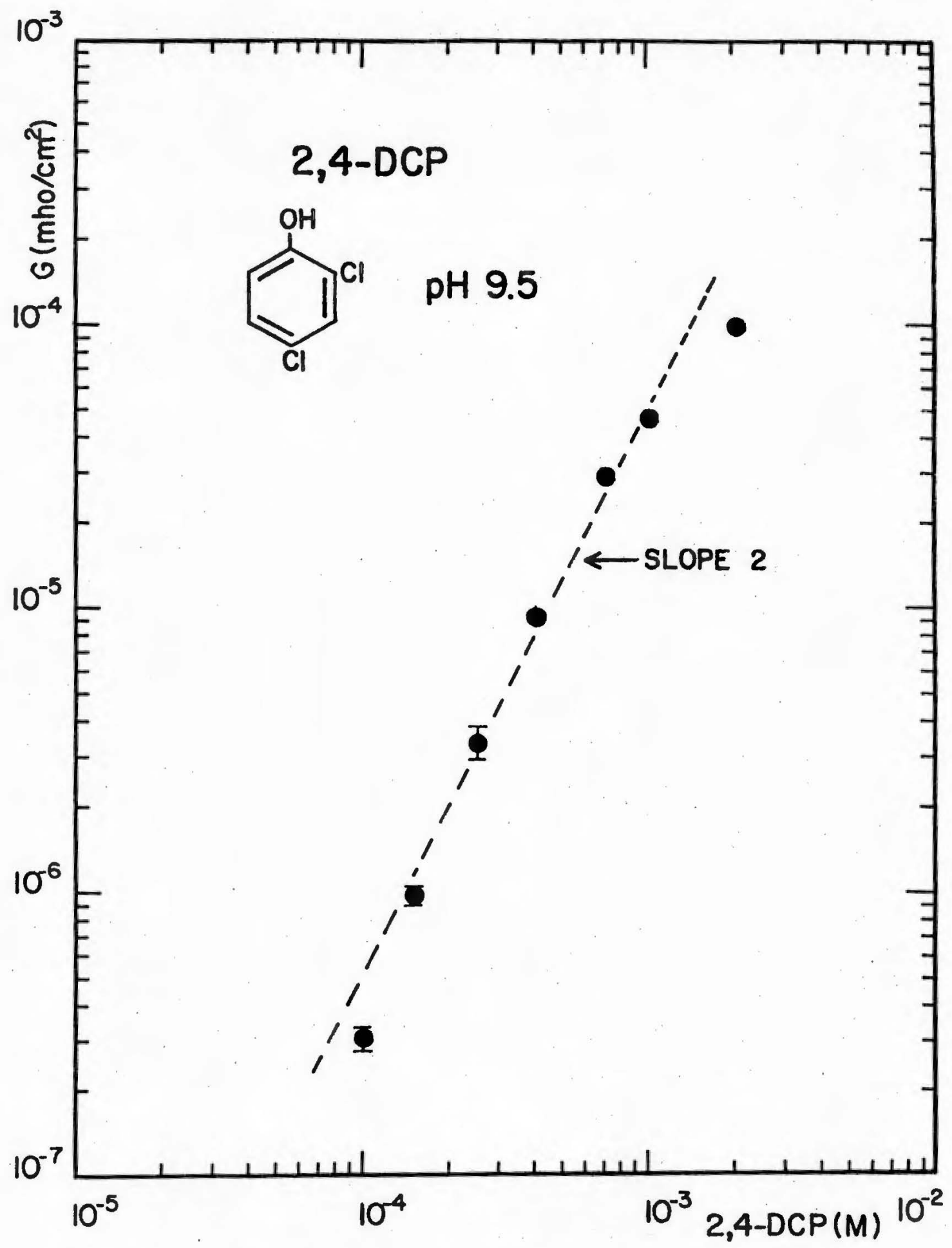

F1gure 15. Effect of concentration of 2,4-DCP at $\mathrm{pH} 9.5$ on membrane conductance. 
according to a power law $G \propto c^{n}$, where the exponent $\mathrm{n}$ is a constant. In all cases, with the exception of $2,4-\mathrm{DB}$, the value of $n$ is very close to two. For 2,4-DB the value of $\mathrm{n}$ is between two and three.

\section{B3. Voltage Dependence of Pesticide-induced Membrane Conductivity as a Function of Pesticide Concentration and $\mathrm{pH}$}

The current-voltage curves reveal that the membrane conductance increases with the applied voltage. In addition, the curvature of the current-voltage curves shows some dependence both on $\mathrm{pH}$ of the aqueous phase and on the pesticide concentration. This effect was studied in detail for 2,4-DCP. The experimental results are presented in Figs. 16 and 17 where $G(U) / G(25 \mathrm{mV})$, i.e. the membrane conductance at voltage $\mathrm{U}$ normalized to membrane conductance at $25 \mathrm{mV}$, is plotted vs the applied voltage U. Fig. 16 shows the effect of $\mathrm{pH}$ on the voltage dependence of membrane conductivity. The curvature increases with increasing $\mathrm{pH}$; that is, at high $\mathrm{pH}$ when the proton concentration is low, the conductance is more strongly voltage dependent. Fig. 17 illustrates the effect of pesticide concentration. In this case, the membrane conductance is more voltage dependent at lower concentrations of pesticide.

B4. Effect of Pesticides on the Nonactin-induced Membrane Conductivity

To investigate the charging effect of the membrane by the ions in the solution, nonactin was used as a probe. The experiments with the phenoxy compounds were done at a $\mathrm{pH}$ value in the neighborhood of the conductivity maximum for each compound. Since the $\mathrm{pH}$ range chosen varled between 1.0 and 10.5 , a control experiment was performed to test 


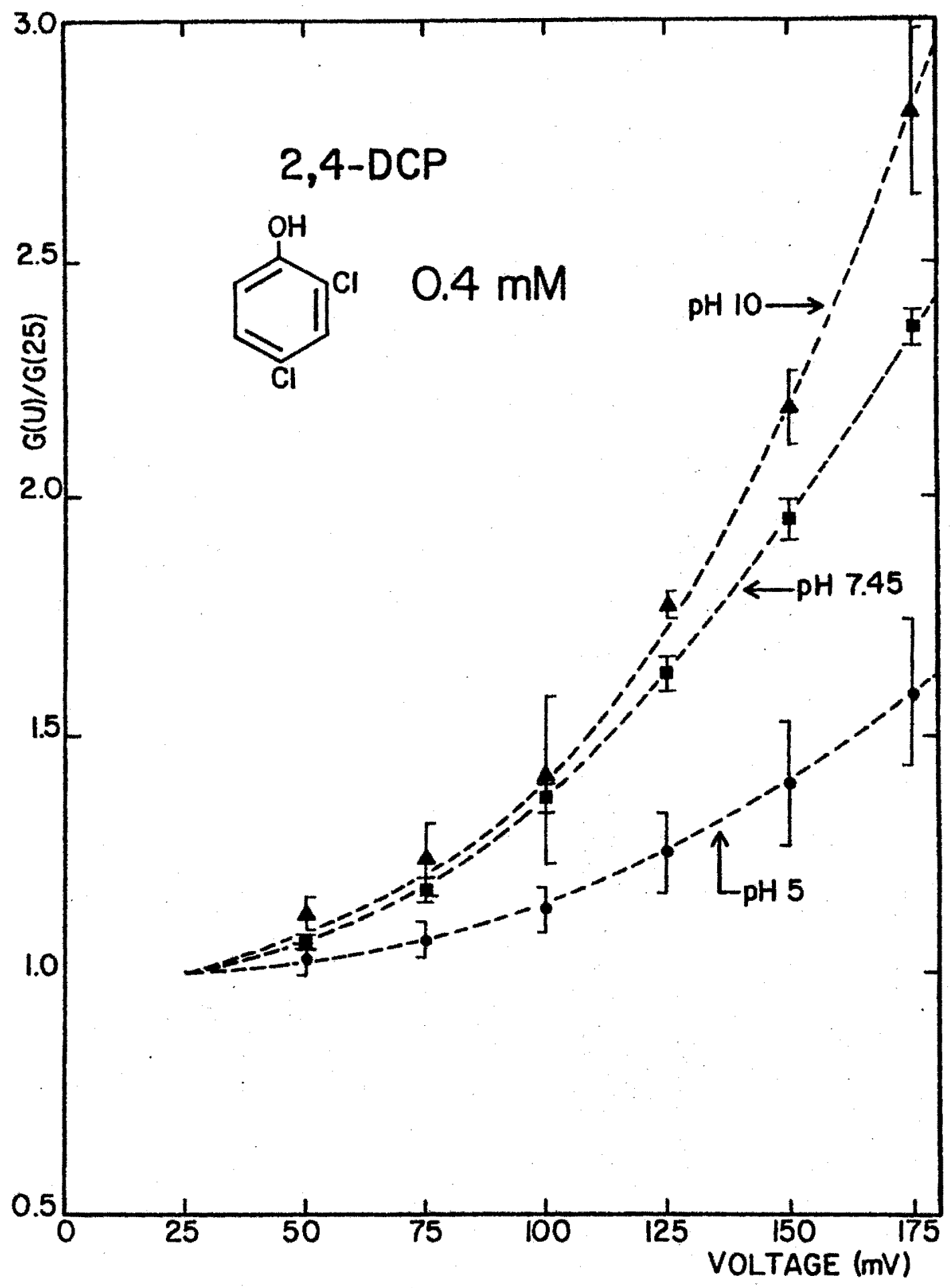

Figure 16. Effect of proton concentration in the aqueous solution on the voltage dependence of membrane conductance for $0.4 \mathrm{mM}$ 2,4-DCP. Membrane conductance is normalized to that at $25 \mathrm{mV}$. 


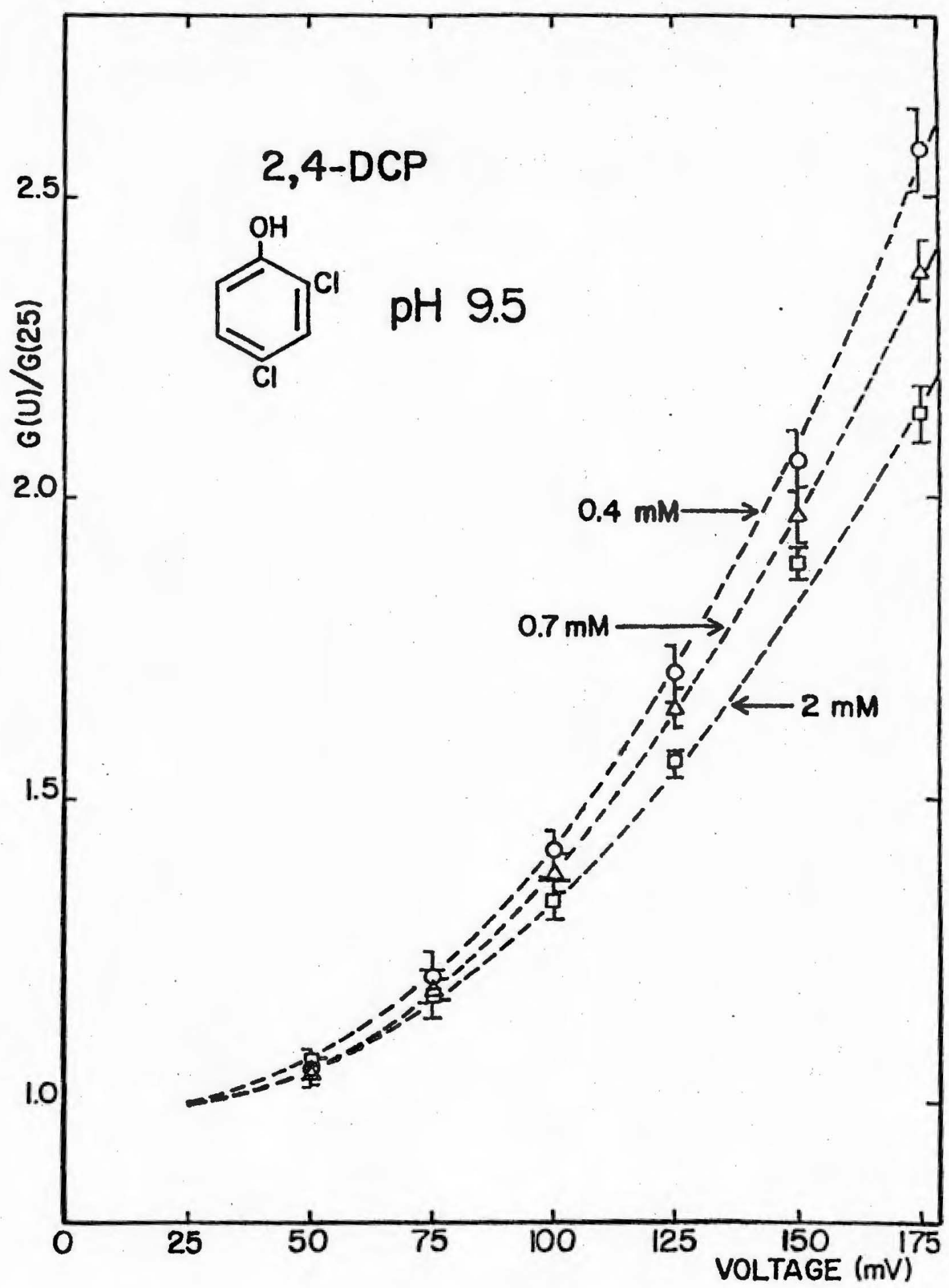

Figure 17. Effect of concentration of 2,4-DCP on the voltage dependence of membrane conductance at pH 9.5.' Membrane conductance is normalized to that at $25 \mathrm{mV}$. 
whether the nonactin-induced conductivity was $\mathrm{pH}$ dependent. In this experiment, the aqueous solution contained $3.9 \times 10^{-6} \mathrm{M}$ of nonactin and $0.2 \mathrm{M} \mathrm{KC1}$. The buffer concentration was reduced to $0.002 \mathrm{M} / 0.002 \mathrm{M} /$ $0.0005 \mathrm{M}$, so that the potassium concentration was primarily determined by the concentration of $\mathrm{KCl}$ and not varied significantly due to the ionization of the buffer constituents. The experimental results of such a study are shown in Fig. 18, from which it was concluded that the nonactin-induced conductivity is essentially independent of $\mathrm{pH}$. This means (a) that the membrane surface remains electrically neutral within the experimental $\mathrm{pH}$ range, and (b) that nonactin does not significantly degrade within the time necessary for completing the experiment.

The effect of pesticides on nonactin-induced membrane conductivity is illustrated in Figs. 19-22. In these experiments the nonactin concentration was about $3 \times 10^{-6} \mathrm{M}$, the salt composition of the electrolyte as well as its $\mathrm{pH}$ value was the same as in the measurements of concentration dependence of the pesticide-induced membrane conductivity. Two sets of data are shown in each figure. The lower set represents the concentration dependence of pesticide-induced membrane conductivity, and the upper set represents the dependence of the nonactin-induced conductivity on pesticide concentration. The broken horizontal line in the middle of each figure indicates the level of nonactin-induced membrane conductivity in the absence of pesticide. The notable feature of these results is that the membrane conductance in the presence of nonactin and pesticide together is much greater than the sum of the conductance due to nonactin and pesticide alone.

To get some insight into the effect described in the preceding 


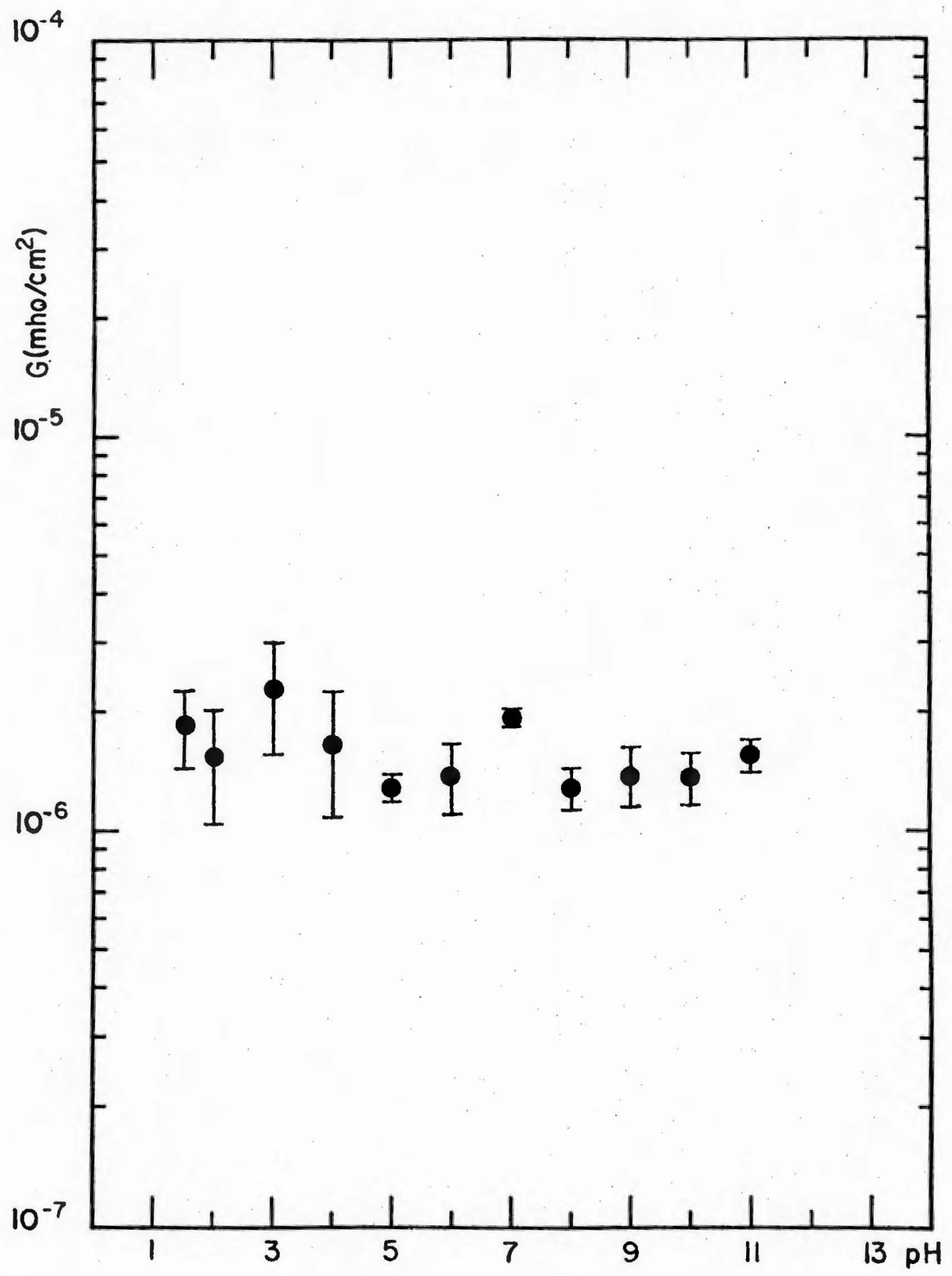

F1gure 18. Nonactin- $\mathrm{K}^{+}$- induced membrane conductivity as a function of $\mathrm{pH}$ in the absence of pesticides. Nonactin concentration was $3.9 \mu \mathrm{M} ; \mathrm{KCl}, 0.2 \mathrm{M}$; and buffer, $0.002 \mathrm{M} / 0.002 \mathrm{M} /$ $0.0005 \mathrm{M}$. 


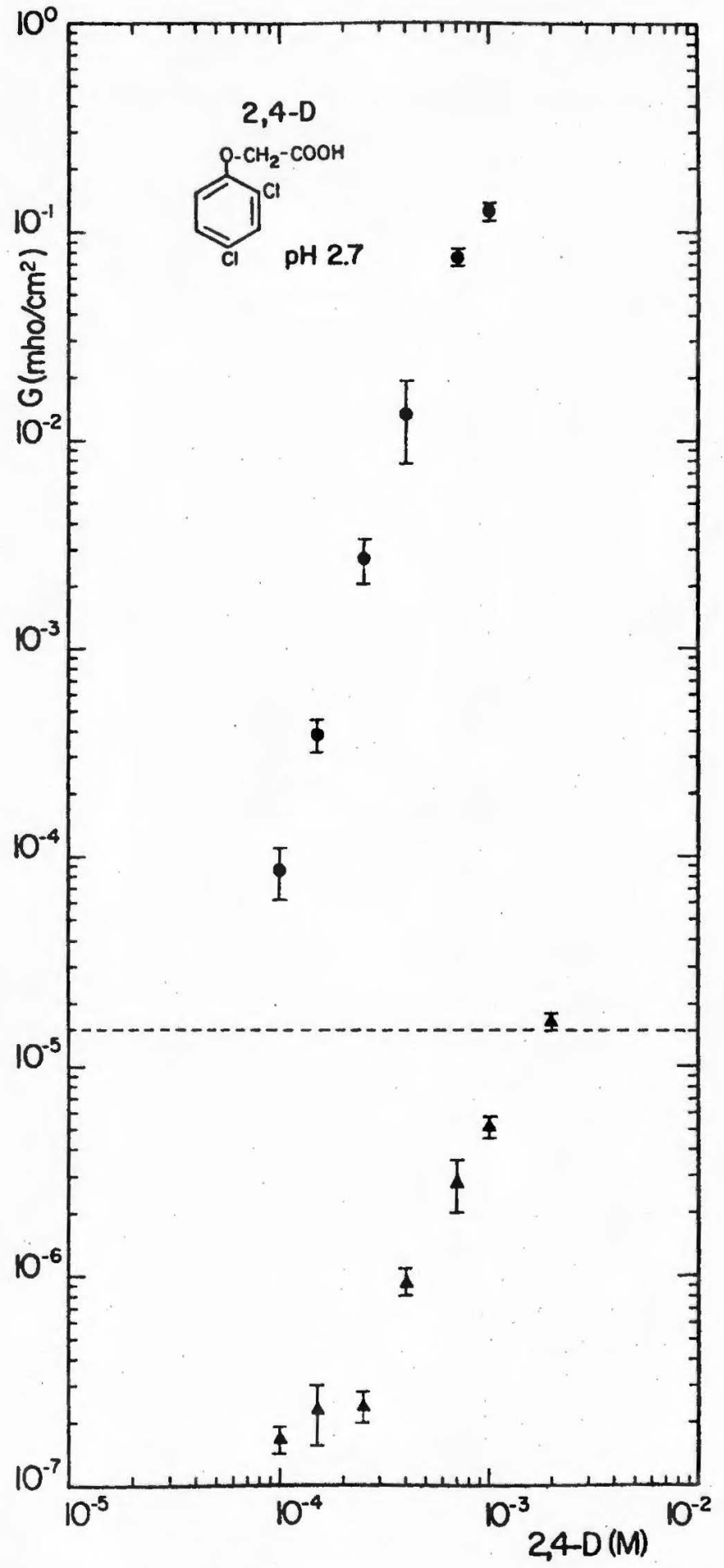

Figure 19. The effect of presence of 2,4-D on the conductivity induced by nonactin- $\mathrm{K}^{+}$complex at $\mathrm{pH} 2.7$. Nonactin concentration was $3.5 \mu \mathrm{M} ; \mathrm{KC1}, 0.1$; buffer, $0.2 \mathrm{M} / 0.2 \mathrm{M} / 0.05 \mathrm{M}$. The horizontal broken line represents the nonactin-K conductivity at $25 \mathrm{mV}$ in the absence of 2,4-D. Triangles - membrane conductance at $25 \mathrm{mV}$ due to the pesticide. Circles - nonactin-induced conductance in the presence of pesticide in the aqueous phase. 


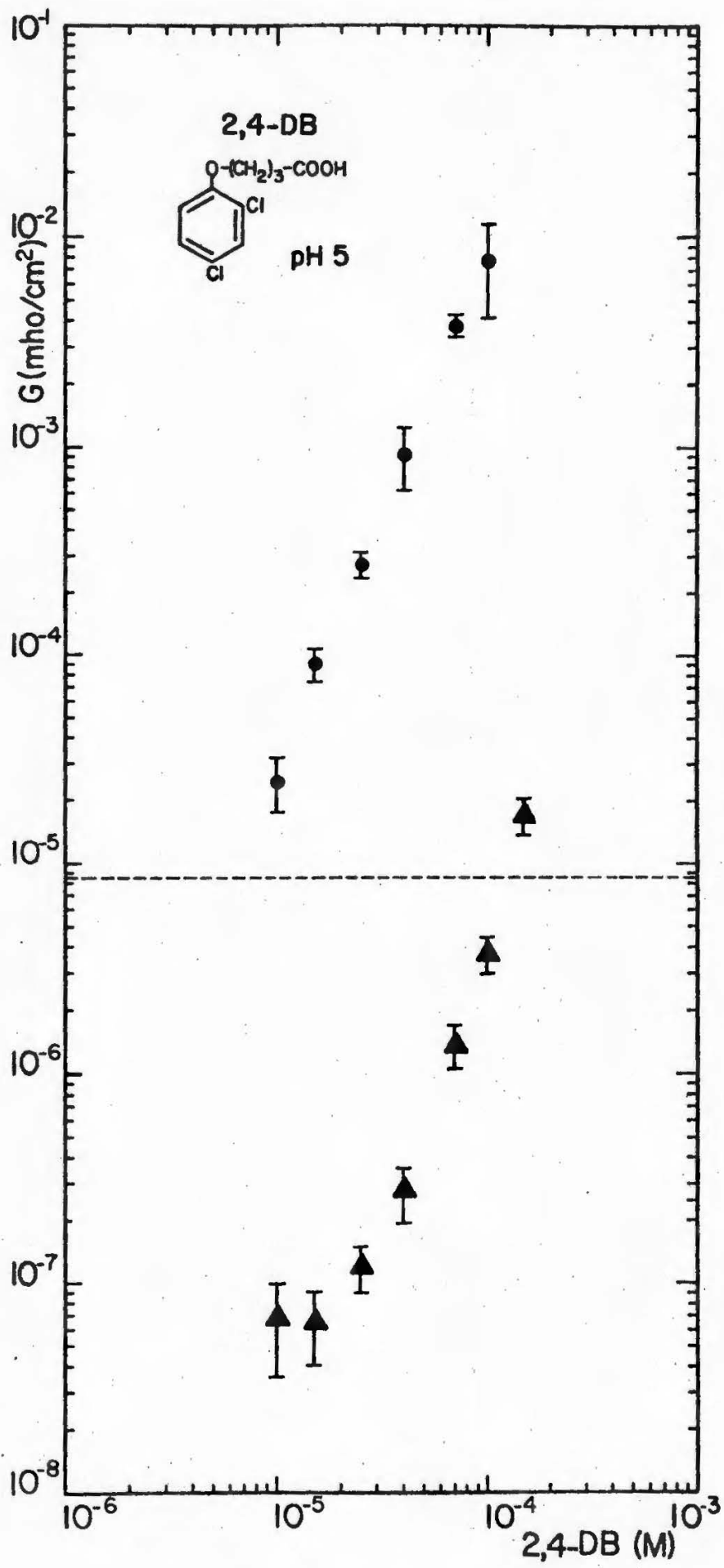

Figure 20. The effect of presence of 2,4-DB on the conductivity induced by nonactin- $\mathrm{K}^{+}$complex at $\mathrm{pH} 5.0$. Nonactin concentration was $3.5 \mu \mathrm{M} ; \mathrm{KCl}, 0.1 \mathrm{M}$; buffer, $0.2 \mathrm{M} / 0.2 \mathrm{M} / 0.05 \mathrm{M}$. The horizontal broken line represents the nonactin- $\mathrm{K}^{+}$conductivity at $25 \mathrm{mV}$ in the absence of 2,4-DB. Triangles - membrane conductance at $25 \mathrm{mV}$ due to the pesticide. Circles - nonactin-induced conductance in the presence of pesticide in the aqueous phase. 


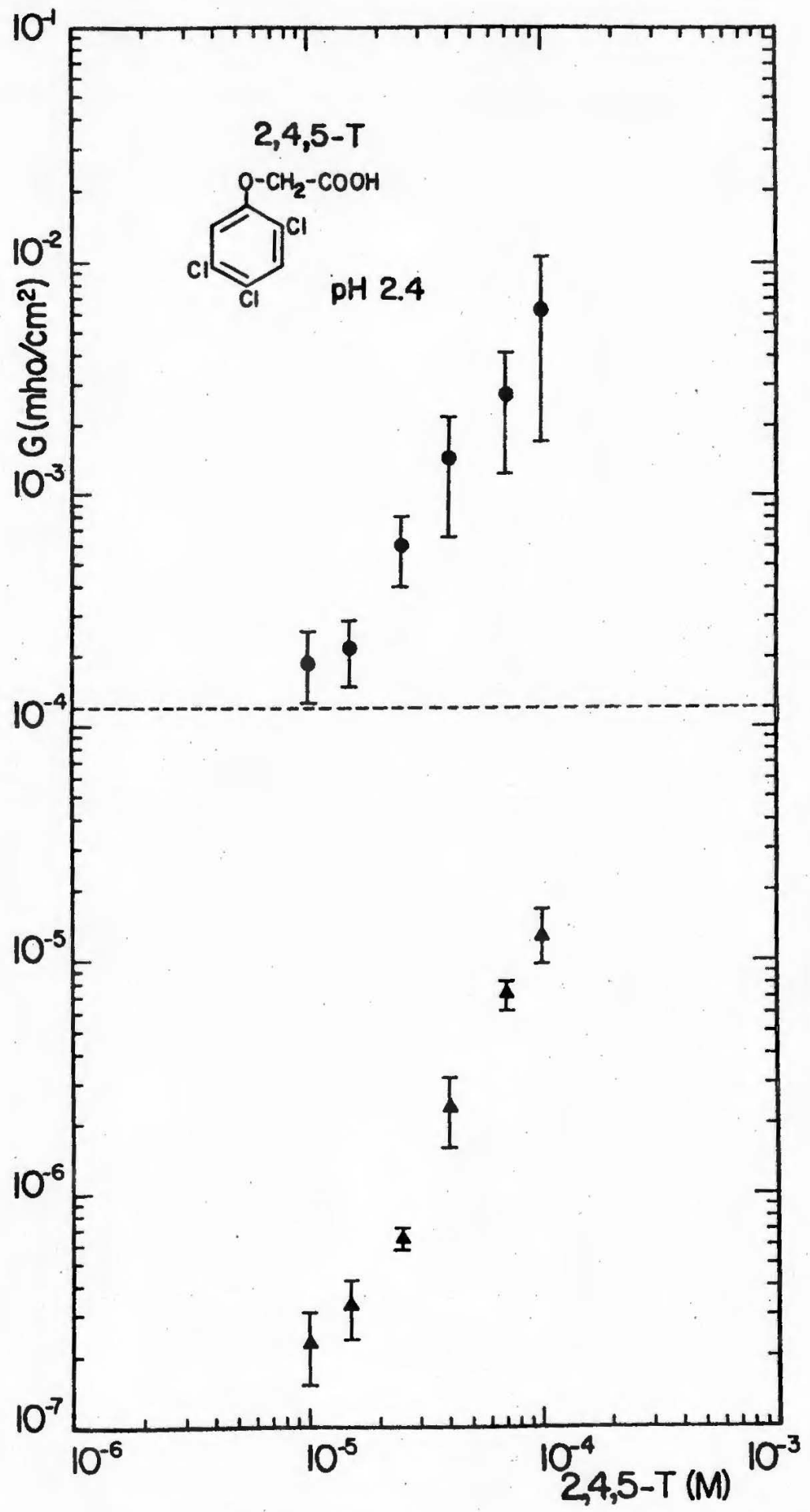

F1gure 21. The effect of presence of 2,4,5-T on the conductivity Induced by nonactin- $\mathrm{K}^{+}$complex at $\mathrm{pH} 2.4$. Nonactin concentration was $3.5 \mu \mathrm{M} ; \mathrm{KCl}, 0.1 \mathrm{M}$; buffer, $0.2 \mathrm{M} / 0.2 \mathrm{M} / 0.05 \mathrm{M}$. The horizontal broken line represents the nonactin- $\mathrm{K}^{+}$conductivity at $25 \mathrm{mV}$ in the absence of 2,4,5-T. Triangles - membrane conductance at $25 \mathrm{mV}$ due to the pesticide. Circles - nonactin-induced conductance in the presence of pesticide in the aqueous phase. 


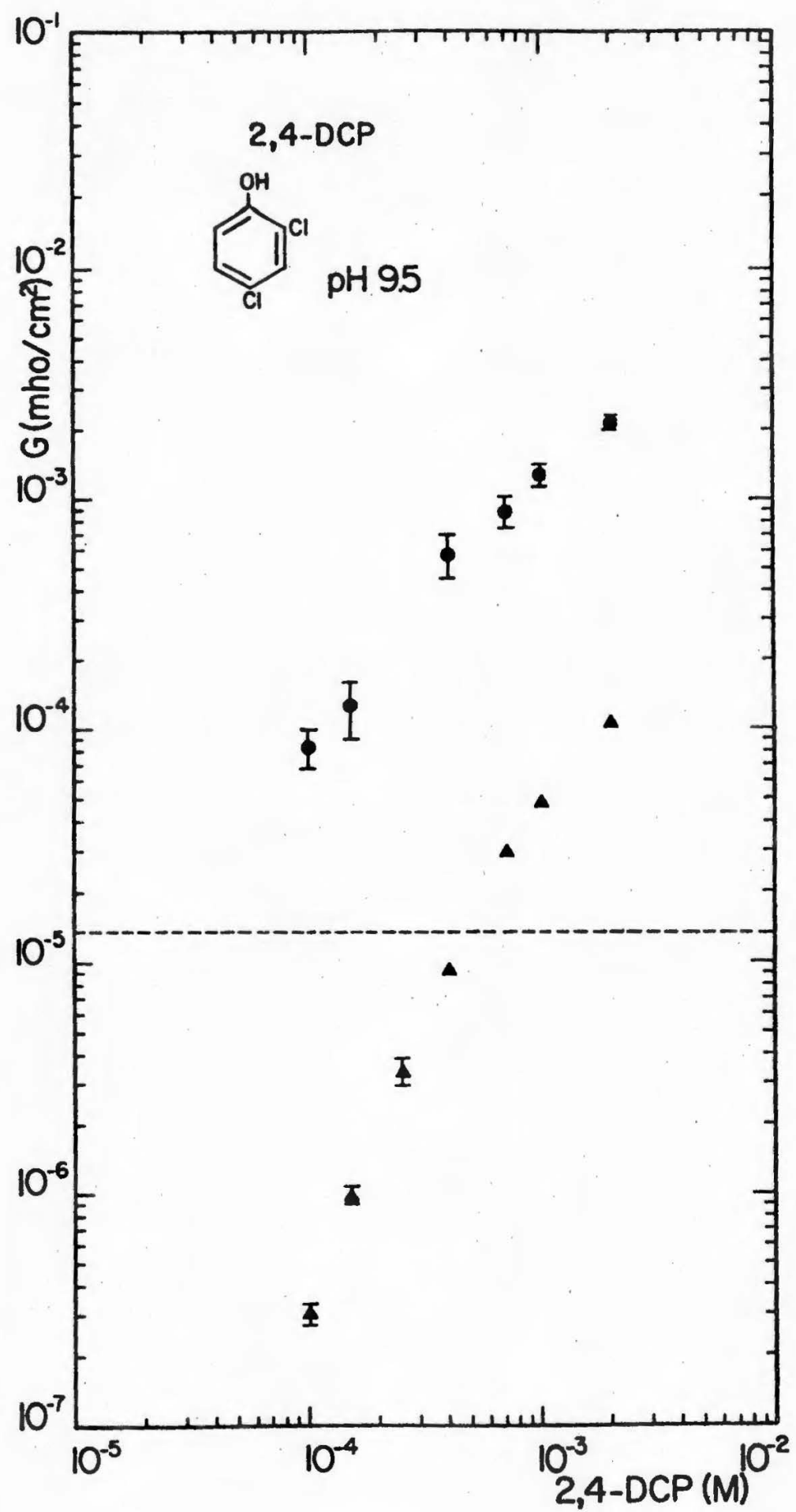

Figure 22. The effect of presence of 2,4-DCP on the conductivity induced by nonactin $-\mathrm{K}^{+}$complex at $\mathrm{pH} 9.5$. Nonactin concentration was $3.5 \mu \mathrm{M} ; \mathrm{KCl}, 0.1 \mathrm{M}$; buffer, $0.2 \mathrm{M} / 0.2 \mathrm{M} / 0.05 \mathrm{M}$. The horizontal broken line represents the nonactin- $\mathrm{K}^{+}$conductivity at $25 \mathrm{mV}$ in the absence of 2,4-DCP. Triangles - membrane conductance at $25 \mathrm{mV}$ due to the pesticide. Circles - nonactin-induced conductance in the presence of pesticide in the aqueous phase. 
section, another set of experiments was designed to study the effect of Ionic strength of the aqueous solution on the pesticide enhancement of nonactin-induced membrane conductivity. To control the level of ionic strength, LiCl was used because nonactin does not bind significantly with 1ithium Ions; it does with potassium ions (38). Two sets of measurements of nonactin-induced membrane conductivity were done at different concentrations of 2,4-D; one for low, and another for high lonic strength of aqueous solution. For low lonic strength, $0.05 \mathrm{M} \mathrm{KC1}$ was used, while for high ionic strength $0.45 \mathrm{M} \mathrm{LiC1}$ with $0.05 \mathrm{M} \mathrm{KC1}$ were used. Because it was necessary that the ionic strength be determined by $\mathrm{KCl}$ and by $\mathrm{LiC1}$, the buffer concentration was reduced to $0.0002 \mathrm{M} /$ $0.00002 \mathrm{M} / 0.00005 \mathrm{M}$. Experiments were done at $\mathrm{pH} 2.7$ with nonactin concentration at $3.9 \times 10^{-6} \mathrm{M}$. As the experimental results in Fig. 23 indicate, there is no significant difference in the nonactin-induced conductivity at these levels of fonic strength. 


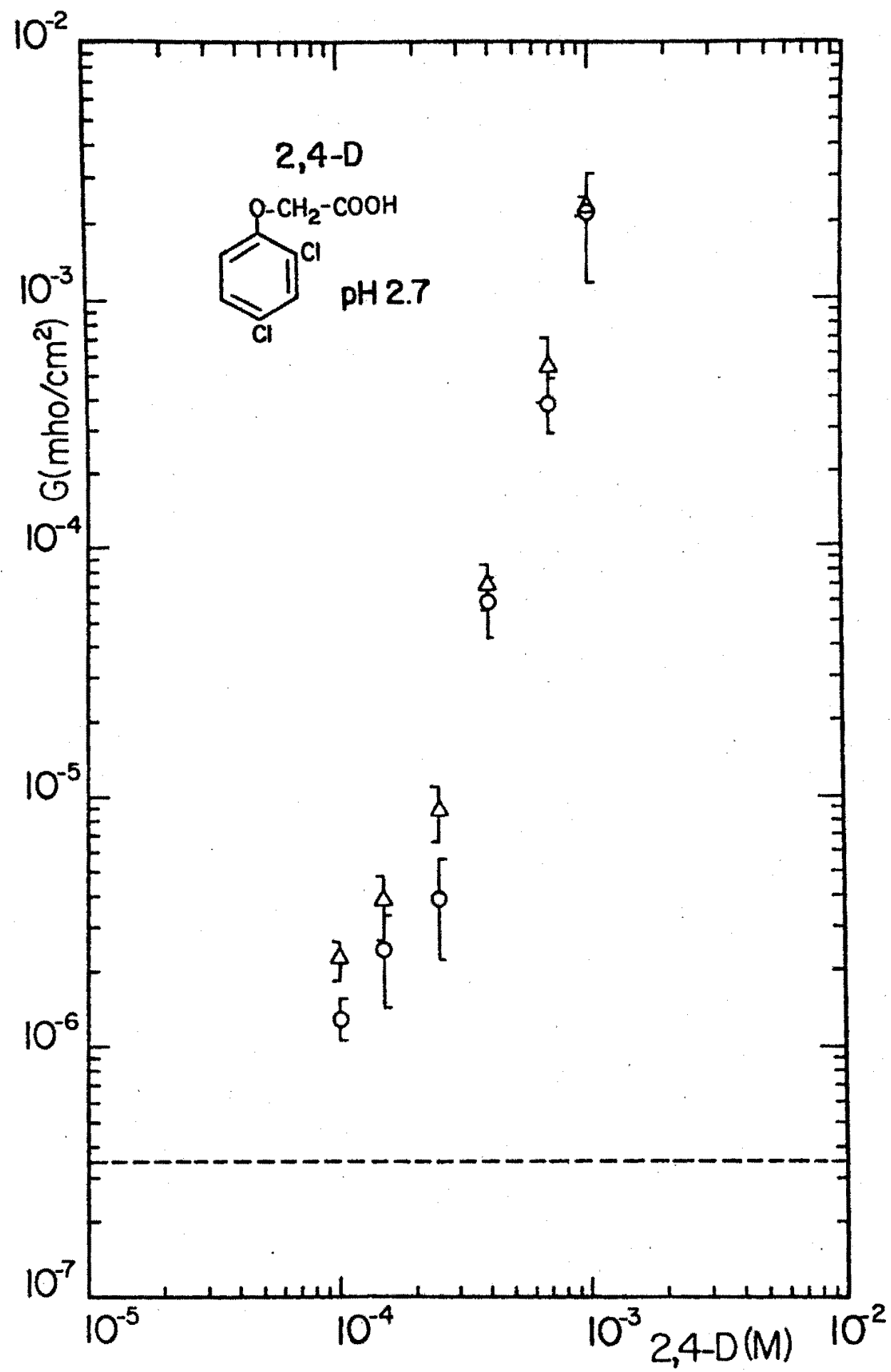

Figure 23. Effect of Ionic strength of the aqueous solution on the level of nonactin-induced conductivity (at $25 \mathrm{mV}$ ) enhanced by the presence of 2,4-D. Triangles represent induced conductance at low ionic strength case, $0.05 \mathrm{M} \mathrm{KCl}$; circles represent the high ionfic strength case, $\mathrm{KCl} 0.05 \mathrm{M}$ and $\mathrm{LICl} 0.45 \mathrm{M}$. Nonactin concentration was $3.9 \mu \mathrm{M}$ buffer, $0.0002 \mathrm{M} / 0.0002 \mathrm{M} / 0.00005 \mathrm{M}$. 
CHAPTER IV

\section{DISCUSSION}

A. Exploratory Experiments with Endotha11, Paraquat and Diquat

Membrane conductivity measurements have indicated that the Ionized forms of endotha11, paraquat and diquat are membrane impermeable. This "Impermeability" is primarily due to the low density of these Ions in the hydrocarbon region of the lipld bllayer. In general, the distribution coefficient of Ions between the membrane and the water phase is proportional to the Boltzmann factor $\exp (-\Delta E / k T)$ where $\Delta E$ Is the difference in the Ion self energy between the membrane and the water phase. For a charged sphere of radius $R$ the potential energy difference is given by Eq. (2),

$$
\Delta E=\frac{q^{2}}{8 \pi \varepsilon_{o} R}\left(\frac{1}{\varepsilon_{m}}-\frac{1}{\varepsilon_{w}}\right)
$$

where typically, $\varepsilon_{\mathrm{m}} \simeq 3$ and $\varepsilon_{\mathrm{w}} \simeq 80$.

In case of endotha11, the negative charge is located at the carboxyl group $-\mathrm{COO}^{-}$. Thus the radius $\mathrm{R}$ is expected to be about $2-3^{\circ} \mathrm{A}$ which results in $\Delta \mathrm{E}$ of about $0.92 \mathrm{eV}$. It appears that the excess charge delocalization in the fon is one of the major factors determining the membrane permeability. For example, the membrane permeable negative Ion of tetrapheny1 borate (3) has the excess electron density distributed over four benzene rings. This should result in a large 
effective Ion radius $R$, and therefore in considerably smaller potential energy difference $\Delta E$.

In the case of paraquat and diquat lons the excess charge is, to some degree, spread in the heterocyclic rings. However, these species carry a positive charge of $2 \mathrm{e}$ and since the potential difference $\Delta \mathrm{E}$ is proportional to the square of the Ion charge, the limited Ion delocalization is apparently insufficient to offset the effect of double charge. In this case the value of $\Delta \mathrm{E}$ is sufficiently large to prevent observation of membrane conductivity due to paraquat and diquat ions. Measurements of nonactin-induced membrane conductivity have indicated that there is no detectable evidence for membrane surface charge caused by endothall, paraquat and diquat. Apparently the van der Waal interaction between the ions and the membrane head groups is not sufficiently strong to cause ion adsorption at the membrane surface.

B. Experiments with 2,4-D, 2,4-DB, 2,4,5-T, and 2,4-DCP

In contrast, these compounds induce electrical conductivity in lipid bilayers; in addition, they adsorb at the membrane surface in quantities that are sufficient to change the membrane surface potential significantly. Apparently the above mentioned energetic conditions are met so that a sufficlently large density of these pesticides in Ionized form exists in the membrane interior. Since these compounds also act as uncouplers of oxidative phosphorylation, discussion of the experimental results will be based on the existing theories proposed to explain the membrane conductivity due to uncouplers.

According to the dependence of uncoupler-induced membrane 
conductivity on the bulk concentration of the substance, uncouplers can be categorized into two classes. The features of class I uncouplers are: (a) the direct proportionality of the membrane conductance (b) the saturation effects of the current-voltage curves and (c) the occurrence of the conductivity maximum on the alkaline side of the pK of the uncoupler. None of the substances which have been studied show any of these properties. Since the molecular structure of these compounds is similar to that of pentachlorophenol and dinitrophenol, which exhibit the properties, of class II uncouplers, one may expect that $2,4-D, 2,4-D B$, 2,4,5-T and 2,4-DCP will also exhibit the properties of class II uncouplers. In fact, they do. For example: (a) the current-voltage curves do not saturate with the applied voltage in the range used, (b) the conductivity dependence on the concentration of the compound is quadratic instead of linear, and (c) all compounds show a conductivity maximum at a $\mathrm{pH}$ of the aqueous phase close to their respective pK values. Therefore, discussion of the experimental results will be based on the dimer transport mechanism proposed to explain the behavior of class II uncouplers. Detailed comparison of the experimental results with the proposed model is presented in the following section.

\section{B1. Kinetic Scheme of Charge Transfer for Class II Uncouplers.}

The kinetic scheme considered by Cohen et al. $(39,40)$ for tetrachloro-2-trifluoromethylbenzimidazole (TTFB) and dichlorotrifluoromethylbenzimidazole (DTFB), and by Smejtek et al. (24) for pentachlorophenol (PCP) is represented in Fig. 24. According to this scheme there are two types of membrane permeable specles: (a) HA, the neutral molecule 


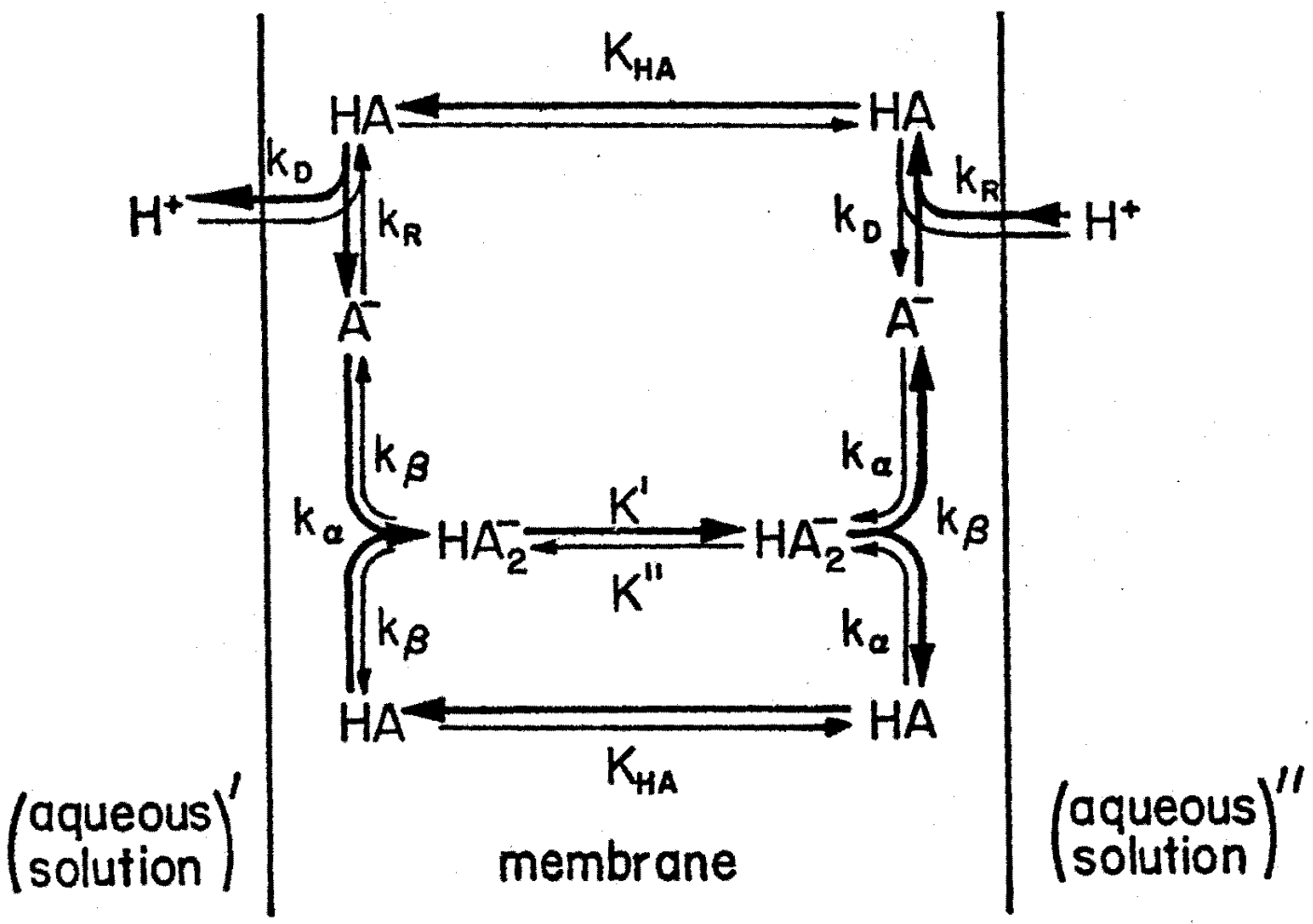

Fig. 24. Kinetic scheme of charge transfer.

of the uncoupler, and (b) $\mathrm{HA}_{2}^{-}$, the negatively charged molecular complex formed by the combination of the neutral molecule HA with the ionized uncoupler molecule $\mathrm{A}^{-}$. In the figure, the right side of the membrane is considered to be at a higher potential than the left side. Due to this potential difference, there is a net flow of dimers from the left side to the right side of the membrane. Consequently, there is a temporary excess of dimers on the right interface. Because of their limited life time, the dimer complexes dissociate into $\mathrm{HA}$ and $\mathrm{A}^{-}$; thus an excess of each is produced at the right interface. The excess anions, $\mathrm{A}^{-}$, are neutralized by combining with protons from the solution in the right 
compartment, and the excess neutral molecules, HA, diffuse to the left side of the membrane, where they dissociate into $\mathrm{H}^{+}$and $\mathrm{A}^{-}$. The protons are then released into the solution in the left compartment, while the anions combine with the undissociated neutral molecules to form dimer complexes. The transport cycle is then repeated again. In the course of this transport mechanism, a proton from the solution in the right compartment is transported across the membrane to the solution in the left compartment in the form of a neutral molecule.

Schematically, the dimer formation is given by:

$$
\mathrm{HA}_{\mathrm{m}}+\mathrm{A}_{\mathrm{m}}^{-} \frac{\mathrm{k}_{\alpha}}{\mathrm{k}_{\beta}} \mathrm{HA}_{2 \mathrm{~m}}^{-}
$$

where $\mathrm{HA}_{\mathrm{m}}$ and $\mathrm{A}_{\mathrm{m}}{ }^{-}$are the neutral and the ionized molecules on the membrane surface, and $k_{\alpha}$ and $k_{\beta}$ are the rate constants in the forward and backward directions respectively. For the transfer of dimer molecules across the membrane due to an external applied electric field, the equation is given by:

$$
\left(\mathrm{HA}_{2}^{-}\right)^{\prime} \frac{\mathrm{K}^{\prime}}{\mathrm{K}^{\prime \prime}}\left(\mathrm{HA}_{2}^{-}\right)^{\prime \prime}
$$

where $\left(\mathrm{HA}_{2}^{-}\right)_{\mathrm{m}}^{\prime}$ is the dimer species at the left side of the membrane and $\left(\mathrm{HA}_{2}^{-}\right)^{\prime \prime} \mathrm{m}$ is that at the right side of the membrane. For simplicity, the rate of transfer will be expressed in terms of the Eyring's model (41), in which the membrane is represented as a single potential energy barrier at the center of the membrane. Thus, the rate constant for the dimer crossing from left to right is:

$$
\mathrm{K}^{\prime}=\mathrm{K}_{\mathrm{o}} \exp (\mathrm{eU} / 2 \mathrm{kT})
$$


and the rate constant for the dimer crossing from right to left is:

$$
\mathrm{K}^{\prime \prime}=\mathrm{K}_{\mathrm{o}} \exp (-\mathrm{eU} / 2 \mathrm{kT})
$$

where $e$ is the electronic charge; $U$, the applied potential difference; and $\mathrm{K}_{\mathrm{o}}$, the rate constant of the dimer crossing the membrane in both directions without any applied voltage.

To maintain a constant flow of charge across the membrane, a heterogeneous recombination-dissoctation process is assumed to take place at the membrane interface. This means that at the interface either protons in the aqueous phase combine with the uncoupler anions at the membrane surface, or the neutral molecules dissociate into protons and anions, the anions remaining at the membrane surface and the protons going into the solution. For this recombination-dissociation process the equation is given by:

$$
\mathrm{A}_{\mathrm{m}}^{-}+\mathrm{H}_{\mathrm{aq}}^{+} \frac{\mathrm{k}_{\mathrm{R}}}{\mathrm{k}_{\mathrm{D}}} \mathrm{HA}_{\mathrm{m}}
$$

The aqueous concentration of protons $\mathrm{H}^{+}$is kept constant by means of a buffer.

The charge flow from one side of the membrane to the other side can be described in terms of the five processes shown in Fig. 24. In the following equations, the molecular species at the left side of the membrane will be denoted with a single prime (') and those at the right side with a double prime (").

1. Proton transfer across the left interface with the formation of $A_{m}^{-}$;

$$
J / F=k_{D} H_{m}^{\prime}-k_{R} H_{a q}^{+} A_{m}^{-\prime}
$$


2. Formation of the dimer at the left side;

$$
J / F=k_{\alpha} \mathrm{HA}_{\mathrm{m}}^{\prime} A_{\mathrm{m}}^{-}-\mathrm{k}_{B} \mathrm{HA}_{2 \mathrm{~m}}^{-}
$$

3. Dimer crossing the membrane;

$$
J / F=K^{\prime} \mathrm{HA}_{2 \mathrm{~m}}^{-}-\mathrm{K}^{\prime \prime} \mathrm{HA}_{2 \mathrm{~m}}^{-"}
$$

4. Dissociation of the dimer at the right side:

$$
J / F=k_{\beta} \mathrm{HA}_{2 \mathrm{~m}}^{-"}-\mathrm{k}_{\alpha} \mathrm{HA}_{\mathrm{m}} " \mathrm{~A}_{\mathrm{m}}^{-"}
$$

5. Proton transfer across the right side;

$$
J / F=k_{R} A_{m}^{-"} H_{a q}^{+}-k_{D} H_{m}^{\prime \prime}
$$

From Eqs. (5), (6), and (8-12), by eliminating $\mathrm{A}_{\mathrm{m}}^{-}, \mathrm{A}_{\mathrm{m}}^{-"}, \mathrm{HA}_{2 \mathrm{~m}}^{-}, \mathrm{HA}_{2 \mathrm{~m}}^{-} "$ ", $K^{\prime}$ and $K^{\prime \prime}$ the current $J$ is given by:

$$
J=F \frac{\frac{k_{\alpha} k_{D} H^{2}}{k_{\beta} k_{R}^{H}} 2 k_{o} \sinh (e U / 2 k T)}{1+\left(\frac{1}{k_{\beta}}+\frac{k_{\alpha} H A}{k_{\beta} k_{R} H}\right) 2 K_{o} \operatorname{Cosh}(e U / 2 k T)}
$$

In the process of derivation it has been assumed that the membrane permeability to neutral molecules $\mathrm{HA}_{\mathrm{m}}$ is much greater than the permeability to dimer $\mathrm{HA}_{2 \mathrm{~m}}^{-}$. It has been further assumed that the following association-dissoclation processes are at equilibrium; that is, they are not significantly disturbed by the charge flow across the membrane. Therefore, 


$$
\frac{k_{D}}{k_{R}}=k_{1}^{*}=\frac{H^{+} A_{m}^{-}}{H_{m}}
$$

and

$$
\frac{k_{B}}{k_{\alpha}}=K_{2}=\frac{A_{m}^{-} H_{m}}{H A_{2 m}^{-}}
$$

Then the current density is equal to

$$
J=F \frac{2 \frac{\mathrm{K}_{1}^{*}}{\mathrm{~K}_{2}} \mathrm{~K}_{\mathrm{o}} \frac{\mathrm{HA}_{\mathrm{m}}^{2}}{\mathrm{H}} \sinh (\mathrm{eU} / 2 \mathrm{kT})}{1+2 \frac{\mathrm{K}_{\mathrm{o}}}{\mathrm{k}_{B}}+\frac{2 \mathrm{~K}_{\mathrm{o}}}{\mathrm{k}_{2} \mathrm{k}_{\mathrm{R}}} \frac{\mathrm{HA}}{\mathrm{H}} \operatorname{Cosh}(\mathrm{eU} / 2 \mathrm{kT})}
$$

The total concentration of the pesticide in the aqueous phase $c_{T}$, is the sum of the concentrations of the anion and the neutral molecules:

$$
\mathrm{c}_{\mathrm{T}}=\mathrm{A}_{\mathrm{aq}}^{-}+\mathrm{HA}_{\mathrm{aq}}
$$

If $\gamma$ is the distribution coefficient of neutral pesticide molecule between the membrane and the bulk aqueous solution, then the concentration of the neutral species in the membrane phase is given by:

$$
\mathrm{HA}_{\mathrm{m}}=\gamma \frac{\mathrm{c}_{\mathrm{T}} \mathrm{H}}{\mathrm{H}+\mathrm{K}_{1}}
$$

where $K_{1}$ is the dissociation constant of the pesticide HA in the bulk aqueous phase. This is partially justified by the observation of maximum conductivity at the $\mathrm{pH}$ close to the $\mathrm{pK}$ value of the corresponding pesticide. 
Substituting Eq. (17) into Eq. (15), we get,

$$
J=F \frac{2 \frac{k_{1}^{*}}{k_{2}} \gamma^{2} k_{0} \frac{c_{T}^{2} H}{\left(H+k_{1}\right)^{2}} \operatorname{Sinh}(e U / 2 k T)}{1+2 \frac{k_{0}}{k_{B}}+\frac{2 \gamma K_{0}}{k_{R} k_{2}} \frac{c_{T}}{\left(H+k_{1}\right)} \operatorname{Cosh}(e U / 2 k T)}
$$

Eq. (18) gives the current density through the membrane under the applied voltage $U$. At small voltages, 1.e. as $U \rightarrow 0$, the zero voltage conductivity $G$ is equal to:

$$
G=\frac{J}{U}=G_{0} \frac{c_{T}^{2} H}{\left(H+k_{1}\right)^{2}}
$$

where

$$
G_{0}=2 \frac{k_{1}^{*}}{k_{2}} \gamma^{2} k_{0} \frac{e F}{2 k T}
$$

Since the conductivity increases with the applied voltage,

$$
2 \frac{k_{o}}{k_{B}}+\frac{2 \gamma k_{O}}{k_{R} k_{2}} \frac{c_{T}}{H+k_{1}}<1
$$

Eq. (19) predicts the basic features of class II uncouplers. It Indicates that the conductivity is proportional to the square of the uncoupler concentration, and the maximum conductivity occurs when the $\mathrm{pH}$ value of the aqueous solution is equal to the $\mathrm{pK}$ value of the uncoupler. 
These properties are in partlal agreement with the experimental results. For $2,4-\mathrm{D}, 2,4-\mathrm{DB}$, and $2,4,5-\mathrm{T}$ the membrane displays highest conductivity in the vicinity of the pK value of each pesticide. Above the pK value, the conductivity decreases with the decrease of proton concentration as predicted from Eq. (19). However, for the $\mathrm{pH}<\mathrm{pK}$ the data do not agree with the above model. At the present time the existence of a conductivity plateau in this $\mathrm{pH}$ range can not be explained.

The agreement between the experimental and the theoretical $\mathrm{pH}$ dependence of conductivity is much better in case of $2,4-\mathrm{DCP}$ ( $\mathrm{pK}=7.8$ ) as shown in Fig. 11. It should be noted that for this compound the conductivity plateau at low $\mathrm{pH}$ is not well developed. It is possible that the data Indicate the presence of two different mechanisms of charge transport across the membrane.

The kinetic model is more satisfactory with regard to the concentration dependence of conductivity. For all compounds the experimental membrane conductance is very closely proportional to the square of the uncoupler concentration.

Eq. (18) indicates that the membrane behaves as a nonlinear circuit element, and the nonlinearity of the current-voltage characteristics reflects the kinetics of the various processes associated with charge transfer across the membrane.

B2. Analysis of the Current-Voltage Characteristics.

In this section only the membrane conductivity induced by 2,4-DCP is analyzed and the kinetic model tested. As follows from Eq. (18), it 
Is to be expected that the voltage dependence of membrane conductance is a function of both the $\mathrm{pH}$ of the aqueous phase and the pesticide concentration.

The ratio of the membrane conductance at voltage $U, g(U)$, to the conductance at $25 \mathrm{mV}, G(25)$, denoted by $G^{\prime}(U)$ is equal to

$$
\begin{aligned}
G^{\prime}(U) & =\frac{G(U)}{G(25)}=\frac{J(U) / U}{J(25) / 25} \\
& =\frac{\frac{25}{U}\left(\operatorname{Sinh} \frac{25 e}{2 k T}\right)^{-1}\left(\operatorname{Sinh} \frac{e U}{2 k T}\right)\left(1+\left(Q+R \frac{C_{T}}{H+K_{1}}\right) \operatorname{Cosh} \frac{25 e}{2 k T}\right)}{1+\left(Q+R \frac{C_{T}}{H+K_{1}}\right) \operatorname{Cosh} \frac{e U}{2 k T}}
\end{aligned}
$$

where

$$
\begin{aligned}
& Q=2 K_{0} / k_{B} \\
& R=2 \frac{\gamma K_{o}}{k_{R} K_{2}}
\end{aligned}
$$

From Eq. (20), the value of $Q+R \frac{c_{T}}{H+K_{1}}$, denoted as $x\left(c_{T}, H\right)$, is equal to

$$
\begin{aligned}
& x\left(c_{T}, H\right)=Q+R \frac{c_{T}}{H+K_{1}} \\
& \frac{25}{U}\left(\operatorname{Sinh} \frac{25 e}{2 k T}\right)^{-1} \operatorname{Sinh} \frac{e U}{2 k T}-G^{\prime}(U) \\
& =\frac{G^{\prime}(U) \cosh \frac{e U}{2 k T}-\frac{25}{U} \operatorname{Cosh} \frac{25 e}{2 k T}\left(\operatorname{Sinh} \frac{25 e}{2 k T}\right)^{-1} \operatorname{Sinh} \frac{e U}{2 k T}}{}
\end{aligned}
$$

To test the effect of concentration on the voltage dependence 
of the membrane conductance, the experimental values of $G^{\prime}(U)$ are compared with the theoretical values $G^{\prime}(U){ }_{t}$ reconstructed from calculated values of $x\left(c_{T}, H\right)$ for given $\mathrm{pH}$. The analysis was carried out at $\mathrm{pH} 9.5$ and concentrations of $0.1,0.25,0.4,0.7$, and $2 \mathrm{mM}$. The values of $x\left(c_{T}, H\right)$ were calculated from Eq. (23) using the experimental values of $G^{\prime}(U)$ for each data point. Since the values of $x\left(c_{T}, H\right)$ are voltage dependent, the average values $\bar{x}\left(c_{T}, H\right)$ obtained from vartous values of $U$ were used for analysis. The experimental value of $G^{\prime}(U)$ and the theoretical curves are compared in Figs. 25-29. The solid line represents the theoretical values of $G^{\prime}(U)$ calculated from the average values of $x\left(c_{T}, H\right)$ for the voltages: $50,75,100,125,150$, and $175 \mathrm{mV}$, while the broken line represents the average values for the set of higher voltages: $100,125,150$, and $175 \mathrm{mV}$. It appears that the broken line is better fit to the experimental data.

To test the kinetic model on the effect of $\mathrm{pH}$ on the voltage dependence of membrane conductance, the kinetic parameters $Q$ and $R$ given in Eqs. (21) and (22) are needed. These values can be obtained from the curve of $\bar{x}\left(c_{T}, H\right)$ plotted against the pesticide concentration $\mathrm{c}_{\mathrm{T}}$. The curve is shown in Fig. 30. In order not to exclude any data polnts, the average values calculated from the voltage range between 50 and $175 \mathrm{mV}$ were used; although the average values from the high voltage range give a better fit to the experimental data of $G^{\prime}(U)$. The values of $Q$ and $R$ thus obtained are found to be equal to $8.96 \times 10^{-2}$ and $2.64 \times 10^{-7}$ respectively. The test of the kinetic model, using these values, was carrled out in the following way. The normalized conductance $G^{\prime}(U)$ was calculated from Eq. (20) 


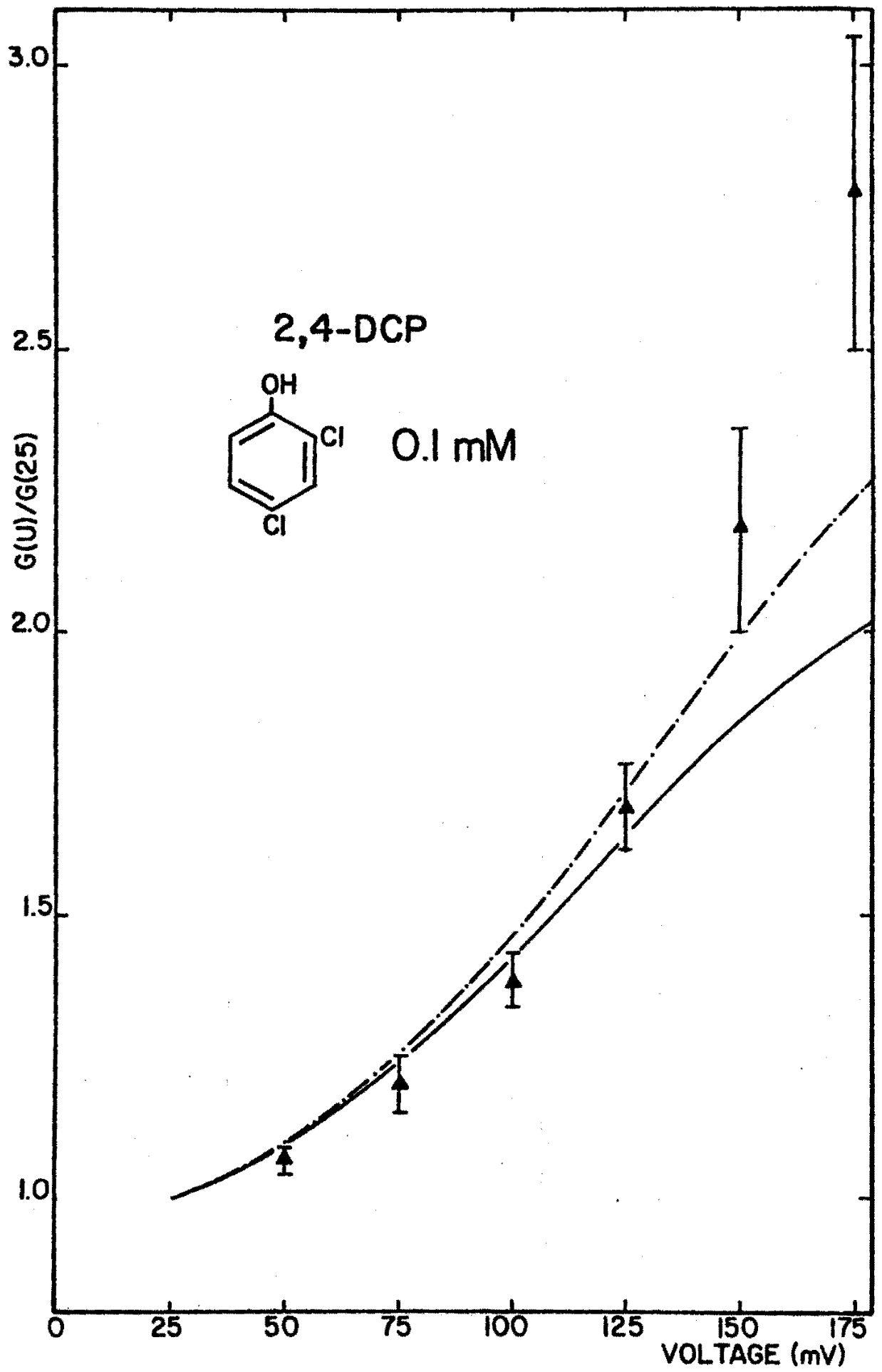

F1gure 25. Comparison of theoretical and experimental voltage dependence of membrane conductance for $0.1 \mathrm{mM} \mathrm{2,4-DCP}$. Solid line is the theoretical curve for the normalized conductance predicted from Eq. (20), using $x$ averaged for all the voltages. Dashed line represents the normalized conductance obtained for $x$ averaged at higher voltages $(100,125,150$, and $175 \mathrm{mV}$. 


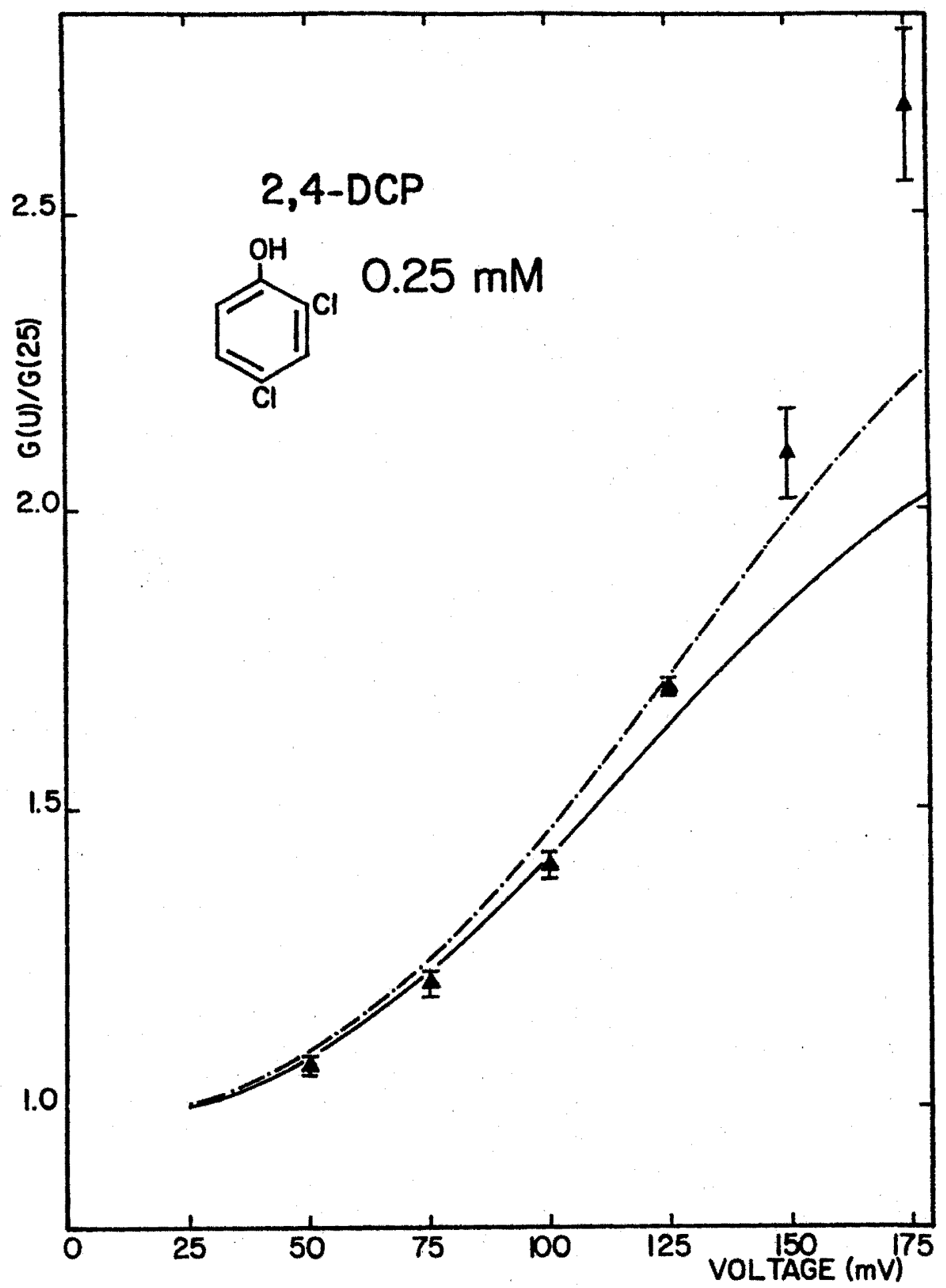

Figure 26. Comparison of theoretical and experimental voltage dependence of membrane conductance for $0.25 \mathrm{mM} \mathrm{2,4-DCP.} \mathrm{Solid} \mathrm{1ine}$ is the theoretical curve for the normalized conductance predicted from Eq. (20), using $x$ averaged for all the voltages. Dashed 1 ine represents the normalized conductance obtained for $\mathbf{x}$ averaged at higher voltages $(100,125,150$, and $175 \mathrm{mV}$. 


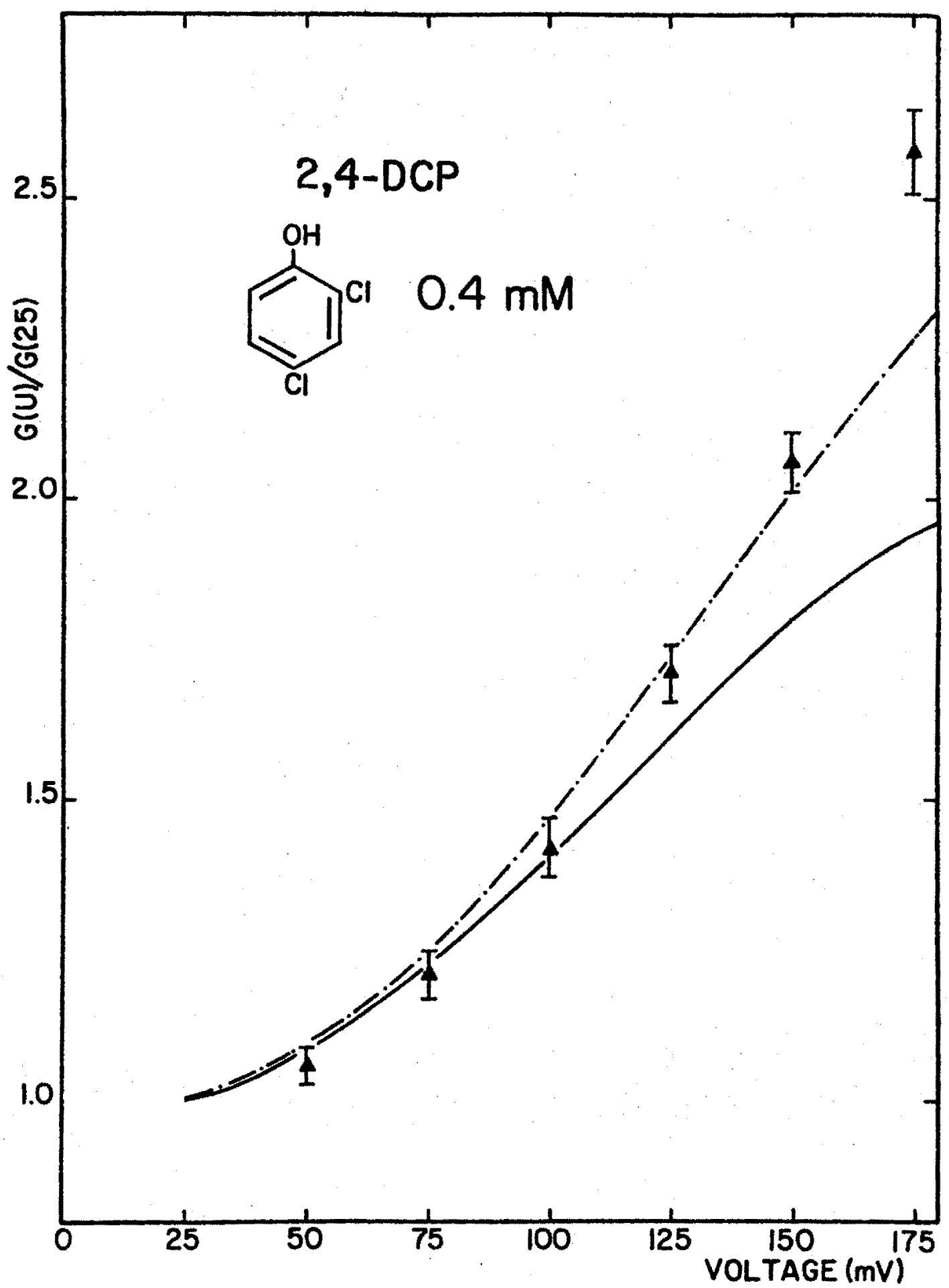

Figure 27. Comparison of theoretical and experimental vo1tage dependence of membrane conductance for $0.4 \mathrm{mM} \mathrm{2,4-DCP.} \mathrm{Solid} \mathrm{line}$ is the theoretical curve for the normalized conductance predicted from Eq. (20), using $x$ averaged for all the voltages. Dashed line represents the normalized conductance obtained for $\mathbf{x}$ averaged at higher voltages $\left(100,125,150\right.$, and $175^{\circ} \mathrm{mV}$ ) 


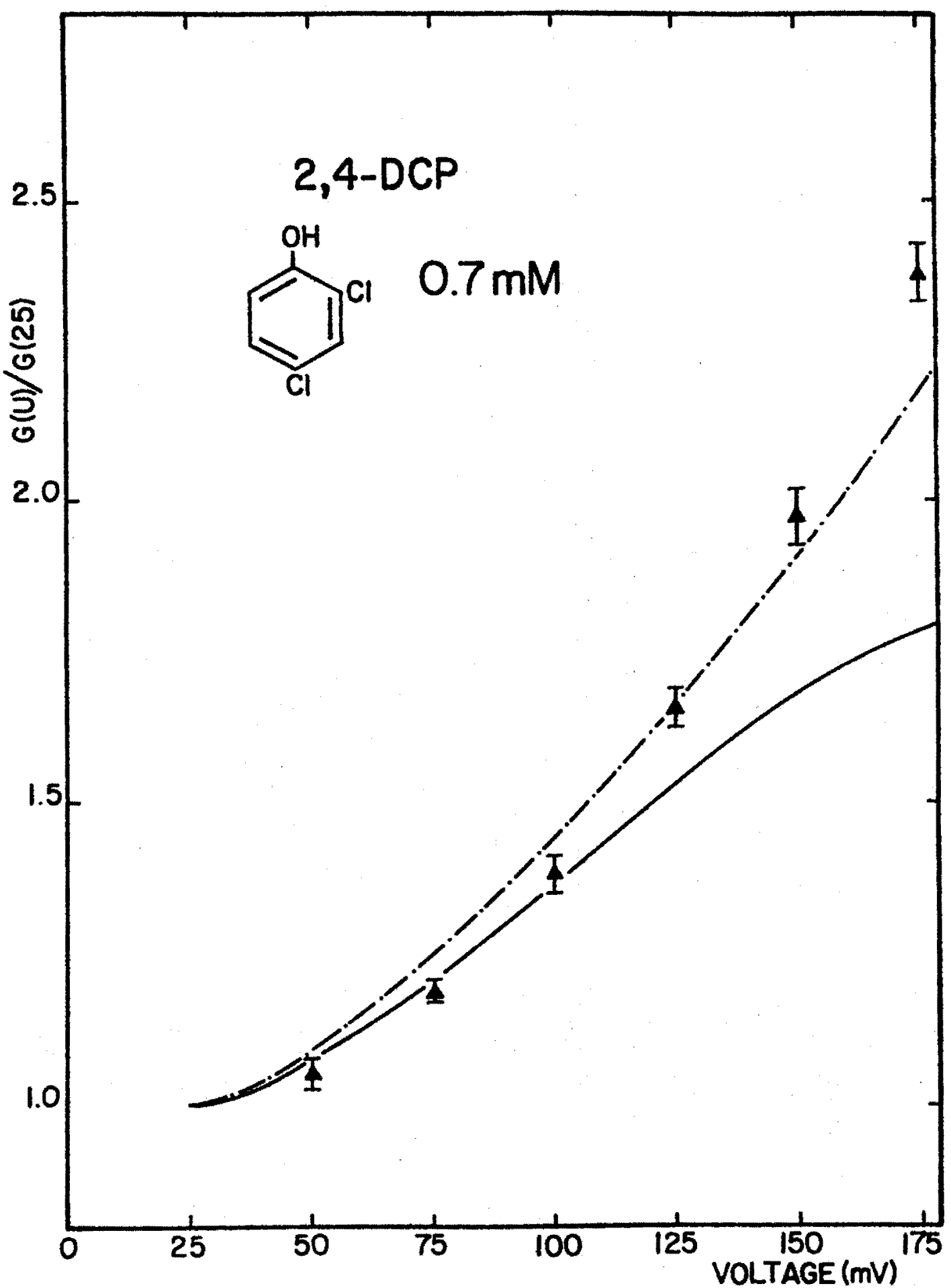

F1gure 28. Comparison of theoretical and experimental voltage dependence of membrane conductance for $0.7 \mathrm{mM} \mathrm{2,4-DCP.} \mathrm{Solld} \mathrm{line}$ is the theoretical curve for the normalized conductance predicted from Eq. (20), using $x$ averaged for all the voltages. Dashed line represents the normalized conductance obtained for $x$ averaged at higher voltages $(100,125,150$, and $175 \mathrm{mV}$. 


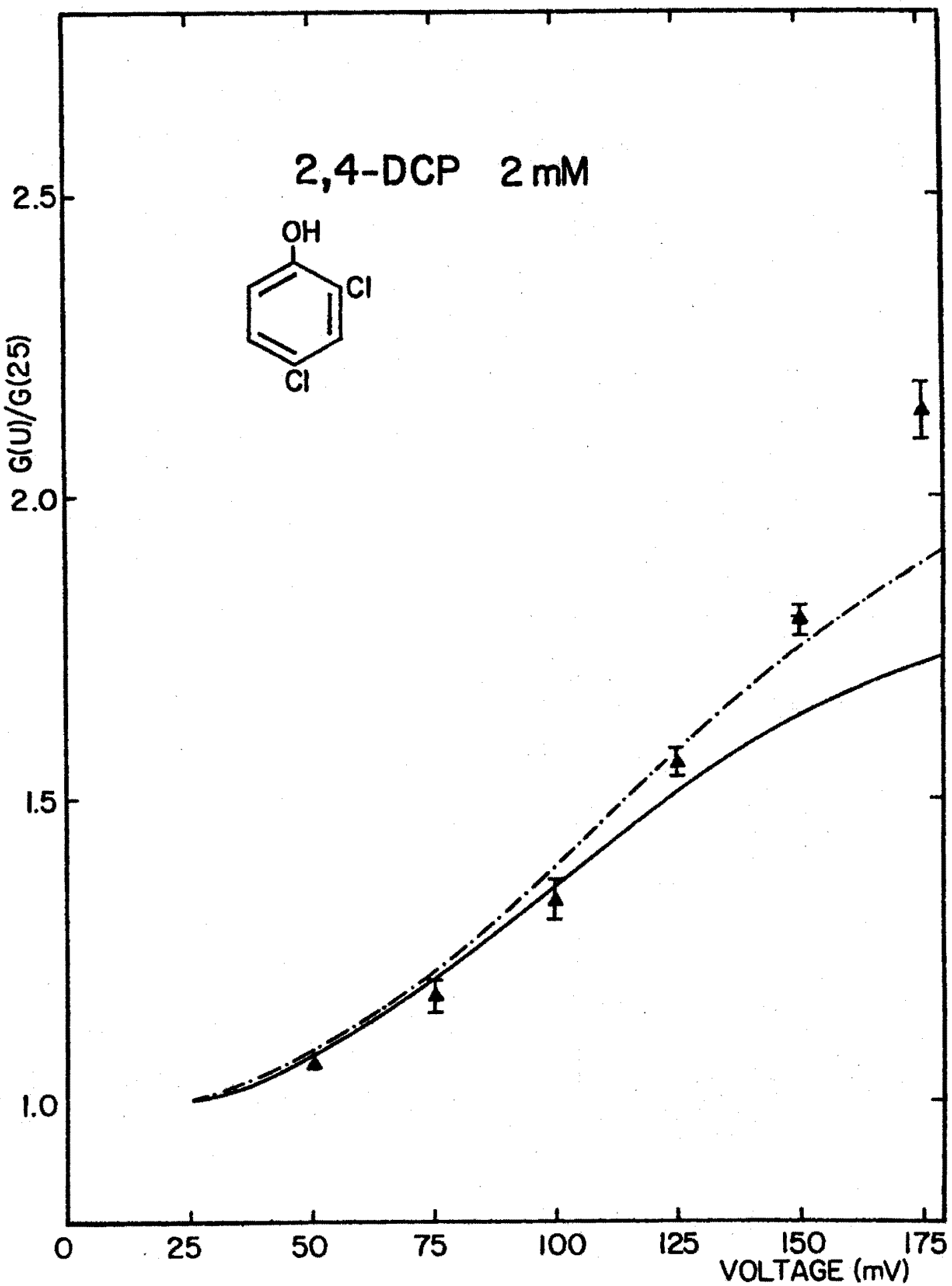

Figure 29. Comparison of theoretical and experimental voltage dependence of membrane conductance for $2 \mathrm{mM} \mathrm{2,4-DCP.} \mathrm{Solid} \mathrm{line}$ is the theoretical curve for the normalized conductance predicted from Eq. (20), using $x$ averaged for all the voltages. Dashed line represents the normalized conductance obtained from $x$ averaged at higher voltages $(100,125,150$, and $175 \mathrm{mV}$. 


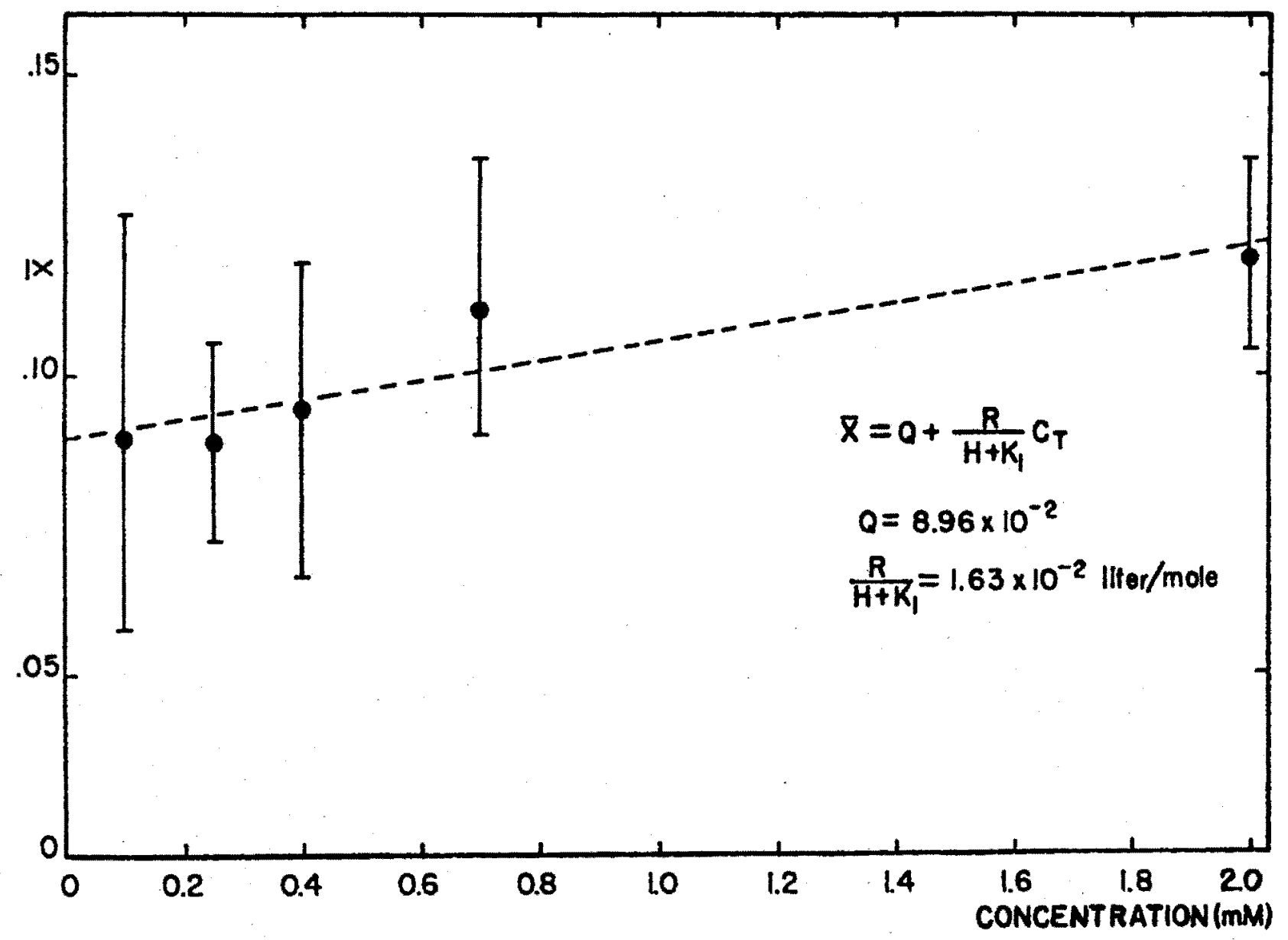

Figure 30. Dependence of $\bar{x}$ on the concentration of 2,4-DCP. Value of $x$ was obtained by averaging $x$ for the voltage range between 50 and $175 \mathrm{mV}$. $x$ were calculated according to Eq. (23). Error bars represent the maximum possible experimental error. 
with $\mathrm{pH}$ as a variable parameter and the concentration $\mathrm{c}_{\mathrm{T}}$ at $0.4 \mathrm{mM}$. The calculated values are presented in Fig. 31. It appears that the pH effect from the kinetic model is opposite to that observed in the experiment. According to the model, the membrane conductance is expected to be less voltage dependent as the proton concentration in the aqueous phase is decreased. In fact, as the experimental results indicate, the conductivity is more voltage dependent as the $\mathrm{pH}$ is increased.(Figs. 16, 31). The $\mathrm{pH}$ effect observed in these experiments does not have a simple interpretation. However, it can not be due to unstirred layers, since in this case the weakest voltage dependence is to be expected at $\mathrm{pH} 7.5$.

\section{B3. Membrane Surface Charge.}

It has been shown that various substances, either in ionic or neutral form, affect the transport of lons across lipid membranes. This phenomenon is in some cases due to adsorption of these substances in the ionic form on the membrane surface. The presence of membrane surface charge has been reported for salicylates (29), uncouplers of oxidative phosphorylation such as dinitrophenol (33), and pentachlorophenol (24), the fluorescent probe 1-anilino-8-napthalene sulphonate (ANS), urany1 and thorium ions (31), and chaotropic ions such as perchlorate and thiocyanates (32): The chlorophenoxy acids and 2,4-DCP exist predominantly in the ionic form in an aqueous solution when the $\mathrm{pH}$ is greater than the $\mathrm{pK}$ value of the substance. There is a possibil1ty that some of the effects described in the present work are assoclated with adsorption of the above compounds on the membrane 


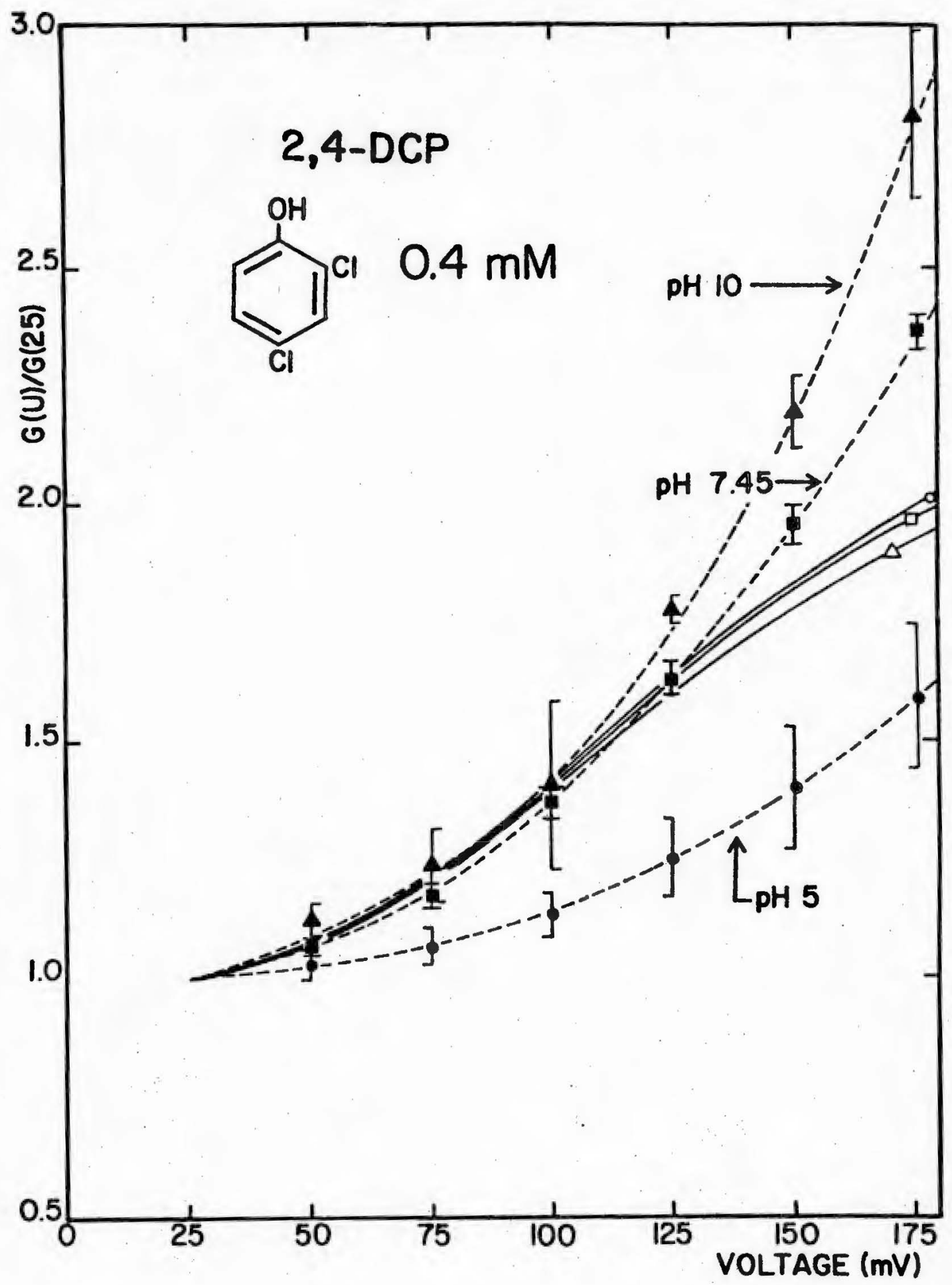

Figure 31. Effect of $\mathrm{pH}$ on the voltage dependence of membrane conductance normalized at $25 \mathrm{mV}$. Broken lines represent the experimental data. Solid line represents the theoretical normalized conductance calculated from Eq. (20) using $Q=8.96 \times 10^{-2}$ and $R=$ $2.64 \times 10^{-7}$. Symbols on the solid lines $(0,0, \Delta)$ indicate the corresponding $\mathrm{pH}$ values for the comparison with the experimental data. 
surface.

In general, adsorption of ions at the membrane surface can result in two processes of electrical origin which affect the membrane conductivity: (a) creation of a surface charge that changes the density of membrane permeable ions at the membrane surface and (b) reorientation of dipoles associated with the polar head groups of 1ipids that affects the membrane permeability.

It will be shown that there is a change of membrane surface potential due to the presence of $2,4-D, 2,4-D B, 2,4,5-T$, and $2,4-D C P$ In the aqueous phase. In section B3 a., the theory of the ionic double layer and the relationship between the surface charge density and the surface potential will be discussed, as well as the use of nonactin as a probe of the membrane surface potential. In section $\mathrm{B} 3 \mathrm{~b}$., an analysis and discussion of the data will be presented.

B3 a. Theory of Diffuse Double Layer and the Use of Nonactin as a Probe for Membrane Surface Potential.

In the theory of the double layer proposed by Gouy and Chapman (42), the ions are considered as point charges, and the dielectric coefficient of the aqueous phase is assumed to be constant and equal to the bulk value up to the membrane surface.

The relationship between the electrical potential and the space charge density follows from the Poisson equation:

$$
\begin{gathered}
\frac{d^{2} \psi(x)}{d x^{2}}=-\frac{4 \pi}{\varepsilon} \rho(x) \\
\rho(x)=\sum_{1} e z_{i} N_{1}(x)
\end{gathered}
$$


$\psi(x)$ is the electrostatic potential; $\rho(x)$, the charge density; $\mathbb{N}_{i}(x)$, the concentration of ions of the species 1 , at a distance $x$ from the surface; and $a_{1}$, the valence of the lonic species 1 . The distribution of ions in the solution in the direction normal to the surface is given by

$$
N_{i}(x)=N_{i}(\infty) \exp \left(-e z_{i} \psi(x) / k T\right)
$$

Is is assumed that at $x=\infty$ the potential is equal to zero. It will be shown in the appendix, that in the presence of only one kind of ion of valence $z$, the density of the charge at the membrane surface, $\sigma$, is related to the surface potential $\psi(0)$, according to:

$$
\sigma=\left(\frac{2 R T \varepsilon c}{\pi}\right)^{\frac{2}{2}} \operatorname{Sinh}(z F \psi(0) / 2 R T)
$$

where $c$ is the molar concentration of the electrolyte. McLaughlin et al. $(29,30)$, White (43), MacDonald and Bangham (44), have shown that the simple Gouy-Chapman theory adequately describes the effect of membrane surface charge and the Ionic strength of the aqueous phase on the membrane conductivity, capacitance, and the surface potential.

The use of nonactin as a probe of membrane surface potential was first proposed and tested by McLaughlin (29-33, 45). It is based on the observation that the conductivity of lipid membranes increases in the presence of nonactin and small cations in the surrounding solution. This effect is due to the formation of membrane permeable $1: 1$ complex between the neutral nonactin molecule and the cation. The density 
of the membrane permeable nonactin- $\mathrm{K}^{+}$complex at the membrane-water Interface is expected to be dependent upon the membrane potential; thus In the presence of potassium lons, the nonactin-induced membrane conductance is given by:

$$
\begin{aligned}
G_{\text {non-K }} & =\frac{F^{2}}{d} u_{1 s} k_{1 s} K_{1 s}^{+}\left(K^{+}\right)(N O N) \exp (-F \psi(0) / R T) \\
& =G_{\text {non-K }}^{0} \exp (-F \psi(0) / R T)
\end{aligned}
$$

where $F$ is the Faraday constant; d, the thickness of the membrane, $u_{\text {is }}$ the mobility of the charged complex in the membrane; $k_{1 s}$, the membrane solution partition coefficient [assuming that there is no change in $u_{\text {is }}$ and $k_{1 s}$, due to change $\left.1 n \psi(0)\right] ; . K_{1 s}$, the association constant for the formation of the complex; and $\psi(0)$, the surface potential, $\left(\mathrm{K}^{+}\right)$and (NON) are the concentrations of potassium and nonactin respectively. As follows from Eq. (27), the nonactin-induced conductivity is a function of membrane potential. Thus the change of electrostatic potential of the membrane surface can be inferred from Eq. (27) and from the measurement of membrane conductance.

Uncouplers of oxidative phosphorylation, such as dinftropheno1 (33) and pentachlorophenol (24) have been shown to cause the membrane surface to be negatively charged, presumably due to adsorption of the Ionized form at the membrane surface. Since the compounds investigated in the present work are of the same category, a similar effect has been expected to take place.

B3 b. Analysis and Discussion of the Data on Membrane Surface Charge. 
According to the above hypothesis, the membrane surface can acquire a negative surface charge, which would result in the increase of the density of nonactin- $\mathrm{K}^{+}$complex at the interface. Therefore it may be expected that in the presence of pesticides, the nonactin-induced conductivity will be increased. Furthermore, this conductivity may increase with the increase of pesticide concentration in the system. The data do show that the nonactin- $\mathrm{K}^{+}$conductivity increases in the presence of pesticide. Thus they are in agreement with the hypothesis that the effect is most 1ikely caused by the adsorption of the negatively charged form of the pesticide at the membrane surface.

On the other hand, one might consider the alternative hypothesis, that the increase of nonactin conductivity is due to the reorientation of dipoles in the polar head group layer in the presence of pesticides. For this, one has to assume that the degree of favorable reorientation of the dipoles of the polar head group resulting in facilitation of the flow of nonactin- $\mathrm{K}^{+}$complex increases with the pesticide concentration. Since the dipole reorientation facilitating the transport of positive ions should have a blocking effect with regard to the negative ions (46), one should expect a decrease in the exponent of the concentration dependence of the pesticide-induced conductivity. However, this was not observed (Figs. 12-14); instead, the exponent of the concentration dependence of the pesticide-induced conductivity was found to be concentration independent. For this reason the first process is most likely to take place; that is, the increase of nonactin conductivity with pesticide concentration is due to the presence of a negative surface charge on the membrane surface. If the concentration dependence of both 
pesticide and nonactin-induced conductivity is to be compatible with the dipole layer reorientation process, the pesticide related permeable species should be positively charged. This is most unlikely to be the case; for if it were so, the membrane permeable species would have to be protons!

In addition, there is a possibility that the membrane potential could be changed at a very low or very high $\mathrm{pH}$ of the aqueous solution because of the presence in the polar head region of a negative phosphate group $\left(\mathrm{PO}_{4}^{-}\right)$and a positive choline group $\left(\mathrm{N}^{+}\left[\mathrm{CH}_{3}\right]_{3}\right)$ in the case of lectthin. If such were the case, the nonactin-induced membrane conductivity with or without pesticide would have to show the corresponding change, for very low or very high pH. But the experimental results (FIg. 18) do not indicate any change in surface potential in the pH range studied.

With the assumption that the change of the membrane potential is due to the adsorption of negatively charged species on the membrane surface, the analysis was carried out in two steps; the surface potential due to the adsorption of the charges was evaluated, and the consequences of such adsorption were examined.

Evaluation of the surface potential was based on Eq. (27) giving $\psi(0)$ equal to:

$$
\psi(0)=\frac{R T}{F} \log \frac{G_{\text {non-K }}^{0}}{G_{\text {non-K }}}
$$

where $G_{\text {non-K }}^{\circ}$ and $G_{n o n-K}$ are the nonactin-1nduced conductivity in the absence and in the presence of pesticlde respectively. The results of such analysis are summarized in Fig. 32. The magnitude of the charge 


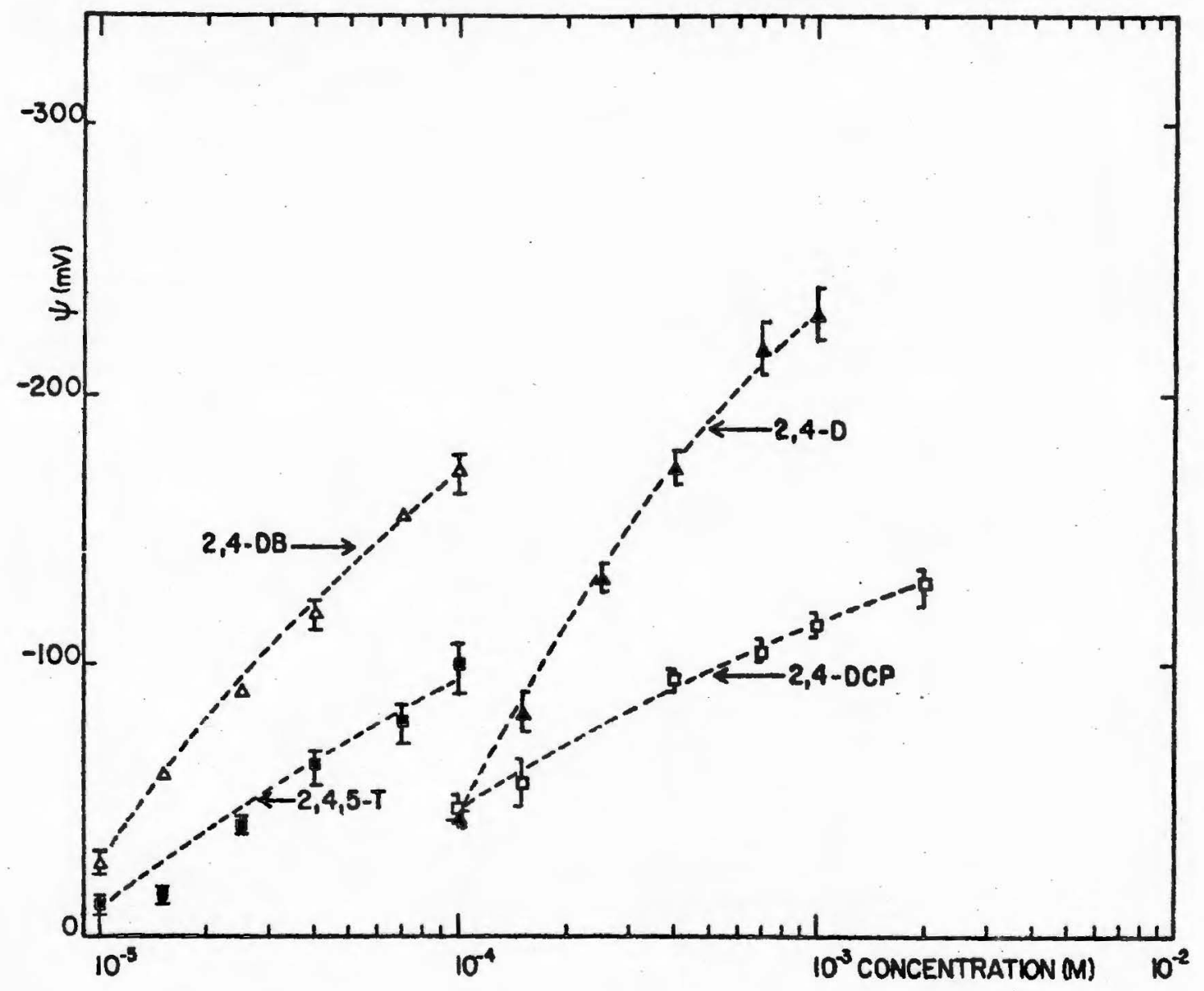

Figure 32. Change in the membrane surface potential as a function of the pesticide concentration for $2,4-\mathrm{D}$ at $\mathrm{pH} 2.7 ; 2,4-\mathrm{DB}$ at $\mathrm{pH} 5.0 ; 2,4,5-\mathrm{T}$ at $\mathrm{pH} 2,4$; and 2,4-DCP at $\mathrm{pH} 9.5$. $\psi(0)$ was calculated from Eq. (28) using nonactin- $\mathrm{K}^{+}$complex as a probe for the membrane surface charge. 
of the surface potential is comparable to, or greater than, that reported by McLaughlin for DNP (33), Na salicylate (29), and the chaotropic anions (32).

Let us now consider the class II uncouplers. As shown in the preceding section, the membrane conductance is expected to be proportional to the square of the pesticide concentration. McLaughlin has pointed out that the exponent of concentration in the power law expressing the relationship between membrane conductance and uncoupler concentration may be different from two if the membrane surface charge changes in the presence of uncoupler. Specifically, due to repulsion between the negatively charged membrane surface and negatively charged membrane permeable species, the conductivity is expected not to increase as much with the pesticide concentration as in the case of a surface charge free membrane. He proposed to use the membrane surface potential $\psi(0)$ as obtained from the nonactin conductivity measurements (Eq. 28) to reconstruct the concentration dependence of pesticide-induced conductivity corrected for the membrane surface charge. The correction consists of multiplication of the conductance for each point in the concentration dependence of the pesticide conductivity by the Boltzmann factor $\exp (-\mathrm{e} \psi(0) / \mathrm{kT})$, where the membrane surface potential is determined from the increase of nonactin conductivity for each point in the pesticide concentration dependence of nonactin-induced conductivity. Results of such analysis for 2,4-D, 2,4-DB, 2,4,5-T, and 2,4-DCP are presented in Tables 2-5, and the reconstructed conductance data are shown in Figs. 33-36. The most important feature of the reconstructed concentration dependence of pesticide-induced conductivity is that the 
ANALYSIS OF NONACTIN-2,4-D DATA TO DETERMINE MEMBRANE CHARGING AT $\mathrm{pH} 2.7$

\begin{tabular}{|c|c|c|c|c|}
\hline $\begin{array}{l}\text { Concentration } \\
\text { of } 2,4-D \mu M\end{array}$ & $\begin{array}{c}G / G^{0} \\
\exp (-F \psi(0) / R T) \\
(\times 10)\end{array}$ & $\begin{array}{l}\psi(0) \mathrm{mV} \\
(\mathrm{x}-10)\end{array}$ & $\begin{array}{l}G^{\prime} \text { mho-cm } \\
\left(\times 10^{-5}\right)\end{array}$ & $\begin{array}{r}G^{*} \text { mho-cm } \\
\left(\times 10^{-4}\right)\end{array}$ \\
\hline 0.1 & 0.55 & 4.35 & 0.016 & 0.009 \\
\hline 0.15 & 2.47 & 8.17 & 0.023 & 0.057 \\
\hline 0.25 & 17.5 & 13.2 & 0.024 & 0.42 \\
\hline 0.4 & 87.7 & 17.3 & 0.092 & 8.03 \\
\hline 0.7 & 507 & 21.7 & 0.278 & 140 \\
\hline 1.0 & 832 & 22.9 & 0.515 & 428 \\
\hline
\end{tabular}
MEMBRANE CHARGING AT $\mathrm{pH} 5.0$

\begin{tabular}{|c|c|c|c|c|}
\hline $\begin{array}{l}\text { Concentration } \\
\text { of } 2,4-D B \mu M\end{array}$ & $\begin{array}{c}G / G^{\circ} \\
\exp (-F \psi(0) / R T) \\
(x 10)\end{array}$ & $\begin{array}{l}\psi(0) \mathrm{mV} \\
(\mathrm{x}-10)\end{array}$ & $\begin{array}{l}G^{\prime} \operatorname{mho}^{2} \mathrm{~cm}^{2} \\
\left(\times 10^{-6}\right)\end{array}$ & $\begin{array}{r}\mathrm{G}^{*} \text { mho- } \mathrm{cm}^{2} \\
\left(\times 10^{-5}\right)\end{array}$ \\
\hline 10 & 0.28 & 2.632 & 0.07 & 0.02 \\
\hline 15 & 1.03 & 5.94 & 0.065 & 0.067 \\
\hline 25 & 3.14 & 8.78 & 0.0112 & 0.377 \\
\hline 40 & 10.6 & 11.91 & 0.284 & 3.02 \\
\hline 70 & 43.8 & 15.5 & 1.37 & 60.2 \\
\hline 100 & 89.1 & 17.3 & 3.69 & 328 \\
\hline
\end{tabular}

$G^{*}$ is the product of the original conductivity $\left(G^{\prime}\right)$ and $\exp (-F \psi(0) / R T)$ 


\section{ANALYSIS OF NONACTIN - 2,4,5-T DATA TO DETERMINE MEMBRANE CHARGING AT PH 2.4}

$\begin{array}{ccccc}\begin{array}{c}\text { Concentration } \\ \text { of } 2,4,5-\mathrm{T} \mu \mathrm{M}\end{array} & \begin{array}{c}\mathrm{G} / \mathrm{G}^{0}= \\ \exp (-\mathrm{F} \psi(0) / \mathrm{RT}\end{array} & \begin{array}{c}\psi(0) \mathrm{mV} \\ (\mathrm{x}-10)\end{array} & \left.\begin{array}{c}\mathrm{G}^{\prime} \begin{array}{c}\mathrm{mho}-\mathrm{cm}^{2} \\ (\mathrm{x} \mathrm{10})\end{array} \\ 10\end{array} \mathrm{G}^{-6}\right) & \begin{array}{c}\text { mho- } \mathrm{cm}^{2} \\ (\mathrm{x} \mathrm{10})\end{array} \\ 15 & 0.157 & 1.15 & 0.23 & 0.036 \\ 25 & 0.181 & 1.51 & 0.33 & 0.059 \\ 40 & 0.496 & 4.08 & 0.65 & 0.322 \\ 70 & 1.17 & 6.26 & 2.37 & 2.77 \\ 100 & 2.24 & 7.92 & 7.11 & 15.9 \\ & 5.21 & 10.1 & 12.9 & 67.0\end{array}$

TABLE V

ANALYSIS OF NONACTIN-2,4-DCP DATA TO DETERMINE MEMBRANE CHARGING AT pH 9.5

Concentration of 2,4-DCP $\mu \mathrm{M}$

$$
\begin{aligned}
& \mathrm{G} / \mathrm{G}^{\circ}= \\
& \psi(0) \mathrm{mV} \\
& \exp (-\mathrm{F} \psi(0) / \mathrm{RT} \\
& (\mathrm{x}-10) \\
& \begin{array}{l}
\mathrm{G}^{\prime} \text { mho-cm } \\
\left(\times 10^{-5}\right)
\end{array}
\end{aligned}
$$

$\begin{array}{lllll}0.1 & 0.615 & 4.63 & 0.003 & 0.019 \\ 0.15 & 0.912 & 5.63 & 0.01 & 0.089 \\ 0.4 & 4.11 & 9.46 & 0.922 & 3.79 \\ 0.7 & 6.3 & 10.5 & 2.93 & 18.3 \\ 1.0 & 9.14 & 11.5 & 4.75 & 43.3 \\ 2.0 & 12.8 & 12.8 & 10.4 & 158.0\end{array}$

$G^{*}$ is the product of the original conductivity $\left(G^{\prime}\right)$ and $\exp (-\mathrm{F} \psi(0) / \mathrm{RT})$ 


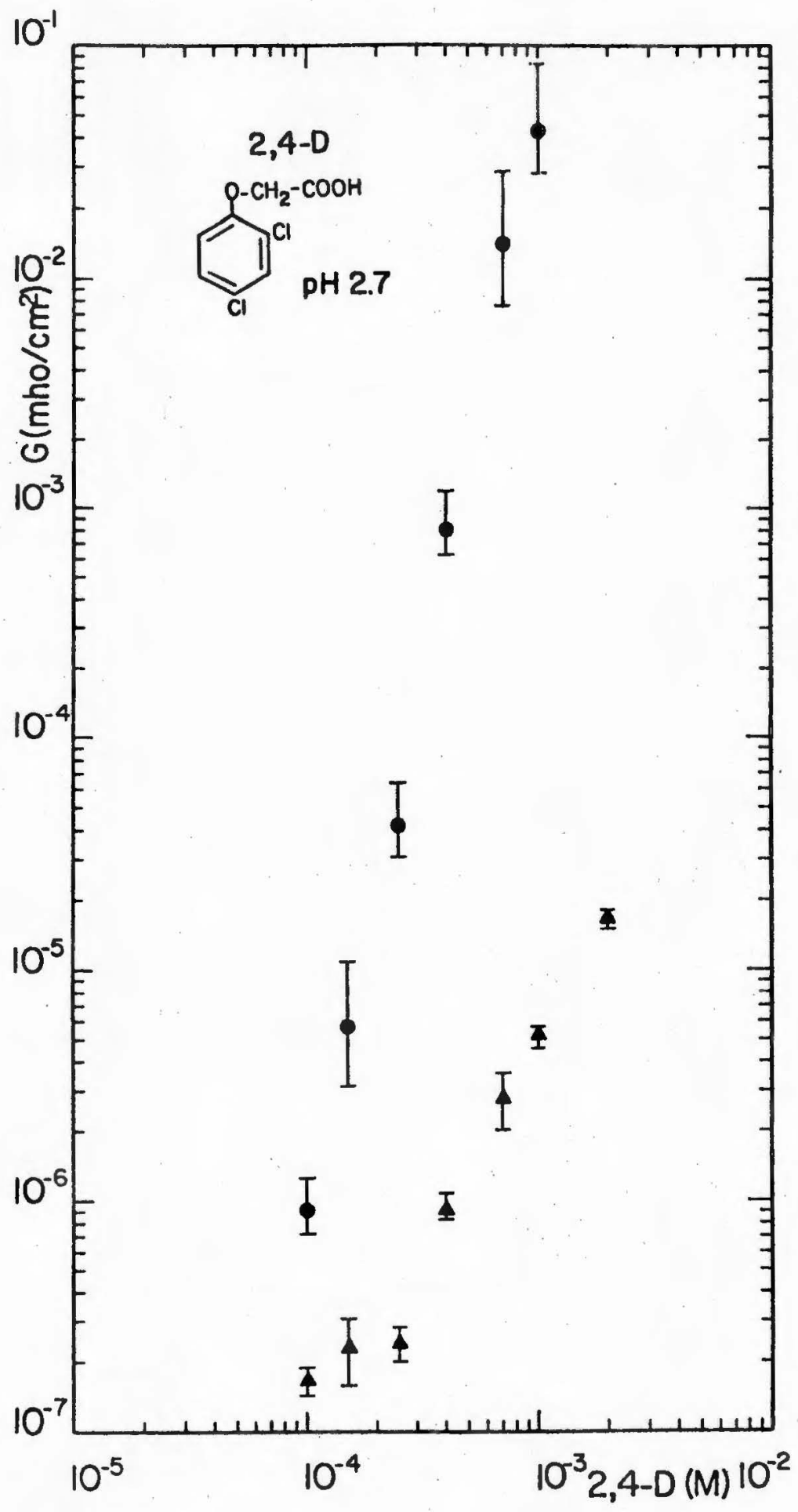

F1gure 33. Concentration dependence of membrane conductivity Induced by 2,4-D at $\mathrm{pH}$ 2.7. Triangles represent the experimental values. Circles represent the reconstructed conductance obtained from the data shown in F1gures 19 and 31, and from the Gouy-Chapman double layer theory. 


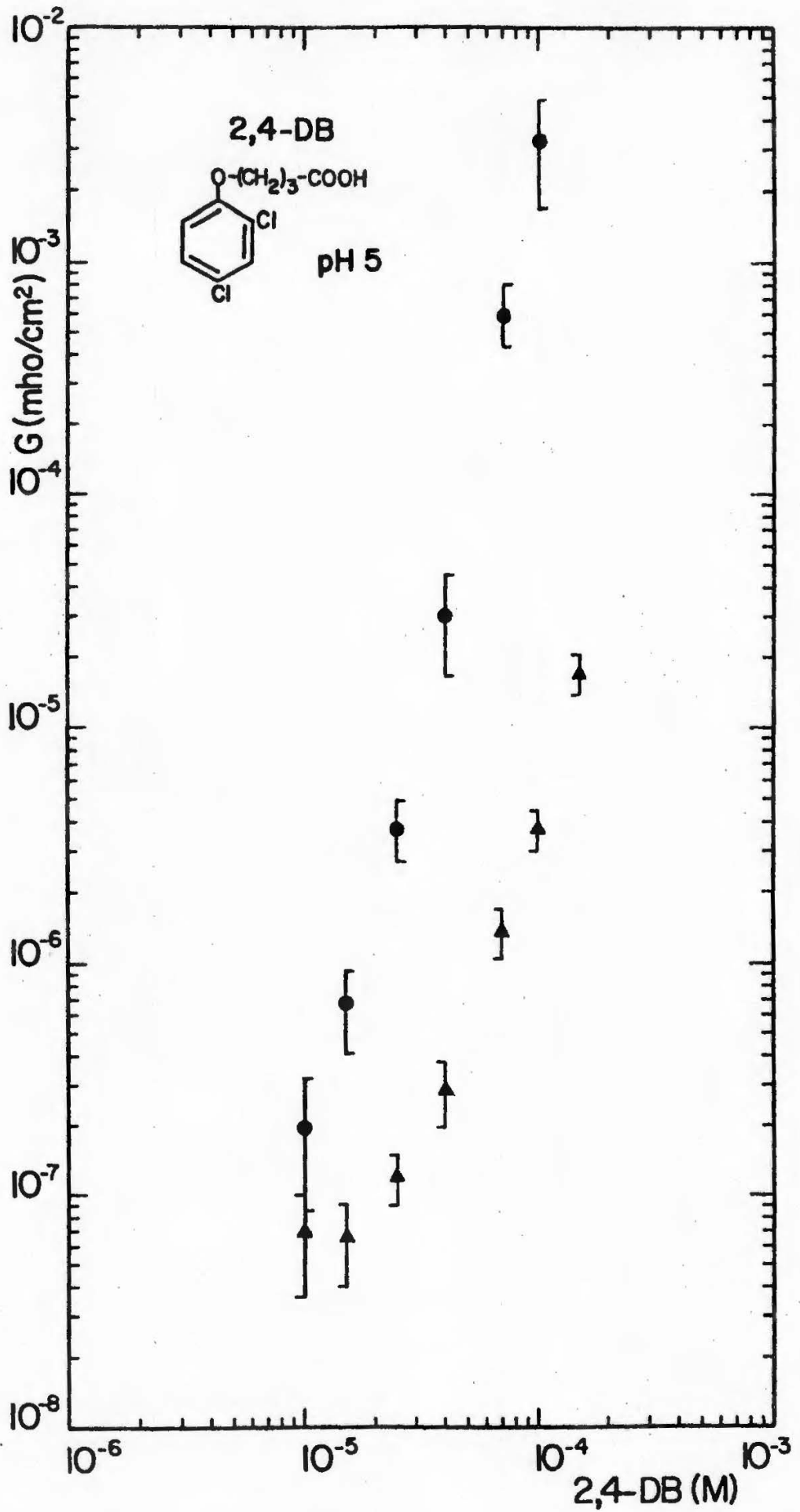

F1gure 34. Concentration dependence of membrane conductivity induced by 2,4-DB at $\mathrm{pH}$ 5.0. Triangles represent the experimental values. Circles represent the reconstructed conductance obtained from the data shown in F1gs. 20 and 31, and from the Gouy-Chapman double layer theory. 


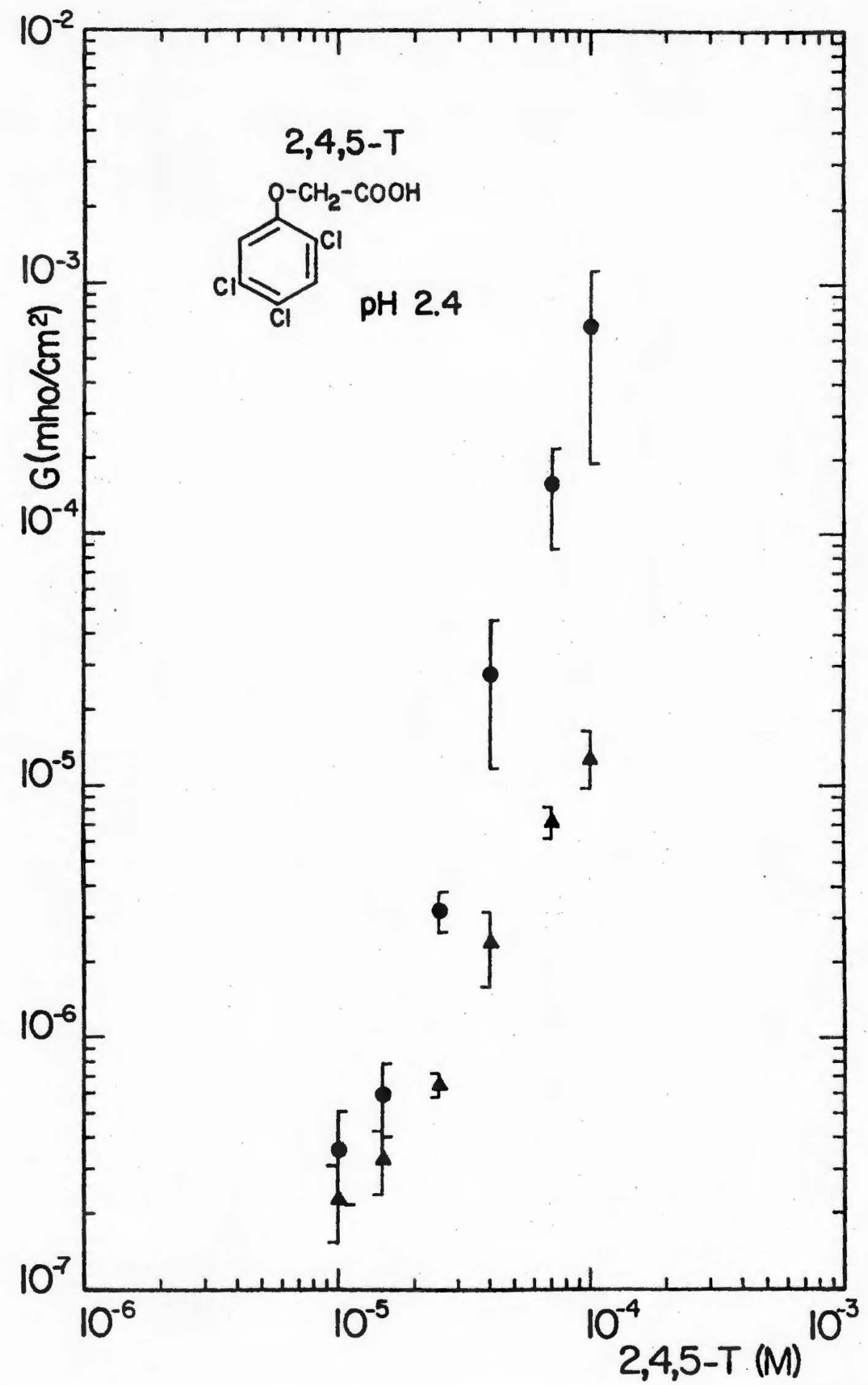

Figure 35. Concentration dependence of membrane conductivity 1nduced by 2,4,5-T at $\mathrm{pH} 2.4$. Traingles represent the experimental values. Circles represent the reconstructed conductance obtained from the data shown in Figures 21 and 31 and from the Gouy-Chapman double layer theory. 


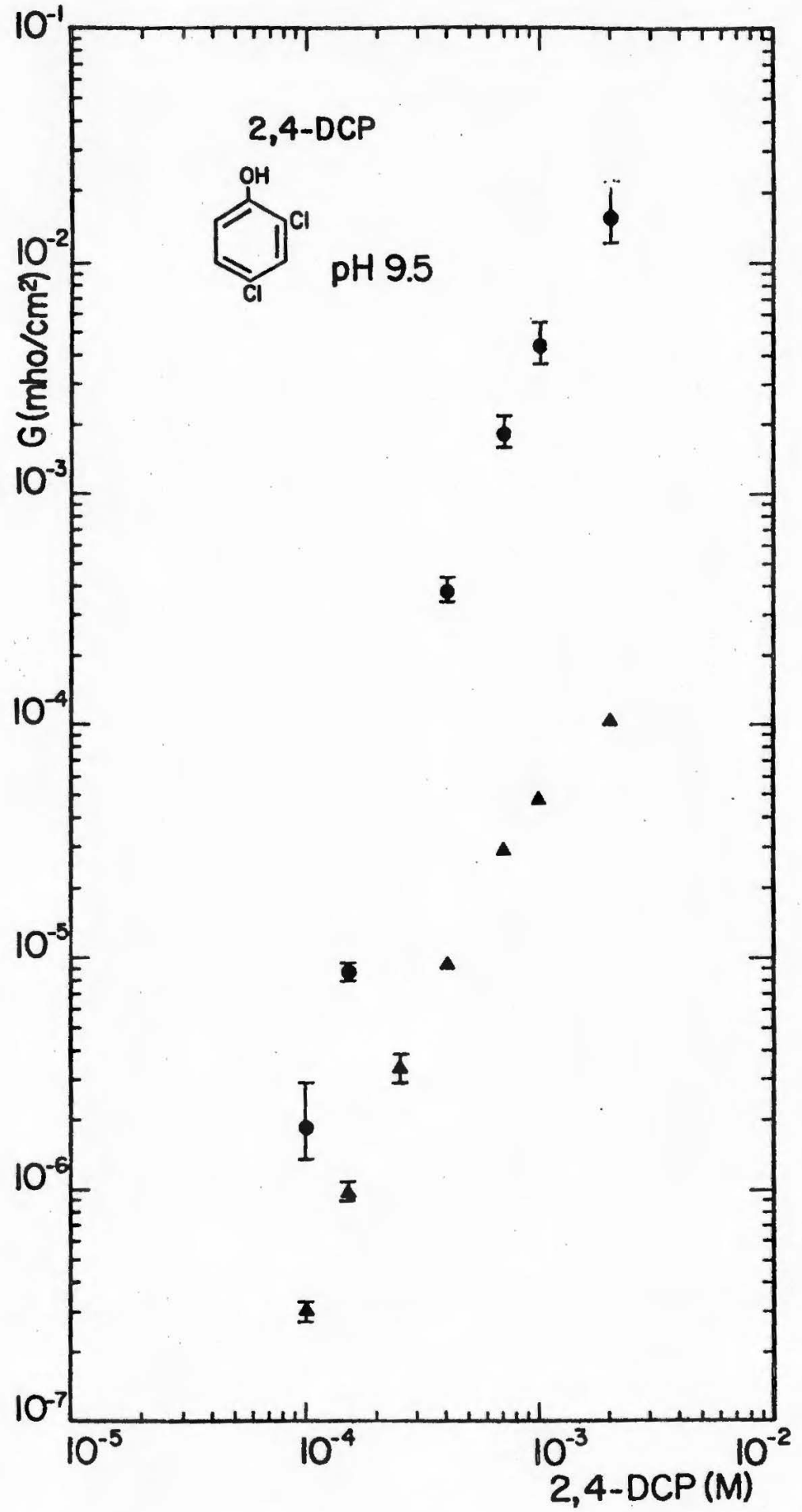

Figure 36. Concentration dependence of membrane conductivity induced by 2,4-DCP at $\mathrm{pH}$ 9.5. Triangles represent the experimental values. Circles represent the reconstructed conductance obtained from the data shown in Figs. 22 and 31, and from the Gouy-Chapman double layer theory. 
plot of the $10 \mathrm{~g}$ of the conductance vs. the $10 \mathrm{~g}$ of the pesticide concentration is, in all cases, significantly greater than two. Such a result is incompatible with the hypothesis that dimers are the membrane permeable species.

Rather than rejecting the dimer hypothesis, another experiment was designed to test the applicability of the double layer theory to the membrane pesticide system. It should be stressed at this point that originally there was no apparent need for such tests since the double layer theory was tested on lipid bilayers by other authors $(29,30,43,44)$ and found adequate. Also, from the experiments with nonactin it was concluded that the nonactin- $\mathrm{K}^{+}$complex is an excellent probe of membrane surface charge (45), and the experimental results were found to be compatible with the double layer theory as outlined above.

According to Gouy-Chapman theory of the diffuse double layer the relation between the surface potential $\psi(0)$ and the surface density $\sigma$ is given as

$$
\operatorname{Sinh}(F \psi(0) / 2 R T)=\left(\frac{\pi}{2 R T \varepsilon}\right)^{\frac{1}{2}} \frac{\sigma}{c^{\frac{1}{2}}}
$$

The above expression is valid for a monovalent electrolyte of molar concentration $c$. It follows that the surface potential is a function of the density of the surface charge as well as the electrolyte concentration. The current understanding is that the surface potential of the membrane, which is governed by the electrolyte concentration, will affect the density of the nonactin- $\mathrm{K}^{+}$complex at the membrane surface. This in turn will cause a change in the magnitude of the nonactin-induced conductivity. It follows that an increase of electrolyte concentration should create a 
smaller negative surface potential which would result in a decrease of nonactin- $\mathrm{K}^{+}$conductivity. The experiments were done with concentrations of monovalent electrolyte at $0.05 \mathrm{M}$ and $0.5 \mathrm{M}$. Since the concentration of buffer and 2,4-D are considerably below $50 \mathrm{mM}$ the concentration $c$ in Eq. (29) is that of the monovalent electrolyte in the first approximation. When the electrolyte is changed from low fonic strength to high Ionic strength, the corresponding change of the membrane surface potential and the expected change of the nonactin-induced conductivity was calculated as follows:

(a) Membrane surface potential due to adsorbed pesticide at low lonic strength (0.05) was calculated using the Eq. (28) from the experimental data.

(b) The expected surface potential at high lonic strength (0.5) was calculated using Eq. (29), assuming that the surface charge density, $\sigma$, due to the adsorbed species remains the same.

(c) The expected nonactin conductivity at high lonic strength (0.5) was calculated using Eq. (28) and the expected surface potential.

The experimental data and theoretical results are presented in Table (6) and compared In FIg. 37. All data correspond to the conductance at $25 \mathrm{mV}$. The disagreement between the experimental results and the theoretical predictions based on the Gouy-Chapman theory indicates, in fact, that the standard double layer theory is not applicable to the investigated membrane system when the membrane surface charge is produced by ionized 2,4-D and presumably by other pesticides in this series, as well. The finding that the simple theory of a diffuse double layer fails to predict the membrane surface potential due to adsorbed organic ions is 


\section{ANALYSIS OF THE EXPERIMENTAL DATA FOR THE EFFECT}

OF IONIC STRENGTH OR SURFACE CHARGE

$$
\text { DUE TO } 2,4-D
$$

Concentration of 2,4-D $\mu \mathrm{M}$

0.1

0.15

0.25

0.4

0.7

1.0

Concentration of 2,4-D $\mu \mathrm{M}$ $\psi(0) \mathrm{mV}(\mathrm{c}=0.05 \mathrm{M})$ $\left(x-10^{2}\right)$

$$
\begin{gathered}
G / G^{\circ} \quad(c=0.05 \mathrm{M}) \\
\left(\mathrm{x} 10^{2}\right)
\end{gathered}
$$

0.0593

0.099

0.234

1.83

14.1

59.2

$$
\begin{gathered}
G / G^{\circ}(c=0.5 \mathrm{M}) \\
(\text { experimenta1 }) \\
\left(\mathrm{x} 10^{2}\right)
\end{gathered}
$$

$$
\begin{gathered}
\mathrm{G} * / \mathrm{G}^{0}(\mathrm{c}=0.5 \mathrm{M}) \\
(\mathrm{cal} \text { culated }) \\
\left(\mathrm{x} \mathrm{10^{2 } )}\right.
\end{gathered}
$$

0.1

0.15

0.25

0.4

0.7

1.0
0.038

0.071

0.11

1.74

11.0

65.3
0.019

0.024

0.039

0.20

1.43

5.94 


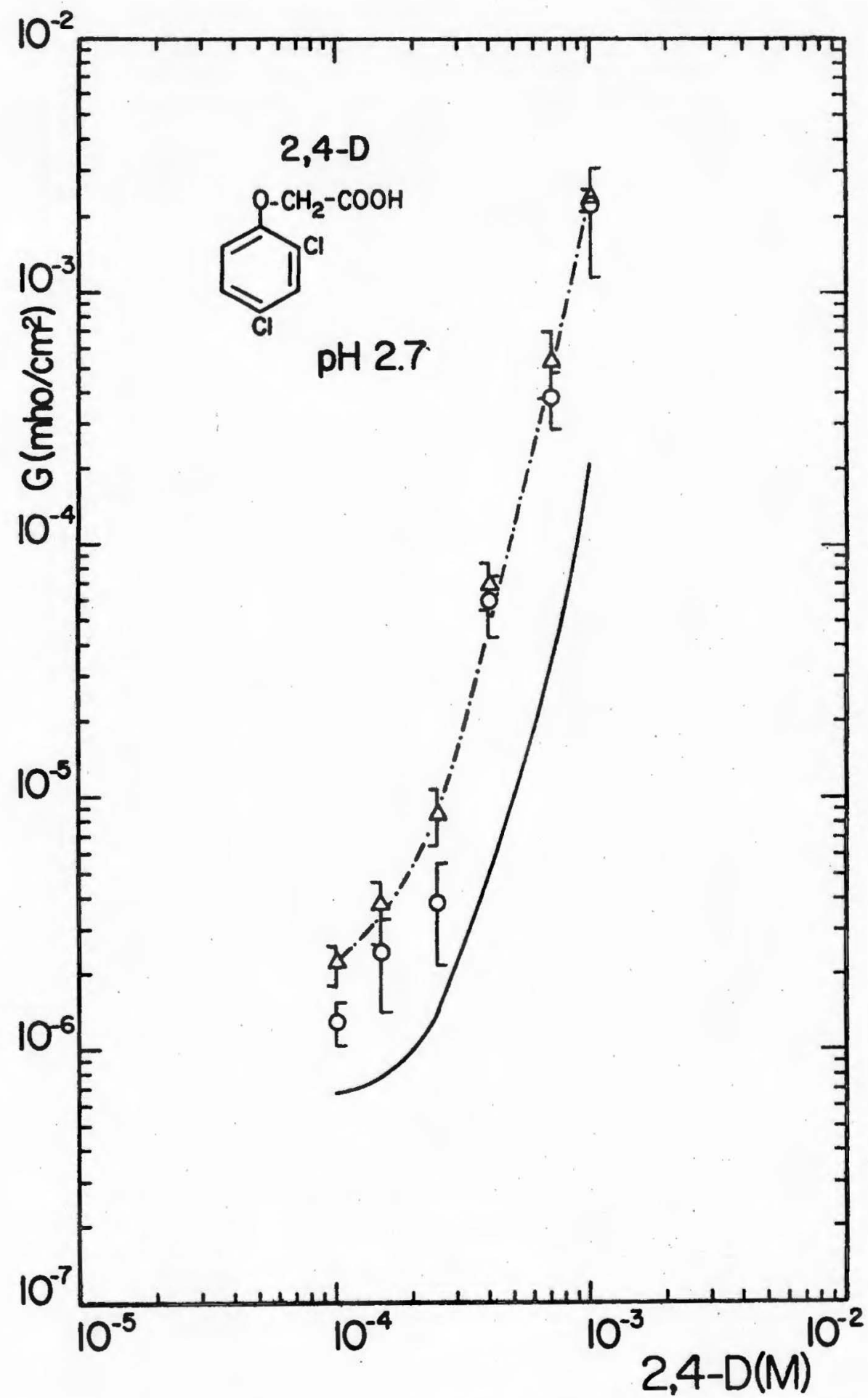

Figure 37. Effect of lonic strength on nonactin- $\mathrm{K}^{+}$conductance enhanced by 2,4-D. Triangles - membrane conductance at $0.05 \mathrm{M}$ $\mathrm{KCl}$. Circles - membrane conductance at $0.05 \mathrm{M} \mathrm{KC} 1+0.45 \mathrm{LiCl}$. The solid line is the expected membrane conductance for $0.05 \mathrm{M}$ $\mathrm{KC} 1+0.45 \mathrm{M} \mathrm{LiC1}$ electrolyte calculated from the data for $0.05 \mathrm{M}$ $\mathrm{KCl}$ and Gouy-Chapman double layer theory. 
supported by Boguslavsky's observations. He reported recently (47) that the membrane conductance caused by tetrapentylammonium ions is independent of the ionic strength of the electrolyte solution. He proposed a model according to which the membrane "surface charge" is located at some depth from the membrane surface. The present experimental reuslts seem to be in agreement with this hypothesis. If the membrane surface charge is indeed located at some depth inside the polar head group layer, it is to be expected that a large fraction of the electrostatic potential drop will occur within the polar head group region and the inner Helmholtz layer. Thus, the remaining potential difference across the diffuse double layer can be only a small fraction of the total potential difference associated with the layer of adsorbed negative charges. Thus the variation of the potential across the diffuse double layer caused by the change of ionic strength of the aqueous phase can be insignificant, and the membrane conductance can be essentially independent of the fonic strength of the electrolyte, as observed. 


\section{CHAPTER V}

\section{SUMMARY AND CONCLUSIONS}

The present work is concerned with the effect of the following pesticides on DC electrical conductivity of lecithin-cholesterol membranes: endotha11, paraquat, diquat, 2,4-D, 2,4-DB, 2,4,5-T and 2,4-DCP. It is found that the ions of endotha11, paraquat and diquat are membrane impermeable and that they do not bind to the membrane surface. In contrast, $2,4-\mathrm{D}, 2,4-\mathrm{DB}, 2,4,5-\mathrm{T}$ and $2,4-\mathrm{DCP}$ induce electrical conductivity in lecithin-cholesterol membranes, and in addition, they cause an increase in nonactin- $\mathrm{K}^{+}$membrane conductivity.

The experimental results on pesticide-induced conductivity were compared with those predicted from several models of ion transport across membranes. A simple kinetic scheme of trans-membrane charge flow was formulated for the dimer model. This was tested for the concentration and $\mathrm{pH}$ dependence of the pesticide induced conductivity and for the effect of the pesticide concentration and $\mathrm{pH}$ on the voltage dependence of conductivity. It was found that the kinetic scheme satisfactorily explains the basic features of the experimental results, such as the effect of pesticide concentration on the magnitude of conductance, and on the voltage dependence of membrane conductance. However, it falls to predict the effect of proton concentration on the voltage dependence of membrane conductance.

The enhancement of nonactin- $\mathrm{K}^{+}$membrane conductance by the 
pesticides is presumably due to the adsorption of the fonized form of the pesticides at the membrane surface, but the Gouy-Chapman theory was found not applicable for the calculation of surface membrane potential due to the adsorbed ions. However, the results are compatible with the idea that the adsorbed pesticide anions are located at some depth within the polar head group layer.

In order to better understand the process of charge transfer across membranes in the presence of these pesticides, an additional set of experiments is needed. These are: (a) conductivity measurements at low buffer capacities of the aqueous phase in order to elucidate the proton transfer mechanism within the membrane-water interface; (b) measurements of nonlinearity of current-voltage characteristics as a function of $\mathrm{pH}$ and pesticide concentration; (c) measurements of the concentration dependence of conductivity for wider range of $\mathrm{pH}$ values; and (d) currentrelaxation measurements. Further there is a need to analyze alternative kinetic models and compare their predictions with the experimental data. 


\section{References}

1. WILKINS, M.H.F., A.W. BLAUROCK, and D.M. ENGELMAN, 1971. Bilayer structure in membranes. Nature New B101. 230:72.

2. MUELLER, P., D.0. RUDIN, H.T. TIEN, and W.C. WESCOTT, 1963. Method for the formation of single bimolecular lipid membranes in aqueous solution. J. Phys. Chem. 67:534.

3. LIBERMAN, YE.A., and V.P. TOPALY. 1969. Permeability of bimolecular phospholipid membranes for lipid soluble ions. Blophysics.

4. STARK, G., and R. BENZ. 1971. The transport of potassium through lipid bilayer membranes by the neutral carriers valinomycin and monactin. J. Membrane Biol. 5:133.

5. KILBOURN, B.T., J.D. DUNITZ, L.A.R. PIODA, and W. SIMEN. 1967. Structure of the $\mathrm{K}^{+}$complex with nonactin, a macrotetralide possessing highly speciflc $\mathrm{K}^{+}$transport properties. J. Mol. B101. $30: 559$.

6. LIBERMAN, YE.A., and V.P. TOPALY. 1968. Transfer of 1ons across bimolecular membranes and classification of uncouplers of oxidative phosphorylation on lipid bilayer membranes. Blofizika. 13:1025.

7. LEBLANC, O.H. 1971. The effect of uncouplers of oxidative phosphorylation on 11pid bilayer membranes. J. Membrane B101. $4: 227$.

8. MARKIN, V.S., L.I. KRISHTALIK, YE.A. LIBERMAN, and V.P. TOPALY. 1969. Mechanism of conductivity of artificlal phospholipid membranes in presence of lon carriers. Blofizika. 14:256.

9. CHIZMADZHEV, YU. A., V.S. MARKIN, and R.N. KUKLIN. 1971. Relay transfer of lons across membranes - 1 . Direct current. B1of1z1ka. $16: 230$.

10. MARKIN, V.S., V.F. PASTUSHENKO, L.I. KRISHTALIK, YE.A. LIBERMAN, and V.P. TOPALY. 1969. Membrane potential and short circult current in artificial phospholipid membranes in the presence of agents uncoupling oxidative phosphorylation. Blofizika. $14: 462$. 
11. LEA, E.J.A., and P.C. CROGHAN. 1969. The effect of 2,4-dinitrophenol on the properties of thin phospholipid films. J. Membrane B1o1. 1:225.

12. FINKELSTEIN, A. 1970. Weak acid uncouplers of oxidative phosphorylation. Mechanism of action on thin lipid membranes. Blochem. Blophys. Acta. 205:1.

13. HILTIBRAN, R.C. 1963. Effect of endothall on aquatic plants. Weeds. $11: 256$.

14. ASHTON, F.M. and A.S. CRAFTS. 1973. In Mode of Action of Herbicides. Wiley Interscience Publication. 400.

15. ASHTON, F.M. and A.S. CRAFTS. L973. In Mode of Action of Herbicides. Wiley Interscience Publication. 185.

16. FUNDERBURK, H.H., and J.M. LAWRENCE. 1964. Mode of action and metabolfsm of diquat and paraquat. Weeds. 12:259.

17. FUNDERBURK, H.H. and G.A. BOZRTH. 1967. Review of the metabolism and decomposition of diquat and paraquat. J. Agr. Food Chem. 15:563.

18. LOTLIKAR, P.D., L.F. REMMERT, and V.H. FREED. 1968. Effects of 2,4-D and other herbicides on oxidative phosphorylation in mitochondria from cabbage. Weed Sc1. 16:161.

19. OVERBEEK, J.V. 1964. Survey of mechanisms of herbicide action. In the Physlology and Biochemistry of Herbicides. L.J. Hudus, Ed. Academic Press. N.Y. 387.

20. SHANNON, J.C., J.B. HANSON, and C.M. WILSON, 1964. RAbonuclease levels in the mesocotyl tissue of zea mays as a function of 2,4-dichlorophenoxy acetic acid application. Plant Physiol. $39: 804$.

21. MORELAND, D.E. 1969. Inhibitors of chloroplast electron transport: Structure activity reactions. In Progress in photosynthesis research. III:1693. Helmut Metznes, Editor.

22. GAUR, B.K. and H. BEEVERS. 1959. Respiratory and assoctated responses of carrot discs to substituted phenols. Plant Phys101. $34: 427$.

23. SINGLETON, W.S., M.S. GRAY, M.L. BROWN, and J.L. WHITE. 1965. Chromatographically homogenous lecithin from egg phospho11p1ds. J. Am. 011 Chem. Soc. 42:53.

24. SMEJTEK, P., K. HSU, and W.H. PERMAN. 1976. Electrical conductivity in lipid bilayer membranes induced by pentachlorophenol. Blophys. J. 16:319. 
25. LANG, L. 1965. Absorption spectra. Vo1. 6. Academic Press, Inc., N.Y.

26. In The Sadtler Standard Infrared Prism Spectra. 1962. Published by Sadtler Research Laboratories. 1315.

27. MULLER, P., D.0. RUDIN, H.T. TIEN, and W.C. WESCOTT. 1964. Formation and properties of bimolecular lipid membranes. In Recent Progress in Surface Science. Vol. 1. J.F. Daniell, K.G.A. Pankhurst, A.C. Riddifor, Ed. Academic Press, Inc., N.Y. 379 .

28. Personal communications with Penwalt Corporation.

29. MCLAUGHLIN, S. 1973. Salicylates and phospholipid bilayer membranes. Nature. 243:234.

30. MCLAUGHLIN. S., G. SZABO, and G. EISENMAN. 1970. Surface charge and the conductance of phospholipid membranes. Proc. Nat. Acad. Sc1. 67:1268.

31. MCLAUGHLIN, S., G. SZABO, and G. EISEMMAN. 1971. Divalent lons and the surface potential of charged phospholipid membranes. J. Gen. Physio1. 58:667.

32. MCLAUGHLIN, S., A. BRUDER, S. CHEN, and C. MOSER. 1975. Chaotropic anions and the surface potential of bilayer membranes. Blochim. Blophys. Acta. 394:304.

33. MCLAUGHLIN, S. 1972. The mechanism of action of DNP on phospho11pid b1layer membranes. J. Membrane B1ol. 9:361.

34. NELSON, N.H. and S.D. FAUST. 1969. Acid dissociation constants of selected aquatic herbicides. Environmental Sclence and Technology. 3:1186.

35. BAILY, G.W. and J.L. WHITE. 1965. Herbicides: a compilation of their physical, chemical, and biological properties. In Residue Reviews. Vol. 10. cumulative index. Springer-Verlag. N.Y. Inc., 97.

36. BLACKMAN, G.E., H.H. PARKE, and G. GARTON. 1955. The physiological activity of substituted phenols. 1. Relationship between chemical structure and physlological activity. Archives of Blochem. Blophys. 54:45.

37. YAGUZHINSKII, L.S., L.A. RATINKOVA, and G.M. KOLESORA. 1973. Quantitative relations between the value of the dissociation constant of uncoupling agents and their efficlency in mitochondrial membranes. Blophysics. 18:483.

38. EISENMAN, G., S. CIANI, and G. SZABO. 1969. The effects of the macrotetralide actin antibiotics on the equilibrium extraction 
of alkali metal salts into organic solvents. J. Membrane B101. 1:294.

39. COHEN, F., S. CHEN, M. EISENBERG, and S. MCLAUGHLIN. 1975. Uncouplers of oxidative phosphorylation: Kinetic studies on black 11pid membranes. Blophys. J. 15:21a.

40. COHEN, F., M. EISENBERG, and S. MCLAUGHLIN, 1976. Kinetic studies of black 1ipid membranes. Blophys. J. 16:11la.

41. AZOLINSKY, B.J., H. EYRING, and C. REESE. 1949. Diffusion and membrane permeability. J. Phys. Collold Chem. 53:1426.

42. OVERBEEK, J.TH.G. 1952. Electrochemistry of the double layer. In Kruyt Colloid Science. Vol. 1. 128.

43. WHITE, S., 1973. The surface charge and double layers of thin lipid films formed from neutral 11pids. Blochim. Biophys. Acta. $323: 343$.

44. MACDONALD, R.C., and A.D. BANGHAM. 1972. Comparison of double layer potentials in 1ipld monolayers and lipid.bilayer membranes. J. Membrane B1o1. 7:29.

45. SZABO, G., G. EISENMAN, S. MCLAUGHLIN, and S. KRASNE. 1972. Ionic probes of membrane structures. N.Y. Acad. Sc1. Ann1. $195: 273$.

46. SZABO, G. 1974. Dual mechanism for the action of cholesterol on permeability. Nature. 242:47.

47. BOGUSLAVSKY, L.I., V.S. VRILOV, YU.A. SCHIPUNOV. 1976. Structure of double electric layers at the interface membrane/aqueous solution in. the presence of tetrapentyl-ammonium cations. Blofizika. 21:266. 


\section{APPENDIX}

OUTLINE OF THE DIFFUSE DOUBLE LAYER THEORY

In the theory of Gouy and Chapman, the Ions are considered as point charges, and the dielectric constant of the aqueous phase is assumed to be constant and equal to the bulk value up to the membrane surface.

The relationship between the electrical potential and the space charge density follows from the Poisson equation:

$$
\frac{d^{2} \psi(x)}{d x^{2}}=-\frac{4 \pi}{\varepsilon} \rho(x)
$$

where

$$
\rho(x)=\sum_{1} e z_{1} N_{1}(x)
$$

$\psi(x)$ is the electrostatic potential; $\rho(x)$, the space charge density; $\mathrm{N}_{1}(x)$, the density of lons of the species 1 at a distance $x$ from the surface; and $z_{1}$, the valence of the lonic species 1 . The distribution of Ions in the solution in the direction normal to the surface is given by:

$$
N_{1}(x)=N_{1}(\infty) \exp \left(-e z_{1} \psi(x) / k T\right)
$$

In the presence of a symmetrical electro]yte (1.e. $z_{+}=z_{-}=z$ ), Eq. (A-1) can be reduced to 


$$
\frac{\mathrm{d}^{2} \psi(x)}{d x^{2}}=-\frac{4 \pi e z}{\varepsilon} N(\infty)[\exp (-\operatorname{ez} \psi / k T)-\exp (\operatorname{ez} \psi / k T)]
$$

Further it is assumed that the charge at the surface $(x=0)$ is positive and at infinity $(x=\infty)$, both the electrostatic potential and its gradient are equal to zero.

Eq. (A-3) can be simplified as $(A-4)$

$$
\frac{d^{2} y}{d \zeta^{2}}=\sinh y
$$

by the following transformations:

$$
\begin{aligned}
& y=\frac{e z \psi}{k T} \\
& \zeta=\beta x .
\end{aligned}
$$

where

$$
\beta^{2}=\frac{8 \pi z^{2} e^{2} N(\infty)}{\varepsilon k T}
$$

Using the boundary conditions, Eq. (A-4) can be solved. The solution is given by:

$$
\left(\frac{d y}{d \zeta}\right)^{2}=4 \sinh ^{2}(y / 2)
$$

Since the potential on the membrane surface has been assumed to be positive (positive surface charge), the electrostatic potential is expected to decrease with increasing distance from the membrane. We therefore take the negative square root of the right side of Eq. (A-7), 
and obtain a linear differential equation relating to $y$ and $\zeta$.

$$
\frac{d y}{d \zeta}=-\sinh (y / 2)
$$

The surface charge of the double layer per unit area $\sigma$, is equal to the negative integral of the space charge density $\sigma$, from the membrane surface to infinity.

$$
\sigma=-\int_{0}^{\infty} \rho d x
$$

Using the relationship between the space charge density and the surface potential given by Eq. (A-1), we obtain after integrating Eq. (A-9) a relationship between the surface charge $\sigma$ and the derivative of the surface potential at the membrane surface.

$$
\sigma=-\frac{\varepsilon}{4 \pi}\left(\frac{\mathrm{d} \psi}{\mathrm{d} \mathbf{x}}\right) \quad \mathbf{x}=0
$$

From Eq. $(A-5),(A-6)$, and (A-9), by eliminating $\left(\frac{d \psi}{d x}\right)_{x=0}$, we get the relationship between the surface charge $\sigma$ and the surface potential $\psi(0)$ of the membrane

$$
\sigma=\left(\frac{2 \mathrm{kT} \varepsilon N(\infty)}{\pi}\right)^{\frac{1}{2}} \operatorname{Sinh}(\operatorname{ez} \psi(0) / 2 \mathrm{kT})
$$

After introducing the molar concentration of the electrolyte c into Eq. (A-11), the relationship between the surface charge and the surface potential is given by 
88

$$
\sigma=\left(\frac{2 \mathrm{RTEC}}{\pi}\right)^{\frac{1}{2}} \operatorname{Sinh}(\mathrm{Fz} \psi(0) / 2 \mathrm{RT})
$$

where $\psi(0)$ is the surface potential; $\sigma$, the surface charge per unit area; $\varepsilon$, the dielectric constant of the aqueous phase; $z$, the valence of the Ions; R, the gas constant; F, the Faraday constant and $T$, the absolute temperature. 